\title{
VERIFICAÇÃO, VALIDAÇÃO E ANÁLISE DE SENSITIVIDADE DE UM MODELO DE SIMULAÇÃO DE EPIDEMIAS PARA A FERRUGEM DO FEIJOEIRO
}

\section{MARCELO GIOVANETTI CANTERI \\ Engenheiro Agrônomo \\ Bacharel em Processamento de Dados}

Orientador: Prof. Dr. ARMANDO BERGAMIN FILHO

Dissertação apresentada à Escola Superior de Agricultura "Luiz de Queiroz", da Universidade de São Paulo, para obtenção do título de Mestre em Agronomia. Área de Concentração: Fitopatologia.

$P|R A C| C A B A$

Estado de São Paulo - Brasil

Dezembro de 1993 
Ficha catalogrática preparada pela Seça de Livras da Divisła de Biblioteca e Documentaçăo - PCLE/USF

\footnotetext{
Canteri, fiarcelo Giovanetti

C217V Verificaçăo, validaçăo e analise de sensitividade de un modelo de simulaçăo de epidenias para é ferrugen do feijoeiro. Firacicaba, 1973. 80p. ilus.

Diss. (Mestre) - ESALQ Eibliografia.
}

1. Feijao - Doença 2. Fungo fitopatogenico j. Fer rugen do feijoeiro - Epidemia - Simulaça I. Escola Superior de Agricultura Luiz de Queiroz, Firacicaba 


\section{VERIFICAÇÃO, VALIDAÇÃO E ANÁLISE DE SENSITIVIDADE DE UM MODELO DE SIMULAÇÃO DE EPIDEMIAS PARA A FERRUGEM DO FEIJOEIRO}

MARCELO GIOVANETTI CANTERI

Aprovada em: 25.02.1994

Comissão julgadora:

Prof. Dr. Armando Bergamin Filho

ESALQIUSP

Prof ${ }^{\mathrm{a}} \mathrm{r}^{\mathrm{a}}$ Lilian Amorim ESALQIUSP

Prof. Dr. Antônio Carlos Maringoni FCA/UNESP,

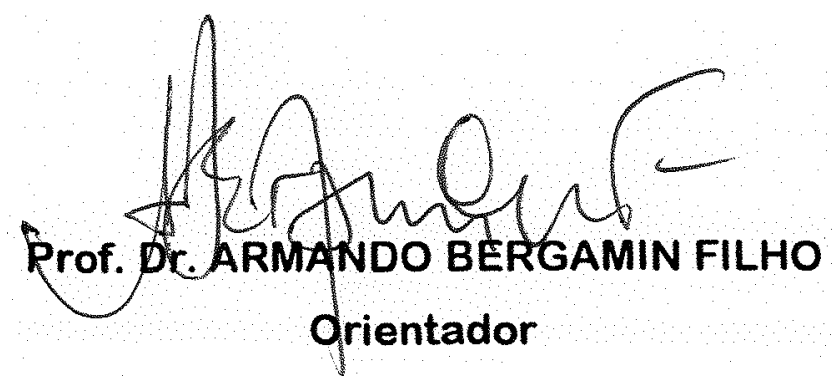


"O principal fundamento lógico para utilizarmos a simulação em qualquer assunto é o incessante desejo do homem em conhecer o futuro" (NAYLOR et al., 1966) 


\section{AGRADECIMENTOS}

Aos meus pais Mário e Rose e minha irmã Maria Helene, pelo apoio e incentivo em todos os instantes de minha vida.

Ao professor Dr. Armando Bergamin Filho, pela orientação e exemplo em objetividade e bom senso na resolução de problemas.

À professora $\mathrm{Dr}^{\mathrm{a}}$. Lilian Amorim, pela disposição em auxiliar e ensinar.

Aos professores Dr. Richard D. Berger, Dr. Jürgen Kranz e Dr. Bernhard Hau, pelo exemplo de dedicação à fitopatologia, em especial à epidemiologia.

Aos professores que me abriram as portas da fitopatologia, professor David de Souza Jaccoud Filho, professora Áurea T. M. Kamikoga e professor Márcio Lopes Siqueira.

À $\mathrm{Dr}^{\mathrm{a}}$. Beatriz M. J. Mendes, ao Dr. Gerhard Weber e às colegas Lilian M. A. Bacchi e Marilene T. Iamauti, que possibilitaram a execução deste trabalho fornecendo dados de seus estudos.

A todos os professores, colegas de pós-graduação e funcionários da ESALQ/USP pelo convívio alegre e estimulante.

À Universidade Estadual de Ponta Grossa pela liberação das atividades de ensino para conclusão do mestrado, e à CAPES pela concessão da bolsa de estudos. 


\section{SUMÁRIO}

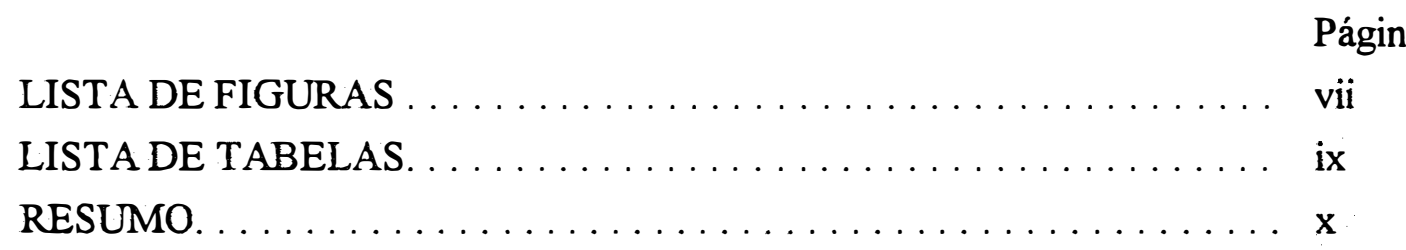

SUMMARY ....................... xii

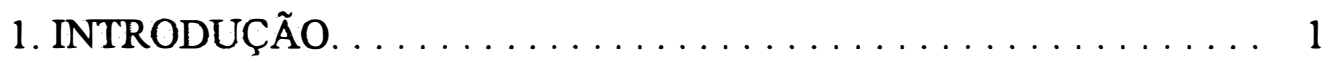

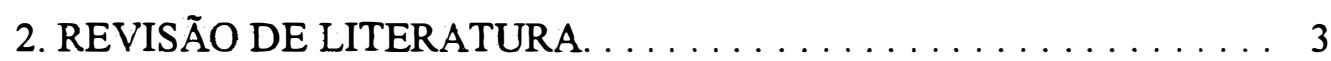

2.1. Ferrugem do feijoeiro: etiologia e epidemiologia. . . . . . . . . 3

2.2. Modelos de epidemias. . . . . . . . . . . . . . . . 5

2.3. Modelos de simulação de epidemias. . . . . . . . . . . . . . 6

2.4. Modelos de previsão de epidemias. . . . . . . . . . . . . 6

2.5. Classificação dos modelos. . . . . . . . . . . . . . . . . 7

2.6. Construção de modelos de simulação . . . . . . . . . . . . . . . 8

2.7. Avaliação de modelos. . . . . . . . . . . . . . . . . . . . . . . . 10

2.7.1. Verificação de um modelo. . . . . . . . . . . . . . . . 10

2.7.2. Validação de um modelo. . . . . . . . . . . . . . . 11

2.7.2.1. Critérios de validação . . . . . . . . . . . . 12

2.7.2.2. Escolha do melhor critério de validação . . . . . . . . 13

2.7.2.3. Cuidados para validação de modelos . . . . . . . . . . 14

2.7.3. Análise de sensitividade . . . . . . . . . . . . . . . . . 14

2.7.4. Exemplos de uso de testes em alguns modelos . . . . . . . . . 15

2.8. Uso de computadores na modelagem . . . . . . . . . . . . . . 16

2.9. Sistemas especialistas ("expert systems") em Fitopatologia . . . . . . . 18

3. MATERIAL E MÉTODOS. . . . . . . . . . . . . . . . . . . . 20

3.1. Programa de simulação FERRUGEM . . . . . . . . . . . . . . . . . 20

3.2. Dados de campo utilizados nos testes . . . . . . . . . . . . . 24

3.2.1. Ensaios com inóculo natural . . . . . . . . . . . . . . 24

3.2.2. Ensaios com inoculação artificial . . . . . . . . . . . . 25

3.3. Avaliação do modelo FERRUGEM . . . . . . . . . . . . . . . . 26

3.3.1. Verificação do modelo . . . . . . . . . . . . . . . . 27

3.3.2. Validação do modelo . . . . . . . . . . . . . . . 28

3.3.3. Análise de sensitividade . . . . . . . . . . . . . . . 31 
Página

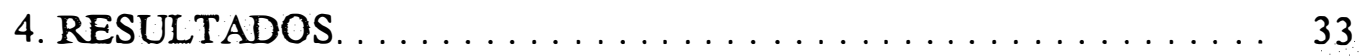

4.1. Verificação do modelo. ....................... 33

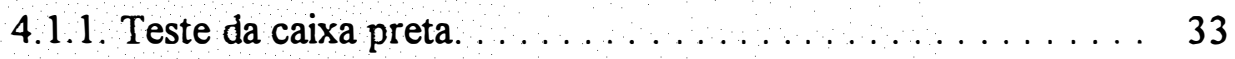

4.1.2. Teste da caixa branca . . . . . . . . . . . . . . 33

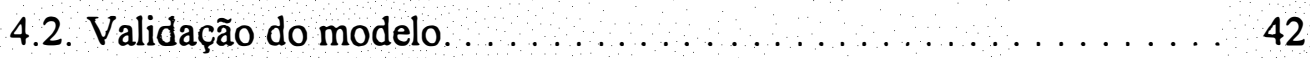

4.2.1. Experimentos com inóculo natural ............. 42

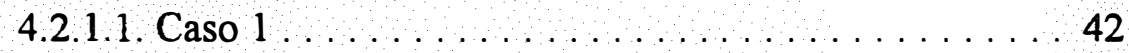

4.2.1.2. Caso 2........................ 42

4.2.1.3. Caso 3......................... 45

4.2.1.4. Caso 4.......................... 46

4.2.1.5. Caso $5 \ldots \ldots \ldots \ldots \ldots \ldots \ldots \ldots \ldots \ldots 46$

4.2.1.6. Caso 6........................... 48

4.2.2. Experimentos com inoculação artificial ............ 49

4.3. Análise de sensitividade do modelo ................. 52

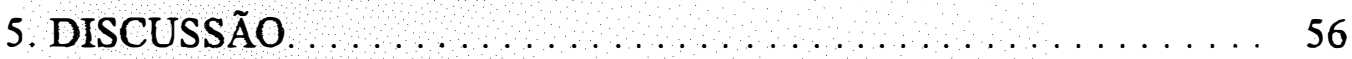

5.1 . Verificação do modelo. ......................... 56

5.2 . Validação do modelo........................ 58

5.2 .1 . Análise nos anos de cultivo $\ldots \ldots \ldots \ldots \ldots \ldots \ldots .58$

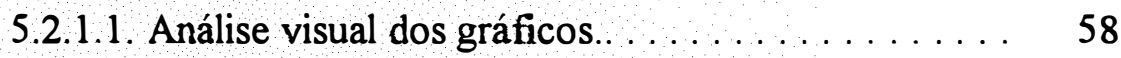

5.2.1.2. Validação Estatística. ............... 60

5.2.1.3. Área sob a curva de progresso da doença (ASCPD). 62

5.2.2. Problemas que influenciaram as simulações. . . . . . . . . 62

5.3. Análise de sensitividade do modelo. . ................ 64

6. CONCLUSÕES ................................... 67

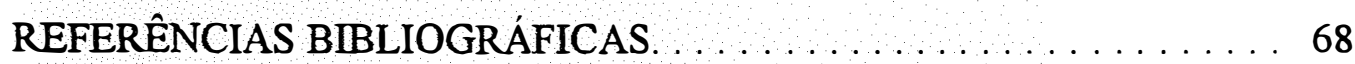

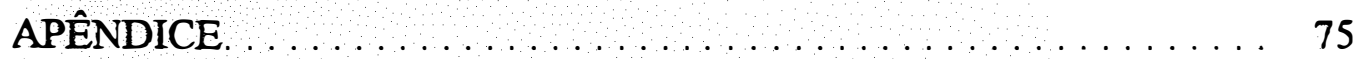




\section{LISTA DE FIGURAS}

Figura 으

Página

1. Curvas de área foliar total, removida e corrigida do hospedeiro, para as cultivares Carioca e Rosinha nos plantios de 1990, 1991 e 1992, obtidos em execuções no programa para simulação de epidemias de ferrugem do feijoeiro.

2. Valores obtidos na execução do programa para simulação de epidemias de ferrugem do feijoeiro. Valores do 'periodo latente' $(p)$ em função da temperatura. Valores da variável 'suscetibilidade da planta' (ahf) . . . . . . 36

3. Valores de 'favorabilidade climática' (fav), em função da temperatura e do molhamento foliar, para as cultivares Carioca e Rosinha, gerados pelo programa para simulação de epidemias de ferrugem do feijoeiro. . . . . . . . . .

4. Dados gerados pelo programa para simulação de epidemias de ferrugem do feijoeiro, para o plantio de 1990: a) 'periodo latente' (p); b) 'favorabilidade climática' (fav) para cv. Rosinha; c) 'favorabilidade climática' (fav) para a cv. Carioca; d) temperatura máxima, temperatura mínima e horas de molhamento observadas no experimento de $1990 \ldots \ldots \ldots \ldots \ldots \ldots \ldots \ldots$

5. Dados gerados pelo programa para simulação de epidemias de ferrugem do feijoeiro, para o plantio de 1991. a) 'periodo latente' (p); b) 'favorabilidade climática' (fov) para cv. Rosinha; c) 'favorabilidade climática' (fav) para a cv. Carioca; d) temperatura máxima, temperatura minima e horas de molhamento observadas no experimento de $1991 \ldots \ldots \ldots \ldots \ldots \ldots \ldots \ldots$

6. Dados gerados pelo programa para simulação de epidemias de ferrugem do feijoeiro, para o plantio de 1992. a) 'periodo latente' (p); b) 'favorabilidade climática' (fov) para cv. Rosinha; c) 'favorabilidade climática' (fav) para a cv. Carioca; d) temperatura máxima, temperatura mínima e horas de molhamento observadas no experimento de 1992.

7. Valores da variável 'incremento diário na área infectada' (id) gerados pelo programa para simulação de epidemias de ferrugem do feijoeiro, nos anos de 1990, 1991 e 1992, para as cultivares Carioca e Rosinha. 
Página

8. Curvas de progresso de epidemia geradas pelo simulador e pontos observados no campo juntamente com o intervalo de confiança de $90 \%$, para os Casos 1,2 e 3, usados, respectivamente, na validação de julho de 1990, julho de 1991 e junho de 1992, com a cultivar Carioca e inóculo natural. . . . . . . . . . . .

9. Curvas de progresso de epidemia geradas pelo simulador e pontos observados no campo juntamente com o intervalo de confiança de $90 \%$, para os Casos 4,5 e 6, usados, respectivamente, na validação de julho de 1990, julho de 1991 e junho de 1992, com a cultivar Rosinha e inóculo natural. . . . . . . . . . . . . .

10. Curvas de progresso de epidemia geradas pelo simulador e pontos observados no campo juntamente com o intervalo de confiança de $90 \%$, para os Casos 7, 8 e 9, usados na validação de maio de 1991 com inoculação artificial de $10^{2}$, $10^{3}$ e $10^{4}$ uredosporos $/ \mathrm{ml}$, respectivamente, para a cultivar Rosinha. . . . . . . 50

11. Curvas de progresso de epidemia geradas pelo simulador e pontos observados no campo juntamente com o intervalo de confiança de $90 \%$, para os Casos 10 e 11 , usados na validação de maio de 1991 com inoculação artificial de $10^{5}$ e $10^{6}$ uredosporos $/ \mathrm{ml}$, respectivamente, para a cultivar Rosinha. . . . . . . . 51

12. Quantidade de doença gerada pelo simulador para ferrugem do feijoeiro no 70 o dia (y70), variando-se o dia da observação e a proporção de doença inicial, usando dados do ensaio de julho de 1990 com a cultivar Carioca. . . . .

13. Curvas de progresso de doença geradas pelo simulador para ferrugem do feijoeiro em função da alteração de a) favorabilidade: foram usados os dados climáticos de julho de 1990, julho de 1991 e junho de 1992; b) crescimento do hospedeiro: foram usados os dados observados em 1990, 1991 e 1992 para as cultivares Rosinha e Carioca. Para a variável $R m$ (c) e 'período latente' (d) alterou-se em $\pm 20 \%$ o valor base ( 26 e 10 , respectivamente). . . . . . . . .

14. Resultados de $r^{2}$ (a), $b_{0}$ (b) e $b_{1}$ (c) da regressão entre os dados observados e simulados para epidemias de ferrugem em feijoeiro, para os Casos que apresentaram teste de $\mathrm{F}$ significativo a $5 \%$ de probabilidade. Para $\mathrm{r}, b_{0}$ e $b_{1} \mathrm{e}$ eram esperados valores 1,0 e 1 respectivamente. Regressão da área sob a curva de progresso da doença (ASCPD) simulada contra a observada (d). . . . 


\section{LISTA DE TABELAS}

Tabela no

Página

1. Algoritmo representando o funcionamento do modelo para simulação de epidemias de ferrugem do feijoeiro.

2. Descrição dos diversos Casos usados na validação do modelo para simulação de epidemias de ferrugem do feijoeiro.

3. Dados obtidos da comparação entre as curvas de progresso de doença observadas e simuladas pelo modelo de simulação de epidemias de ferrugem do feijoeiro. Teste de $\mathrm{F}$ para a regressão dos dados simulados contra os observados. Teste de $\mathrm{t}$ para a regressão do logito dos dados simulados e observados contra o tempo.

4. Análise de sensitividade das variáveis, constantes e rotinas usadas no simulador para ferrugem do feijoeiro. Valores expressos em proporção de doença no $70 \underline{\text { dia }}(y 70)$ e em variação percentual em função do valor base. 


\title{
VERIFICAÇÃO, VALIDAÇÃO E ANÁLISE DE SENSITIVIDADE DE UM MODELO DE SIMULAÇÃO DE EPIDEMIAS PARA A FERRUGEM DO FEIJOEIRO
}

\author{
AUTOR: MARCELO GIOVANETTI CANTERI \\ ORIENTADOR: Prof. Dr. ARMANDO BERGAMIN FILHO
}

\section{RESUMO}

Com o objetivo de avaliar um modelo de simulação de epidemias da ferrugem do feijoeiro (Uromyces appendiculatus), foram realizados testes de verificação, validação e análise de sensitividade.

Os testes de verificação visaram determinar a importância de cada rotina do programa e também se os resultados obtidos através dessas rotinas correspondiam à realidade biológica. Os testes de validação visaram comparar os dados gerados pelo programa com dados observados nos experimentos conduzidos, em Piracicaba-SP, com as cultivares Carioca e Rosinha. A análise de sensitividade observou a importância de cada variável através da alteração provocada no resultado final, em função da alteração no valor da variável.

A verificação do modelo indicou que as rotinas que o compõem apresentaram consistência lógica e reproduziram razoavelmente bem o sistema $U$. appendiculatus feijoeiro. Algumas rotinas foram essenciais para o funcionamento do programa e outras foram responsáveis pela precisão dos resultados.

$\mathrm{Na}$ validação, realizaram-se testes estatísticos e não estatísticos para comparar os dados simulados com os dados observados. Foram feitas comparações visuais de gráficos, teste de $\mathrm{F}$ para análise de regressão, cálculo da área sob a curva de progresso de doença simulada e observada e teste de $t$ para a regressão dos dados simulados e observados contra o tempo. Houve correlação entre os resultados apresentados pelo teste de $\mathrm{t}$ com os resultados da comparação visual. Concluiu-se que o modelo é válido, principalmente, quando se tem alta quantidade de doença no campo. Concluiu-se também que o modelo necessita de alguns ajustes na rotina 'sensibilidade do hospedeiro'. 
A análise de sensitividade determinou que todas as variáveis associadas ao cálculo da área infectada apresentaram-se sensitivas. 'Favorabilidade climática', 'sensibilidade do hospedeiro', 'taxa de infecção corrigida máxima', 'período latente' e 'crescimento do hospedeiro' foram os parâmetros que demonstraram maior sensitividade.

Os resultados da avaliação permitiram concluir que o modelo simulou epidemias de ferrugem do feijoeiro e necessita de ajustes e elaboração de novas rotinas, caso se pretenda transformá-lo em um modelo de previsão de perdas. 


\title{
VERIFICATION, VALIDATION AND SENSITIVITY ANALYSIS OF A SIMULATION MODEL OF BEAN RUST EPIDEMICS
}

\author{
AUTHOR: MARCELO GIOVANETTI CANTERI \\ ADVISER: Prof. Dr. ARMANDO BERGAMIN FILHO
}

\section{SUMMARY}

Seeking to evaluate a simulation model of bean rust epidemics (Uromyces appendiculatus), verification, validation and sensitivity analysis tests were done.

The verification tests had the purpose the determination of each program routine importance and also to certify if the results obtained, with such routines, were equivalent to the biological reality. The validation tests aimed the comparison of the simulated data, generate through the program, with the data observed in experiments carried out in Piracicaba-SP, using the Carioca and Rosinha cultivars. The sensitivity analysis showed the variable importance as matter of the modification promoted in the final result through the variable value alteration.

The model verification indicated logical consistance to the routines that compose it. The program promoted a satisfatory reproduction of the U. appendiculatus bean system. Some routines were essential to the program and others were responsible for the results accuracy.

In the validation, statistical and non statistical tests were done for the comparison of the simulated with observed data. Graphs comparison, F tests for regression analysis, area under the simulated and observed disease progress curves and $t$ tests for the regression of simulated and observed data against time were performed.

There was correlation among the visual graph results with the $t$ test results. It was concluded that the model is valid, specially at high amount disease condition. It can also be concluded that the model requires some adjustment in the 'host sensibility' routine.

The sensitivity analysis determinated as being sensitives all the variables associated with the infected area calculus. 'Weather favourability', 'host sensitivity', 'maximum infection rate', 'latent period' and 'host growth' were the parameters that had more sensitivity. 
The results of the model evaluation permited the conclusion that the model simulated bean rust epidemics and will need some adjustment and elaboration of new routines if there are the purpose of turning it into a crop loss model. 


\section{INTRODUÇÃO}

O feijão é um dos principais produtos de consumo do brasileiro (VIEIRA, 1983). Apesar disso, a produtividade média nacional é baixa. As doenças contribuem para essa redução nos rendimentos (CARDOSO, 1988), e entre elas destaca-se a ferrugem, causada pelo fungo Uromyces appendiculatus, que pode ocasionar perdas de quase a totalidade da produção (TOWNSEND, 1938; NASSER et al., 1977).

A quantificação do progresso de epidemias de ferrugem e a elaboração de modelos de simulação baseados nessa quantificação auxiliam no conhecimento do sistema doença (TENG \& ZADOKS, 1980; KRANZ \& HAU, 1980; TENG \& ROUSE, 1984; PEAK et al., 1986) e é só conhecendo-se a fundo a estrutura de um sistema que se pode pretender modificar seu comportamento (ZADOKS, 1972).

A simulação de epidemias envolve grande número de informações obtidas em experimentos realizados sob condições de ambiente controlado e sob condições de campo, visando a construção de modelos. Esses modelos, além de auxiliarem no conhecimento das relações patógeno/hospedeiro, também podem ser utilizados na previsão do progresso de uma epidemia e na previsão de possíveis perdas da produção (KRANZ \& HAU, 1980).

Pode-se agrupar os modelos em basicamente dois tipos (TENG, 1985; BERGER, 1989): os modelos analíticos, que normalmente são resumidos a uma equação, e os modelos de simulação, nos quais geralmente se empregam várias equações para representar o ciclo de vida do patógeno e utiliza-se do computador para calculá-las (TENG et al., 1991). Para que os modelos de simulação representem a realidade da maneira mais confiável possivel, eles necessitam ser submetidos a avaliações (WAGGONER, 1990). Entre as principais avaliações usadas para simuladores estão a verificação, a validação e a análise de sensitividade (CAMPBELL \& MADDEN, 1990). 
A verificação visa averiguar se os resultados obtidos no simulador correspondem à realidade biológica (CAMPBELL \& MADDEN, 1990). A validação procura comparar os dados gerados pelo simulador com dados observados no campo (TENG, 1981) e a análise de sensitividade avalia a variação nos dados simulados em função da troca nos valores de parâmetros iniciais de um modelo (KRANZ \& ROYLE, 1978).

Com base no exposto, o presente trabalho visa avaliar um modelo de simulação de epidemias para ferrugem do feijoeiro (U. appendiculatus), fazendo sua verificação e executando testes de validação e de análise de sensitividade. 


\section{REVISÃO DE LITERATURA}

\subsection{Ferrugem do feijoeiro: etiologia e epidemiologia}

A ferrugem do feijoeiro é causada pelo fungo Uromyces appendiculatus, que pertence à classe Basidiomycetes, ordem Uredinales, família Pucciniaceae (ALEXOPOULOS, 1979). É um fungo biotrófico, autóico, isto é, completa seu ciclo biológico em um único hospedeiro (KIMATI, 1980). Possui um grande número de raças fisiológicas (MORA NUÑES, 1986) e o principal agente de disseminação do patógeno é o vento. Devido a essas características e por ser o feijoeiro cultivado durante o ano todo, em grande parte do território nacional, em três épocas de cultivo ("águas", "seca", e "inverno"), é grande a probabilidade de ocorrência da doença.

A ferrugem do feijoeiro é uma doença de juros compostos ou de ciclo secundário (BERGAMIN FILHO, 1978). Portanto, uma planta infectada no início, servirá de fonte de inóculo para posteriores infecções no mesmo ciclo da cultura.

Diversos fatores epidemiológicos influenciam a taxa de progresso da ferrugem, entre eles estão o período latente, período de produção de esporos e a taxa básica de infecção corrigida, considerados parâmetros monocíclicos (PARLEVLIET, 1979; MENDES et al., 1984).

A suscetibilidade do hospedeiro, a presença do patógeno e, em especial, as condições climáticas dentro da cultura exercem grande influência sobre as epidemias das doenças de plantas. $O$ estudo dos parâmetros que afetam a taxa de desenvolvimento do patógeno é de grande importância para o entendimento da evolução da doença no campo, bem como para a construção de modelos de simulação de epidemias (TENG et al., 1977; IMHOFF et al., 1981; 1982).

A maior parte dos fungos fitopatogênicos depende da presença de água livre na superficie do hospedeiro para a germinação de seus uredosporos e a temperatura ideal atua como um efeito acelerador dessa reação (AGRIOS, 1988). Portanto, a duração do 
molhamento na superficie da planta e a temperatura nesse período são importantes fatores na previsão de infecções de patógenos foliares (SUTTON, 1988).

Com relação às condições climáticas, períodos prolongados (10-12 horas) de umidade relativa maior que $95 \%$ e temperaturas moderadas $\left(17-27^{\circ} \mathrm{C}\right)$ são favoráveis à infecção por Uromyces appendiculatus em feijoeiro (VARGAS, 1980). MENDES \& BERGAMIN FILHO (1989a) estudaram a influência da temperatura pós-inoculação e do período de umidade na superficie foliar sobre os parâmetros monocíclicos da ferrugem e observaram que a máxima eficiência da doença ocorreu a $17^{\circ} \mathrm{C}$, com 22 horas de umidade sobre a folha, para os cultivares Carioca e Rosinha. Estudos posteriores desenvolvidos por BACCHI (1993), aferiram esses resultados, determinando $15^{\circ} \mathrm{C}$ como melhor temperatura.

As respostas de uma planta à presença de um patógeno dependem, entre outros fatores, do estádio de desenvolvimento da cultura (HAU et.al., 1983). Estudos realizados com folhas de feijoeiro demonstraram um aumento na resistência à ferrugem com a idade, tanto em folhas primárias como em trifoliadas. Folhas primárias são mais resistentes que trifoliadas quando inoculadas na mesma idade (GROTH \& URS, 1982; MENDES, 1985; MENDES \& BERGAMIN FILHO, 1989b).

Um patógeno pode influenciar o desenvolvimento de outro em uma planta doente. Pode ocorrer um efeito sinergístico se um se beneficiar da presença do outro, ou antagônico se houver competição por sítios de infecção ou se alterar a suscetibilidade do hospedeiro (HAU et al., 1985). Recentemente, foram estudados; em câmara de crescimento, o efeito do mosaico dourado do feijoeiro e do crestamento bacteriano (Xanthomonas campestris pv. phaseoli) sobre a ferrugem do feijoeiro. A $X$. campestris reduziu o número de pústulas de ferrugem, enquanto que o vírus do mosaico dourado do feijoeiro provocou redução no número de pústulas apenas para a cultivar Carioca, não afetando o desenvolvimento da ferrugem para a cultivar Rosinha (ITO' ${ }^{1}$ ).

\footnotetext{
1 ITO, M.F. (ESALQIUSP) Influência do mosaico dourado e do crestamento bacteriano (Xanthomonas campestris pv. phaseoli) sobre epidemias de ferrugem do feijoeiro (Uromyces appendiculatus). (Em elaboração).
} 


\subsection{Modelos de epidemias}

Para avaliação do potencial de uso de estratégias no controle de doenças, tais como resistência genética e controle químico, deve-se considerar o máximo de informações a respeito do patógeno, do ambiente e do hospedeiro (BERGAMIN FILHO, 1984). Para se obter essas informações utiliza-se a epidemiologia que tem como um dos principais objetos de estudo o entendimento do curso e da estrutura da epidemia (HAU, 1988).

Uma das ferramentas que a epidemiologia usa para entender a epidemia são os modelos que nada mais são do que uma representação simplificada de um patossistema (PENNING de VRIES et al., 1989). Um modelo pode ser uma descrição verbal, uma hipótese, uma teoria ou uma lei (KRANZ, 1974). Como exemplo de modelos temos a cadeia de infecção, o triângulo doença, ou ainda a representação do progresso de uma epidemia na forma de uma curva, com quantidade de doença ocupando o eixo da ordenada e tempo o eixo da abcissa. Porém, poucas informações podem ser retiradas desse tipo de gráfico, informações como a velocidade de aumento da epidemia, projeção de doença futura, e estimativa de doença inicial só podem ser obtidas após linearização dessas curvas (BERGER, 1981). Assim, diferentes transformações matemáticas têm sido utilizadas por diversos autores na tentativa de linearizar a curva de progresso da doença, obtendo-se diferentes modelos de epidemia.

VANDERPLANK (1963) deu grande impulso a esses estudos quando propôs o modelo monomolecular onde proporção de doença $(x)$ é transformada em $[\ln (1 /(1-x))]$ (doenças monocíclicas), e o modelo logístico onde a transformação usada é $[\ln (\mathrm{x} /(1-\mathrm{x}))]$ (doencas policíclicas). Isto permitiu estudar o aumento da doença com o tempo, além de permitir a comparação de epidemias, avaliando o efeito de medidas de controle no avanço da doença.

Além dos modelos propostos por Vanderplank, outros modelos matemáticos foram estudados para descrever o progresso de doenças, entre eles destaca-se o de Gompertz (MADDEN, 1980). Mas, a limitação inerente ao uso de simples equações para representar a complexidade de epidemias leva ao desenvolvimento de modelos que procuram simular o ciclo de vida do patógeno, são os chamados modelos de simulação. Estes modelos se iniciam com a esporulação, passando por todas as outras fases até chegar a próxima esporulação (TENG et al., 1991). 


\subsection{Modelos de simulação de epidemias}

De acordo com Shannon", citado por CAMPBELL \& MADDEN (1990), simulação é o processo de projetar um modelo de um sistema real e conduzir testes com este modelo com o propósito de entender o comportamento ou avaliar estratégias para a operação do sistema. Pode-se ainda definir simulação como sendo o uso de modelos matemáticos para, quantitativamente, reproduzir alguns aspectos do mundo real tão realisticamente quanto possível (KRANZ \& HAU, 1980). Os modelos de simulação, ou simuladores, são programas de computador codificados numa linguagem de programação, consistindo de submodelos representando componentes da cadeia de infecção (KRANZ, 1974).

Os modelos, após construídos, podem ser utilizados como orientadores de pesquisa indicando qual a fase da cadeia de infecção que precisa ser mais estudada (ZADOKS, 1979) e também na educação de estudantes e instrução a fazendeiros (HAU, 1988). Por outro lado, podem ser úteis no melhoramento genético simulando uma série de epidemias com genótipos diferentes (ZADOKS, 1979), no controle químico de doenças, indicando os efeitos epidemiológicos do uso de fungicidas (KRANZ \& HAU, 1980; MACKENZIE, 1981; SUTTON, 1988) e na previsão do progresso da doença (SAVARY \& ZADOKS, 1992). Todas essas utilidades dos modelos são facilmente executadas se comparadas com o mundo real, devido à possibilidade de se incorporar novas hipóteses ou fatos na sua estrutura (TENG \& ZADOKS, 1980).

A maioria dos modelos de simulação de epidemias tem sido usada por seus elaboradores como ferramenta de pesquisa, para ajudar no incremento do conhecimento a respeito do patossistema modelado, pois para se construir o modelo se necessita conhecer detalhadamente os processos biológicos envolvidos (HAU, 1988; TENG \& ZADOKS, 1980). Um uso mais aplicado dos modelos de simulação é a sua utilização em sistemas de manejo de doença e isso deve ser buscado por seus elaboradores.

\subsection{Modelos de previsão de epidemias}

Ao lado dos modelos de simulação, tem-se os modelos de previsão de epidemias, os quais são normalmente baseados na combinação da ocorrência de condições biológicas e meteorológicas que afetam o desenvolvimento da doença, tais

1 SHANNON, R.E. Systems simulation: the art and science. New Jersey, Prentice-Hall, 1975. 387 p. 
como: temperatura, chuva, número de horas de orvalho, estádio de desenvolvimento do hospedeiro, intensidade e severidade da doença (KRAUSE \& MASSIE, 1975; FRY, 1982; JOHNSON, 1987).

CAMPBELL \& MADDEN (1990) citam o trabalho de Mills ${ }^{1}$ para a sarna da macieira, de 1944, como o pioneiro na previsão de doença ao correlacionar fatores climáticos com severidade da doença. A partir da década de 60 houve um aumento na elaboração de sistemas de previsão. Os modelos de previsão podem ser usados para prever o tempo provável de início ou de aumento rápido da doença, ou então para identificar períodos em que os patógenos estão relativamente inativos. Mas o principal objetivo do estudo de previsão de doenças é determinar quando e como utilizar as estratégias de controle (CAMPBELL \& MADDEN, 1990).

A validade da utilização de sistemas de previsão está relacionada a características do sistema patógeno/hospedeiro, entre elas que a doença seja de ocorrência esporádica (FRY, 1982) e que o patógeno seja sensível às condições específicas do ambiente (JOHNSON, 1987). No caso do sistema U. appendiculatus feijoeiro, estas características foram observadas por MENDES (1987) e MENDES \& BERGAMIN FILHO (1988), sugerindo que os dados podem ser utilizados na construção de um modelo de previsão de epidemia.

\subsection{Classificação dos modelos}

KRAUSE \& MASSIE (1975) sugerem a classificação dos modelos de simulação de epidemias em empíricos e básicos, segundo o método pelo qual foram desenvolvidos. Os sistemas empíricos são desenvolvidos por estudo e por comparação de dados históricos de ocorrência da doença, com os dados simultâneos das condições de clima do local ou de local próximo. Segundo GASPAROTTO (1988), os sistemas básicos, de previsão são elaborados a partir de dados obtidos experimentalmente no laboratório e/ou no campo, relacionando as condições biológicas e climáticas que governam as interações hospedeiro/patógeno. Mas, KRAUZE \& MASSIE (1975), reiteram sua opinião citando a arbitrariedade em se classificar os sistemas de previsão de doença em empíricos e básicos pois frequentemente um sistema básico é originado de um sistema empírico.

1 MILLS, W.D. Efficient use of sulfur dusts and sprays during rain to control apple scab. NY Agric. Exp. Stn. (Ithaca) Ext. Bull 630, 1944. 
Para KRANZ \& ROYLE (1978), os modelos matemáticos podem ser descritivos, preditivos ou conceituais. $\mathrm{O}$ modelo descritivo expressa uma hipótese ou resultados experimentais. Tem a limitação de somente operar dentro da faixa de condições testadas. Os modelos preditivos são também descritivos, mas permitem que se façam estimativas e previsões. Os modelos conceituais procuram representar os mecanismos do sistema natural num modelo simples ou numa série de submodelos interligados para representar uma parte ou todo o sistema.

Segundo FEGIES \& BERGAMIN FILHO (1986), não há uma maneira perfeita para se classificar os modelos utilizados na agricultura. Vários trabalhos (BERGER, 1989; TENG, 1985) têm argumentado que a maioria dos modelos epidêmicos é analíticos ou de simulação. Um modelo analítico é frequentemente uma só equação com poucos parâmetros biológicos e geralmente pode ser resolvida matematicamente. As equações para curva de progresso da doença de VANDERPLANK (1963) são clássicos exemplos desses modelos (TENG et al., 1991).

Modelos de simulação comumente compreendem uma série de equações que descrevem o comportamento dos subsistemas, por exemplo germinação, penetração, colonização e esporulação, e quantificam a influência das condições climáticas nesses subsistemas (TENG et al., 1991). Normalmente, para sua execução requerem solução numérica com o uso de computadores.

\subsection{Construção de modelos de simulação}

Os primeiros modelos de simulação de epidemias desenvolvidos por WAGGONER \& HORSFALL (1969) e KRANZ et al. (1973) baseavam-se no conceito de cadeia de infecção, descrevendo a epidemia da maneira mais precisa possível, requeriam um grande número de dados experimentais, os quais nem sempre podiam ser obtidos com precisão (ZADOKS, 1979), interferindo na confiabilidade do modelo.

Visando evitar esse problema, SUTTON (1988) sugere que para a construção do modelo, o sistema possua um fator crítico ou determinante para a ocorrência da doença, pois do contrário torna-se de dificil compreensão (HAU et al., 1983).

Estudos demonstraram que, para doenças foliares, a temperatura, a umidade, a idade da planta e suas características genéticas são algumas das variáveis que têm demonstrado maior influência no desenvolvimento de epidemias (KRANZ \& HAU, 1980; MENTEN \& BERGAMIN FILHO, 1981; MENDES, 1985; SUTTON, 1988). 
A premissa básica para construir um modelo de simulação é que o patossistema possa ser dissecado em subsistemas interagentes (TENG et al., 1991). Um patossistema é considerado um sistema, pois de acordo com Shannon ${ }^{1}$ citado por TENG (1981) um sistema é um grupo ou conjunto de objetos unidos por alguma forma de interação ou interdependência para realizar uma função específica. Para pesquisa de um sistema têm-se duas fases (TENG, 1981): a análise do sistema e a síntese do sistema. Na análise do sistema se estabelece a identificação do problema, especificação dos objetivos, aprende-se sobre o sistema, formula-se um modelo conceitual e coletam-se dados. A fase de síntese do sistema compreende os estágios de especificação de um modelo detalhado do sistema, de verificação do modelo, de validação do modelo e de experimentação usando o modelo.

TENG et al. (1991) citam que há discordância entre os fitopatologistas na maneira de como tratar os subsistemas para construção de modelos. Há a técnica "topdown", isto é, do geral para o específico, onde parte-se de uma equação ou modelo simples (ex. modelo logístico) e se constroem mais e mais detalhes biológicos até a obtenção de um modelo de simulação completo. TENG \& ZADOKS (1980) ilustraram essa abordagem para a ferrugem da folha do trigo, entretanto citam que a equação logística, mesmo quando modificada para latência e período infeccioso, poderá não incorporar algum conhecimento sobre influências do ambiente em epidemias.

Por outro lado há a abordagem "bottom-up", onde desenvolve-se um módulo para cada subsistema. É feita uma definição inicial do patossistema e uma pesquisa na literatura, ou trabalhos são realizados para obter toda a informação ao nível de subsistemas (TENG et al., 1991). Entretanto este tipo de modelo é criticado por conter somente conhecimento lógico e parâmetros não variáveis conforme Dent \& Blackie ${ }^{2}$, citado por TENG et al. (1991)

Para a construção dos modelos de simulação necessita-se conhecer os mecanismos que governam cada fase da infeç̧ão para que possam ser transformados em equações matemáticas. No caso da ferrugem do feijoeiro estes trabalhos foram realizados por MENDES (1987), MENDES \& BERGAMIN FILHO (1988) e BACCHI (1993) .

\footnotetext{
I SHANNON, R.E. Systems simulation: the art and science. New Jersey, Prentice-Hall, 1975. 387 p.

2 DENT, J.B. \& BLACKIE, M.J. Systems simulation in agriculture. London, Applied Science, 1979. $189 p$.
} 


\subsection{Avaliação de modelos}

Os modelos são uma aproximação simplificada da realidade, sem significar a própria realidade e sem se constituir na sua réplica (BERGAMIN FILHO, 1978), no entanto não podem perder de vista a precisão na simulação do sistema como um todo (WAGGONER, 1990).

Os testes têm por objetivo determinar se o comportamento do sistema real é bem simulado pelo modelo construído (TENG, 1981).

Os modelos devem ser simples (CAMPBELL \& MADDEN, 1990) e com parâmetros (dados de entrada - INPUT) de fácil observação (VENTURA, 1984) para alcançar sucesso e utilização pelos usuários.

Segundo FEGIES (1985), além de ser essencial que os modelos tenham um objetivo bem definido, é desejável que sejam:

a) razoavelmente simples e consistentemente lógicos;

b) capazes de fornecer previsões;

c) matematicamente corretos;

e principalmente que sejam válidos e confiáveis (KRANZ \& ROYLE, 1978). A correção matemática e a validade do modelo são obtidos através de avaliações durante e principalmente após sua construção.

De acordo com CAMPBELL E MADDEN (1990), as avaliações dos modelos podem ser divididas em verificação, que trata da correção matemática, validação, que compara os dados de saída do modelo como o mundo real, e análise de sensitividade, que permite observar a influência das diversas variáveis no modelo.

A verificação é relativa a aspectos da estrutura do modelo, determina se o simulador foi construído corretamente. A validação é relativa a aspectos de desempenho ("performance") do modelo, ela determina se foi construído o simulador certo (PRESSMAN, 1987).

\subsubsection{Verificação de um modelo}

Alguns textos não fazem distinção entre verificação e validação. Os elaboradores devem ter em mente que são dois testes distintos (JEFFERS, 1988). Verificação envolve a comparação da estrutura e comportamento geral do modelo com o sistema real, isto é, assegura que o modelo faça aquilo que se intenciona que ele faça 
(CAMPBELL \& MADDEN, 1990) e que ele atenda aos seus objetivos iniciais. Outro aspecto da verificação é a checagem da validade das rotinas que compõem o modelo, garantindo a ausência de erros de sintaxe na codificação (TENG, 1981).

A verificação de modelos simples é fácil mas, para modelos de simulação pode ser complexa. Ela é especialmente importante para esclarecer o comportamento do sistema em um nível complexo de conhecimento partindo-se de um nível conhecido (WAGGONER, 1990). Penning de Vries ${ }^{1}$ citado por WAGGONER (1990) afirma que mesmo se construindo cuidadosamente um programa de simulação, frequentemente ocorrem erros técnicos simples, tais como dimensionamento incorreto de parâmetros, variáveis ou equações incompletas. Os avaliadores do modelo deverão eliminar tantos erros quanto possíveis antes de considerá-lo concluído. Entretanto, nenhuma garantia pode ser dada de que o modelo é realmente livre de erros.

\subsubsection{Validação de um modelo}

A validação é uma comparação quantitativa de uma epidemia real com dados de saída ("output") do modelo de simulação, gerados a partir de um conjunto de dados de entrada ("input"), que abrangem condições ambientais, características do patógeno e do hospedeiro (TENG, 1981; CAMPBELL \& MADDEN, 1990).

A abordagem a ser usada para validar um modelo dependerá do ponto de vista sob o qual pretende-se validá-lo (TENG, 1985). Sob o ponto de vista positivista, um modelo é considerado válido se ele for capaz de realizar prognósticos acuradamente sem levar em consideração sua estrutura ou lógica interna. Sob o ponto de vista empiricista, um modelo só é considerado válido se todos os seus postulados e hipóteses forem verificados independentemente por experimentos. Sob o ponto de vista racionalista, o modelo será considerado válido se forem definidas quais devem ser as premissas de verdade inquestionável que originaram a sua estrutura. E o ponto de vista utilitário da validação usa seletivamente os três conceitos, procurando ligar a validade à utilidade do modelo (TENG, 1981).

\footnotetext{
1 PENNING de VRIES, F.W.T. \& VAN LAAR, H.H. Simulation of plant growth and crop production. Pudoc Wageningen, 1982, p.20.
} 


\subsubsection{Critérios de validação}

Baseado no ponto de vista utilitário, a validação pode ser executada basicamente de dois modos: usando-se critérios subjetivos, tais como comparação direta através da plotagem de curvas de epidemias reais contra simuladas, em um gráfico, ou usando critérios estatísticos, tais como análise de regressão e correlação (TENG, 1981; HAU, 1988).

A comparação gráfica subjetiva consiste em se plotar os dados simulados contra dados reais numa mesma escala em ambos os eixos. Dois critérios são importantes na avaliação (CARTER, 1986): a forma das curvas e a concordância quantitativa dos dados. TENG (1985) cita que esse tipo de teste é muito utilizado e HAU et al. (1985) além de aprovarem esse método, sugerem que a plotagem dos dados reais seja feita com um intervalo de confiança de $90 \%$, devido ao erro de amostragem que ocorre na coleta de dados no campo.

Outro teste subjetivo sugerido por TENG (1981) é o teste de Turing. Consiste em se fornecer um conjunto de dados reais e simulados para uma pessoa que seja familiar com o patossistema em questão; se a pessoa conseguir distinguir entre o real e o simulado então há algo errado com o modelo.

Entre os critérios estatísticos de validação, Feldman et al. ${ }^{1}$, citados por HAU (1988), propuseram o uso de procedimentos estatísticos ao invés de testes estatísticos padrões, pois estes não são aplicáveis para séries que envolvem tempo em processos dinâmicos como é o caso de uma epidemia. Um exemplo de procedimento estatístico é a análise de regressão linear dos pontos observados contra os pontos simulados que deve produzir um $b 0$ (ponto de interceptação da linha de regressão) não significativamente diferente de zero e um $b l$ (coeficiente de regressão) e $r$ (coeficiente de correlação) não significativamente diferente de um. Já os testes estatísticos padrões usam o teste de $\mathrm{t}$ ou o teste de F para testar $b 0$ e $b 1$.

Outro exemplo de critério estatístico são os métodos não paramétricos tal como o teste Kolmogorov-Smirnov, que mede a significância da maior distância vertical entre as duas curvas, mas tem a desvantagem de não demonstrar discrepâncias significativas quando os números são baixos (CARTER, 1986).

\footnotetext{
1 FELDMANN, R.M.; CURRY, G.L.; WEHRLY, T.E. Statistical procedure for validating a simple population model. Environ. Entomol. 13:1446-51, 1984.
} 
TENG (1981) em sua revisão sobre validação de modelos de epidemias, sugere para a validação através de critérios estatísticos, o uso da análise de regressão e de correlação. Também sugere testes de ajuste, tais como determinação do coeficiente de correlação $(r)$, testes de média, e análise de variância e covariância. Todos esses testes devem ser aplicados para duas amostras, que no caso dos modelos são os dados do mundo real e os dados do modelo. Para a análise de regressão esse autor sugere que seja feita a regressão dos dados simulados contra os dados reais usando os testes de $\mathrm{F}$ e $\mathrm{t}$ para testar as diferenças. Para determinar o grau de associação entre dados simulados e observados o autor sugere o teste do Chi-quadrado e os testes não paramétricos como o teste Smirnov e teste Cramer-Von Mises.

\subsubsection{Escolha do melhor critério de validação}

Existe discussão sobre qual o critério de validação a se utilizar. CARTER (1986) cita que a validação subjetiva não é inteiramente satisfatória e que para a validação deverão ser utilizados testes estatísticos, porém não informa qual seria o melhor teste para tanto. Já SEEM \& HAITH (1986) alertam que, por serem os modelos baseados em hipóteses científicas, os critérios estatísticos não permitem sua validação, mas somente a invalidação. Afirmam ainda que há uma tendência de se despender esforços para invalidar modelos quando na verdade eles seriam aceitáveis.

HARRISON (1990) tem a mesma opinião de SEEM \& HAITH (1986). Esse autor cita que os procedimentos estatísticos de validação têm muitas armadilhas, principalmente a análise de regressão, e que portanto não são apropriados para validação de modelos. Sugere ainda que os métodos estatísticos sejam usados de maneira referencial e não conclusiva para comparar dados reais com dados gerados pelo modelo, e ainda que estes sejam combinados com procedimentos subjetivos tais como a comparação gráfica.

Há alguma controvérsia quanto a que tipo de critério utilizar para validar modelos, mas de uma maneira geral os autores (TENG, 1985; HAU, 1988; HARRISON, 1990) concordam que os critérios estatísticos podem ser prejudiciais à validação, pois normalmente um modelo é desenvolvido através de várias versões e a invalidade estatística de uma versão preliminar poderia prejudicar o desenvolvimento das versões subseqüentes, as quais podem até ser válidas perante os mesmos testes estatísticos. E, 
ainda deve-se aceitar que a validação é um processo contínuo para se chegar a um nível aceitável de acertos no modelo (TENG, 1981).

\subsubsection{Cuidados para validação de modelos}

Existem alguns cuidados que devem ser tomados na validação de modelos. Primeiramente, os dados de campo coletados de epidemias reais não podem ter sido utilizados no desenvolvimento do modelo (KRANZ \& ROYLE, 1978; TENG, 1981; HAU et al., 1985). Se o modelo tiver sido desenvolvido baseado em câmaras de crescimento então podem ser usados dados de campo sem maiores problemas (HAU et al., 1985).

Outro cuidado é de que a validação deva ser feita com dados não transformados (TENG, 1985; HAU et al., 1985), evitando-se dessa forma ajustes forçados.

HAU et al. (1985) alertam para que os modeladores usem a plotagem dos dados reais contra os simulados, apenas para comparar a forma das curvas. A escolha da melhor concordância é diretamente influenciada pelo ponto de referência em que ambas as curvas deverão ter o mesmo valor. Se for usada somente a intensidade de doença máxima como ponto de referência, poderá haver uma superestimativa da concordância.

\subsubsection{Análise de sensitividade}

Esta análise examina a sensibilidade da variação dos dados de saída (OUTPUT) em função da alteração de parâmetros, de variáveis e de outros fatores contidos em modelos específicos, os subsistemas (CAMPBELL \& MADDEN, 1990). A análise de sensitividade é essencial para simuladores desenhados para aplicações práticas, onde a acurácia dos parâmetros é limitante, pois quanto mais sensivel for a reação do sistema à alteração deste parâmetro, mais acuradamente ele precisa ser medido (KRANZ \& ROYLE, 1978).

Segundo TENG (1981), a análise de sensitividade é considerada um teste do modelo quanto à robustez dos dados de saída ("output") com relação à incorporação de parâmetros. Envolve a acurácia e a proporcionalidade pela qual o modelo responde a determinado fator. A análise de sensitividade pode ser feita com os mesmos dados usados para gerar o modelo (KRANZ \& ROYLE, 1978). 
Dois tipos de análise de sensitividade podem ser executados na construção ou na avaliação de simuladores de doenças de plantas. No primeiro caso, processos (subsistemas) são omitidos do modelo para testar seu efeito global. Para este tipo de análise de sensitividade, o modelo é executado duas vezes com o mesmo conjunto de dados de entrada (INPUT) sendo que uma das vezes é retirado o subsistema que se quer analisar (CAMPBELL \& MADDEN, 1990). Por exemplo, retira-se o subsistema responsável pelo período latente e coloca-se uma constante em seu lugar.

No segundo tipo, pequenas alterações acima ou abaixo do valor inicial são feitas para valores de parâmetros isolados (constantes), para estudar as consequências nos dados de saída do modelo. Por exemplo incrementar ou encurtar em 2 dias o período latente e avaliar os resultados (CAMPBELL \& MADDEN, 1990).

\subsubsection{Exemplos de uso de testes em alguns modelos}

SALL (1980) usou o teste do Chi-quadrado para comparar dados observados e simulados além da comparação visual, para validar um modelo para oídio da videira (Uncinula necator). $\mathrm{O}$ autor fez análise de sensitividade apenas para a variável 'dias das infecções iniciais'.

AUST et al. (1983) usaram apenas a comparação gráfica dos resultados observados e simulados para validar um modelo de simulação para oídio da cevada. Não descreveram testes de verificação nem de análise de sensitividade. Já HAU et al. (1985), também em um modelo para oídio da cevada, executaram os testes de análise de sensitividade para os dados de entrada do programa. A validação foi semelhante à usada por AUST et al. (1983) e não foram descritos testes de verificação.

KNUDSEN et al. (1987) utilizaram, para validar seu modelo para mancha de cercospora em amendoim, a média observada da epidemia no campo com um intervalo de confiança de $95 \%$ ao redor da amostra média plotado contra o resultado do modelo. Utilizaram também a área abaixo da curva de progresso de doença e a percentagem final de doença dos dados simulados comparados com os dados reais.

BOWEN \& PEDERSEN (1989), em um modelo para simulação de doenças em milho, usaram a área sob a curva de progresso da doença e a produtividade da cultura como parâmetros para validar o modelo. A análise de sensitividade foi feita apenas para alguns parâmetros do modelo. 
O trabalho de SAVARY et al. (1990) foi um dos poucos a descrever os três tipos de testes: verificação, validação e análise de sensitividade. Os autores demonstraram de forma gráfica a relação entre condições climáticas (chuva, umidade relativa máxima e mínima e radiação solar) e as principais variáveis do modelo ('variação diária no número de esporos da lesão' e 'fator de multiplicação diário'). Na análise de sensitividade usaram como resultado de comparação a área sob a curva de progresso da doença. Foram analisadas as principais variáveis do programa. A validação utilizou apenas a comparação gráfica dos dados simulados e observados em experimentos para ferrugem do amendoim.

TIMMERMANS (1990) usou apenas a comparação visual de gráficos na validação de um modelo para o sistema Erwinia amylovora - pera.

DJURLE \& YUEN (1991) usaram a variação em mais ou menos $20 \%$ dos valores das variáveis na análise de sensitividade de um modelo de simulação para Septoria nodorum em trigo. Na validação; os autores usaram apenas a comparação gráfica visual dos resultados observados e simulados.

YANG et al. (1991) usaram análise de regressão linear dos dados simulados contra os observados para validar seu modelo para ferrugem da soja.

\subsection{Uso de computadores na modelagem}

Até a década de 1980, os computadores não eram comumente utilizados pelos epidemiologistas e a partir de então, eles tornaram-se mais compactos e com uma maior capacidade de memória, o que aliado à rapidez nas respostas e à precisão matemática difundiu o seu uso (ISHIGURO \& HASHIMOTO, 1991). CAMPBELL \& MADDEN (1990) citam uma relação de pelo menos 19 modelos desenvolvidos para sistemas patógeno/hospedeiro, iniciados a partir de 1969, quando Waggoner e Horsfall ${ }^{1}$ desenvolveram o EPIDEM para a pinta preta do tomateiro.

Os equipamentos mais utilizados atualmente para o desenvolvimento de programas de simulação e de previsão de epidemias são computadores compatíveis com a linha IBM PC, que dispõem de uma base instalada representativa em muitos países, inclusive no Brasil, onde é produzido por diversos fabricantes (AZEVEDO FILHO, 1988).

\footnotetext{
1 WAGGONER, P.E. \& HORSFALL, J.G. EPIDEM, a simulator of plant disease written for computer.
} Conn. Agric. Exp. Bull. 698, 1969. 
As linguagens de programação mais utilizadas para montagem dos programas na área científica são FORTRAN, BASIC, PASCAL, ALGOL e a linguagem C. A linguagem FORTRAN, considerada uma linguagem científica, foi mais utilizada no início dos trabalhos com simuladores, principalmente em computadores de grande porte ("mainframes"). Com o passar do tempo, foi sendo substituida pela linguagem PASCAL, que possui compiladores disponíveis para a quase totalidade dos computadores que se enquadram na categoria dos equipamentos utilizados em aplicações profissionais (AZEVEDO FILHO, 1988). Além disso, a linguagem PASCAL dispõe de recursos que possibilitam a implementação de conceitos de programação estruturada, o que favorece a redução dos custos futuros de manutenção e possibilita um incremento na produtividade da fase de programação e da fase de testes (SHOOMAN, 1985).

A linguagem BASIC tem sido utilizada principalmente devido ao seu fácil aprendizado, o que permite aos epidemiologistas desenvolverem seus próprios programas de simulação de epidemias (BERGER, 1989). Como desvantagem apresenta a carência de melhores recursos gráficos e a falta de compiladores que gerem programas rápidos $\mathrm{e}$ de tamanho aceitável.

Apesar de poderosa, a linguagem " $C$ " na construção de simuladores é de uso ainda incipiente, ela apresenta como vantagem a portabilidade, isto é, pode ser utilizada tanto sob equipamentos de grande como de pequeno porte, e também sob diferentes sistemas operacionais. Como desvantagem está o tempo que requer para o seu aprendizado e a necessidade do uso de bibliotecas de rotinas prontas.

Existem linguagens específicas para simulações, tais como GPSS ("General purpose simulations systems"), GASP IV (baseada em FORTRAN) e SIMULA (baseada em $\mathrm{ALGOL)}$. Elas permitem uma programação mais rápida que as tradicionais pois a sua estrutura já prevê o uso de variáveis randômicas, de várias distribuições e também rotinas de armazenamento para calcular resumos estatísticos, que têm uso intenso na construção de modelos de simulação (MORGAN, 1984). Mas como o acesso a essas linguagens nem sempre é fácil, isto torna-se um fator limitante de sua utilização.

Nos últimos anos surgiram as linguagens de programação para o ambiente windows, entre elas destacam-se Basic e Pascal, que possuem praticamente todos os recursos de suas similares para o ambiente DOS, além de possuírem melhores recursos de apresentação. Como desvantagem têm o grande tamanho dos programas executáveis gerados, além de necessitarem do ambiente windows para executá-los. 
Com relação aos Sistemas Especialistas, eles podem ser desenvolvidos em quase todas as linguagens disponíveis, mas as linguagens orientadas a objeto ou linguagens simbólicas tais como LISP e PROLOG são as tradicionais linguagens da inteligência artificial (TRAVIS \& LATIN, 1991). Entretanto, as linguagens "Object C" e PASCAL têm se tornado mais populares pela rapidez, menor consumo de memória e maior compatibilidade com operações baseadas na linha PC.

Outras linguagens também são utilizadas no desenvolvimento de programas em fitopatologia, tais como linguagem CSMP (TENG et al., 1991), ou ainda são desenvolvidas linguagens, principalmente para sistemas especialistas, tais como 'Insight2+' e 'Savior' (TRAVIS \& LATIN, 1991).

\subsection{Sistemas especialistas ("expert systems") em fitopatologia}

A tradução mais aceita para o termo "Expert systems" tem sido Sistemas Especialistas. São programas de computador que emulam a lógica e a capacidade de resolução de problemas de um especialista ("expert") humano (TRAVIS \& LATIN, 1991), isto é, utilizam-se da inteligência artificial para resolver problemas.

A discussão sobre o uso de Sistemas Especialistas em fitopatologia iniciou em 1987 na reunião anual da American Phytopathological Society. No Brasil, ainda não se tem relato do uso dessa técnica de programação em doenças de plantas.

Os precursores dos sistemas especialistas surgiram no fim da década de 1970. São os modelos de previsão de doença Blitecast (KRAUSE et al., 1975) e o sistema de previsão da sarna da maçã (JONES et al., 1980). Entretanto, os programas escritos para esses modelos utilizavam-se de técnicas convencionais de programação. $O$ primeiro sistema especialista em fitopatologia surgiu em 1983 com o PLANT/ds (MICHALSKI et al., 1983) escrito para diagnóstico de 17 tipos de doenças de soja em Illinois, USA.

Os sistemas especialistas têm a vantagem de sugerir uma solução para o problema, pois empregam, à semelhança dos humanos, a heurística e técnicas de resolução de problemas baseados na experiência. São freqüentemente aplicados como ferramentas que podem interpretar complexas informações e ajudar o usuário no processo de tomada de decisão. São empregados com maior sucesso em áreas bem definidas com problemas específicos em que especialistas podem fornecer o conhecimento requerido. Esse conhecimento é codificado e armazenado em bases de 
dados e poderá ser empregado na tomada de decisão pelo sistema especialista (TRAVIS \& LATIN, 1991).

Uma caracteristica dos sistemas especialistas, que os distinguem dos programas convencionais, é sua habilidade em usar dados incompletos ou incorretos, semelhante a um especialista humano em que, se dados parciais forem fornecidos, ele não dará certeza absoluta na resposta (TRAVIS \& LATIN, 1991).

Técnicas de desenvolvimento, avaliação e adoção de Sistemas especialistas em fitopatologia são explanadas por TRAVIS \& LATIN (1991) e HARRISON (1991). 


\section{MATERIAL E MÉTODOS}

Os trabalhos foram desenvolvidos tendo como objeto de estudo um programa para simulação de epidemias de ferrugem do feijoeiro denominado FERRUGEM (BERGER ${ }^{1}$ ). Foram feitas avaliações buscando-se três aspectos: verificar se os resultados gerados pelo simulador correspondiam à realidade biológica, comparar os dados gerados pelo simulador com os dados observados no campo e analisar a sensitividade do modelo pela alteração no valor dos parâmetros iniciais. Os dados reais de progresso da epidemia de ferrugem do feijoeiro foram coletados nos experimentos conduzidos em Piracicaba-SP (BACCHI, 1993), com as linhagens Rosinha G-2/C-21 e Carioca C-224.

\subsection{Programa de simulação FERRUGEM}

O simulador foi desenvolvido por R.D. Berger, baseado no modelo "daily cohort" (BERGER \& JONES, 1985; BERGER, 1989), utilizando-se dados obtidos sob condições controladas por MENDES \& BERGAMIN FILHO (1989a, 1989b, 1990) e BACCHI (1993). No modelo, para cada dia simulado, todos os sítios do hospedeiro são agrupados em um conjunto chamado "cohort". O modelo se baseia na diferença de quantidade entre tecido sadio, infectado e doente e não na proporção de doença, o que permite a simulação de epidemias em hospedeiro em crescimento. A taxa básica de infecção corrigida (VANDERPLANK, 1963) é decrescente em função do aumento na quantidade de doença.

O programa foi escrito em linguagem Basic, passou por várias versões e posteriormente foi adaptado para a linguagem Pascal por WEBER ${ }^{2}$. Isso foi feito

1 BERGER, R.D. (University of Florida, Plant Pathology Department) Comunicação pessoal, 1993.

2 WEBER, G.W. (Justus-Liebig-University of Giessen, Department of Phytopathology) Comunicação pessoal, 1993. 
buscando-se maior rapidez na execução do programa, otimização no uso da memória pelas variáveis, melhor apresentação dos gráficos e também procurando deixá-lo mais fácil para futuros usuários ("user friendly"). A transcrição constou da identificação das rotinas em Basic com tradução para Pascal, sendo utilizado o compilador Turbo Pascal, versão 6.

O simulador, além de possuir as características do modelo "daily cohort" (BERGER, 1989), apresentava algumas particularidades, a saber: período latente dependente da temperatura, taxa de infecção dependente do molhamento foliar e da temperatura e rotinas de crescimento do hospedeiro para cada cultivar nas diferentes épocas de plantio. Além disso, o modelo se baseava em tecido infectado e não em tecido doente para calcular o progresso da doença. Nas execuções do programa foi usada como dado de entrada a proporção de doença inicial observada no tecido do hospedeiro. Para transformar proporção de tecido doente em proporção de tecido infectado havia a rotina 'Distribuição das Primeiras Infecções', que fazia a estimativa baseando-se no período latente.

Os parâmetros usados para construção das rotinas 'Latência' e 'Favorabilidade' foram obtidos de uma série de experimentos em câmaras de crescimento (MENDES \& BERGAMIN FILHO, 1989a, 1989b; BACCHI, 1993).

Um algoritmo com as rotinas do programa pode ser visto na Tabela 1. A ordem de chamada das rotinas pode ser resumida da seguinte forma:

\section{Início}

Rotina Zerar

Rotina Entrada de Dados

Rotina Ciclo Diário

Rotina Saída de Dados

$\underline{\text { Fim }}$ 
Tabela 1: Algoritmo representando o funcionamento do modelo para simulação de epidemias da ferrugem do feijoeiro.

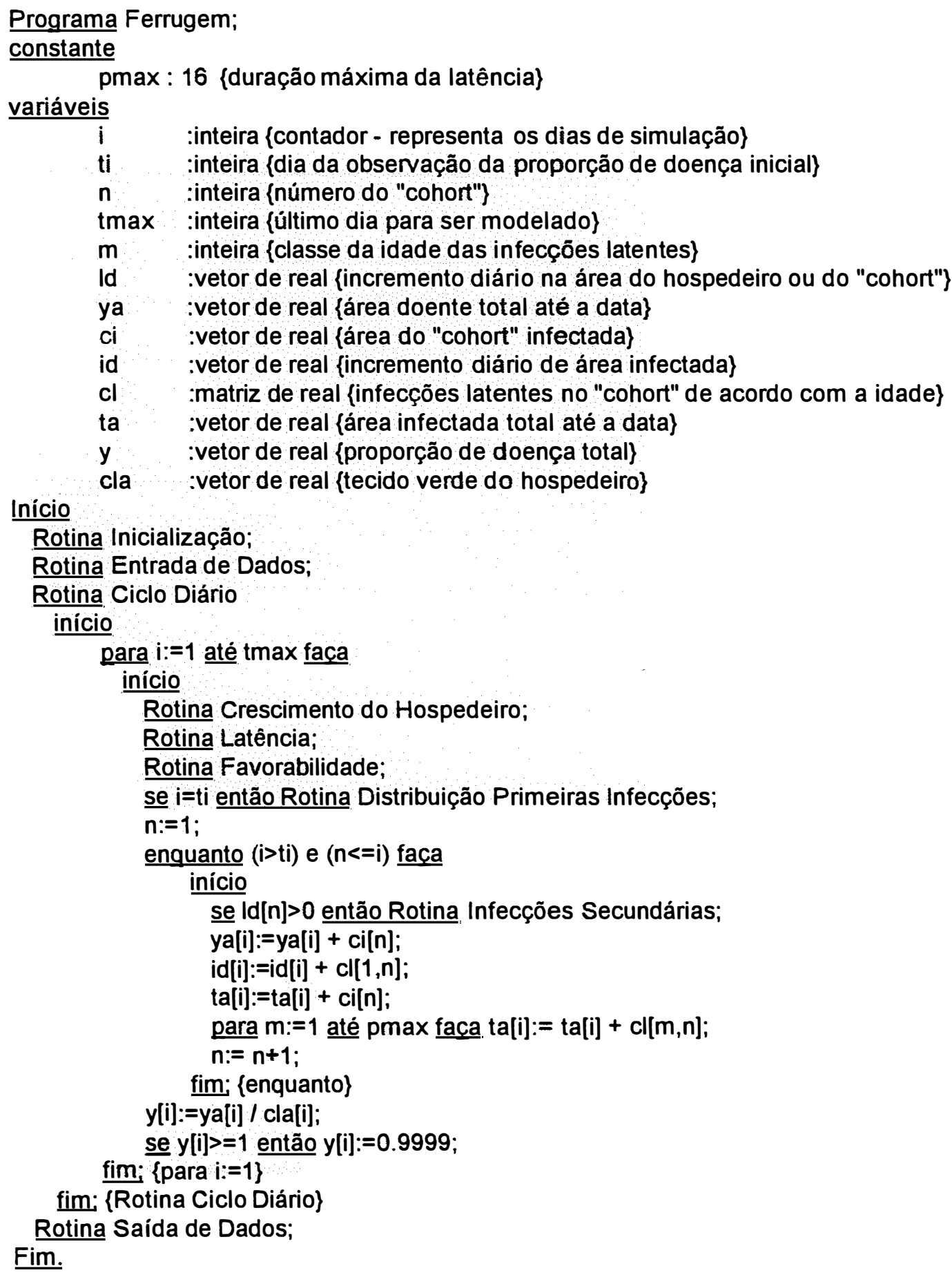


Dentro da rotina 'Ciclo Diário' são chamadas as rotinas 'Crescimento do Hospedeiro', 'Latência', 'Favorabilidade', 'Distribuição Primeiras Infecções', 'Infecções Secundárias', e ainda dentro da rotina 'Infecções Secundárias', é chamada a rotina 'Sensibilidade do Hospedeiro'.

A rotina 'Zerar' substitui por zero 0 valor de todas as variáveis utilizadas no programa, a fim de evitar erros com resíduos da execução de simulações anteriores. A rotina 'Entrada de Dados' permite que se forneçam os valores das variáveis que serão utilizadas nos transcorrer da simulação. São elas:

host : determina as constantes a serem usadas na rotina 'Crescimento do Hospedeiro';

tr : dia da primeira remoção na área foliar do hospedeiro;

tmax : último dia a ser modelado;

$R m$ : taxa básica de infecção corrigida máxima (BERGER, 1989);

fi : proporção de doença inicial no tecido do hospedeiro;

ti : dia da observação da proporção de doença inicial;

ein_name: nome do arquivo que contém os dados de temperatura máxima, mínima e horas de molhamento.

A rotina 'Ciclo Diário' é a principal do programa e a rotina 'Saída de Dados' cria arquivos gravados em disco com o valor de todas as variáveis para cada execução da rotina 'Ciclo Diário'.

Todas as subrotinas que compõem a rotina 'Ciclo Diário' são importantes para os cálculos executados no programa. A rotina 'Crescimento do Hospedeiro' utiliza a variável host, fornecida na rotina 'Entrada de Dados', para selecionar as constantes a serem usadas no cálculo do crescimento. A equação que realiza o cálculo do crescimento do hospedeiro é:

$$
l a=b 1 *\left(1-\exp (b 2+b 3 * i)^{b 4}\right)
$$

onde $l a$ é a área total do hospedeiro até o dia $I$. As principais constantes da equação são $b 1$ e $b 3$. A determinação da quantidade máxima de área foliar do hospedeiro é função de $b 1$, e $b 3$ é responsável por determinar o início do crescimento acelerado do hospedeiro, influenciando o formato da curva de crescimento. A rotina 'Latência' usa dados de temperatura máxima e mínima, fornecidos pelo arquivo ein_name, para calcular o 'período latente' $(p)$ de cada dia simulado. Há um patamar máximo fixado em 16 , caso o 'periodo latente' ultrapasse esse valor. A rotina 'Favorabilidade', além dos dados de temperatura, utiliza os dados de horas de molhamento também fornecidos pelo arquivo ein_name. Portanto é essa rotina juntamente com a rotina 'Latência' que definem a 
importância do clima na infecção. A rotina 'Distribuição Primeiras Infecções' transforma a 'proporção de doença inicial' $(f)$ em proporção de infecção inicial, já que o modelo se baseia em área infectada e não em área doente. A rotina 'Sensibilidade do Hospedeiro' realiza cálculos para simular a tendência de aumento na resistência do hospedeiro a novas infecções com o passar do tempo.

Dentro da rotina 'Infecções Secundárias' encontra-se a equação central do programa responsável pelo cálculo da área infectada:

$$
c i d=R m * a c f * f a v * y a(i-1) * l d / l a *(1-c t i / l d) ;
$$

onde cid é a 'área infectada' dentro do 'incremento diário de área foliar do hospedeiro' (ld). Para seu cálculo necessita-se da 'taxa básica de infecção corrigida máxima' $(R m)$, da 'suscetibilidade do hospedeiro no "cohort" ' (acf), da 'favorabilidade climática' (fav), da 'área doente total no dia anterior' $(y a(i-I))$, da razão entre o 'incremento diário' e a 'área total do hospedeiro' (ld/la), e da 'proporção de área foliar não infectada no hospedeiro' $(1-c t i / l d)$.

O parâmetro $R m$ é fornecido na rotina 'Entrada de Dados'. O acf é calculado na rotina 'Sensibilidade do Hospedeiro'. O fov é calculado na rotina 'Favorabilidade' em função dos dados de temperatura máxima, mínima e horas de molhamento fornecidos no arquivo ein_name. O ya(i-1) é calculado dentro da rotina 'Infecções Secundárias', e necessita do cálculo do 'período latente' $(p)$ fornecido pela rotina 'Latência'. Os parâmetros relativos à área foliar do hospedeiro são calculados na rotina 'Crescimento do Hospedeiro'. Portanto observa-se que a equação central necessita do auxílio de todas as subrotinas do programa para calcular a 'área infectada' (cid).

\subsection{Dados de campo utilizados nos testes.}

Com o objetivo de obter dados para a validação do modelo, foram conduzidos ensaios experimentais com a cultura do feijoeiro em Piracicaba - SP.

\subsubsection{Ensaios com inóculo natural}

Foram utilizados dados de três campos experimentais (BACCHI, 1993), com datas de cultivos diferentes, tendo como fonte de inóculo apenas esporos vindos de outros campos de feijoeiro. As semeaduras foram realizados em julho de 1990, julho de 
1991 e junho de 1992, na área pertencente ao campo experimental do Departamento de Fitopatologia da ESALQ/USP.

Foram utilizadas linhas de $15 \mathrm{~m}$ de comprimento, sendo 10 linhas da cultivar Carioca e 10 de Rosinha, formando uma parcela de $90 \mathrm{~m}^{2}$ para cada cultivar. Foi deixado um espaço de $1,20 \mathrm{~m}$ entre as duas parcelas. 0 espaçamento entre linhas foi 0,60 m com densidade de semeadura de 15 sementes por metro linear.

Os campos receberam os mesmos tratos culturais de uma lavoura comercial, incluindo controle de pragas se necessário. Não foi aplicado fungicida em qualquer um dos campos. Um abrigo metereológico contendo termohigrógrafo foi colocado entre as duas parcelas, sendo que o sensor de molhamento ficou entre as primeiras linhas úteis dentro de uma das parcelas. $\mathrm{O}$ equipamento registrou a temperatura e o período de molhamento durante todo o tempo que a cultura ficou no campo.

As avaliações iniciaram-se no quarto dia após a emergência das plantas e seguiram numa periodicidade de 3 à 7 dias até o fim do ciclo da cultura. A área útil foi considerada como sendo as 8 linhas centrais dentro de cada parcela.

Em cada data de avaliação, cinco plantas de cada cultivar foram arrancadas e suas folhas foram desenhadas para posterior cálculo da área foliar. Foi anotada a posição de cada folha na planta e foi contado o número de pústulas com seus respectivos diâmetros em cada folha. A doença foi expressa em proporção de área foliar doente, através do cálculo da área das pústulas de diferentes diâmetros. A área foliar ocupada com halos não foi considerada na avaliação da quantidade de doença.

\subsection{Ensaios com inoculação artificial}

Foram utilizados dados de um campo experimental implantado no dia 29

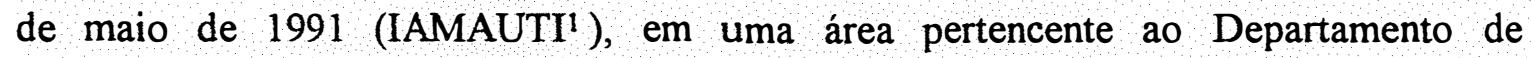
Fitopatologia da ESALQ/USP.

A semeadura foi feita com espaçamento de $0,50 \mathrm{~m}$ entre linhas, semeandose um número suficiente de sementes para obter 10 plantas por metro linear no "stand" final. Todas as práticas culturais recomendadas, tais como tratamento de semente, fertilização, controle de insetos e de plantas daninhas, foram feitas para permitir condições ideais de desenvolvimento da cultura.

\footnotetext{
1 IAMAUTI,M.T. (ESALQ/USP) Avaliação de perdas ocasionadas por Uromyces appendiculatus em feijoeiro. (Em elaboração).
} 
A emergência ocorreu oito dias após a semeadura e quando as plantas apresentaram o quarto trifólio foram marcadas $25 \mathrm{com}$ fitas coloridas. Estas plantas foram escolhidas ao acaso dentro de cinco parcelas (6 linhas de 6 metros), onde uma área útil de 4 linhas de 4 metros foi demarcada, ficando o restante como bordadura para evitar a interferência entre parcelas.

As cinco parcelas foram inoculadas com uma suspensão de uredosporos de $U$. appendiculatus, nas seguintes concentrações em uredosporos $/ \mathrm{ml}: 10^{2}, 10^{3}, 10^{4}$, $10^{5}, 10^{6}$, respectivamente. A inoculação foi feita 27 dias após a emergência, quando as primeiras pústulas de ferrugem foram observadas no campo. Para essa operação foi usado um equipamento de pulverização a ultra-baixo-volume (UBV), que permite uma boa distribuição para pequenos volumes de água.

As avaliações iniciaram-se aos 28 dias após a emergência e foram repetidas a intervalos de 3 a 4 dias até o fim do ciclo da cultura, com exceção das duas últimas feitas a intervalos de 10 e 7 dias, respectivamente. Durante as avaliações, para todas as plantas marcadas, a área foliar e a severidade de doença foram medidas. A área foliar foi obtida contando-se o número de folhas trifolioladas e medindo-se a largura do folíolo intermediário, desde que esse fosse maior que $2 \mathrm{~cm}$. Os dados foram substituídos na equação

$$
Y=2.137 *\left(X^{1.964}\right)+(-2.701) \text {, }
$$

onde $Y$ representa a área da folha trifoliolada e $X$ a largura do foliolo (IAMAUTI ${ }^{1}$ ).

A área foliar doente foi medida nas plantas marcadas contando-se o número de pústulas presentes em todas as folhas da planta. Durante a contagem, as pústulas eram classificadas de acordo com seu tamanho, com a ajuda de uma escala, que permitiu calcular a área de cada pústula. A doença foi expressa em proporção de área foliar doente para cada planta em cada avaliação. A área foliar ocupada com halos não foi considerada na avaliação da área doente.

\subsection{Avaliação do modelo FERRUGEM}

Os testes foram realizados em microcomputador padrão IBM-PC (AT386) e foram divididos em verificação, validação e análise de sensitividade.

1 IAMAUTI, M.T. (ESALQ/USP) Comunicação pessoal, 1993. 


\subsubsection{Verificação do modelo}

A verificação foi realizada com o propósito de averiguar se o modelo realmente simulava o progresso de uma epidemia de ferrugem do feijoeiro. Foram executados o teste da caixa preta ("black box") e o teste da caixa branca ("white box") (PRESSMAN, 1987).

O teste da caixa preta se preocupou com os dados de entrada e saída das subrotinas do programa, sem se preocupar com o processamento. Foram testadas as subrotinas que compõem a rotina 'Ciclo Diário': 'Crescimento do Hospedeiro', 'Latência', 'Favorabilidade', 'Distribuição Primeiras Infecções', 'Infecções Secundárias' e 'Sensibilidade do Hospedeiro'. Para cada subrotina fez-se duas execuções do programa. $\mathrm{Na}$ primeira, retirou-se a rotina em questão e verificou-se o comportamento do simulador. Na segunda, incorporou-se a rotina e esperou-se que a simulação apresentasse um incremento diário na quantidade de doença. Foram usados como dados de entrada os parâmetros obtidos para a cultivar Carioca em 1990.

O teste da caixa branca procurou verificar se as principais rotinas do programa se comportavam de acordo com a realidade biológica e se apresentavam uma consistência lógica em seu processamento. As subrotinas testadas, que pertenciam à rotina 'Ciclo Diário', foram: 'Crescimento do Hospedeiro', 'Latência', 'Favorabilidade' e 'Sensibilidade de Hospedeiro'.

O teste para a rotina 'Crescimento do Hospedeiro' foi feito através das variáveis 'área foliar total do hospedeiro' (la), 'área foliar removida do hospedeiro' $(r a)$ e 'área foliar corrigida do hospedeiro' ( $(l a)$. Executou-se várias vezes o programa e os valores das variáveis foram plotados em gráficos para cada ano de plantio, para as cultivares Carioca e Rosinha.

Para a rotina 'Latência' foram criados treze arquivos auxiliares de clima, com temperaturas máxima e mínima constantes. As temperaturas mínimas utilizadas foram $26,24,22,20,18,16,14,12,10,8,6,4$ e $2{ }^{\circ} \mathrm{C}$, e as temperaturas máximas foram os valores de temperatura mínima acrescidos de $8(34,32,30,28,26,24,22,20,18,16$, 14, 12 e 10). Usando-se estes arquivos executou-se várias vezes o programa. Em função dos resultados da variável 'período latente' $(p)$ construiu-se um gráfico associando temperatura com 'período latente'.

A rotina 'Favorabilidade' foi testada com a ajuda de um arquivo auxiliar de clima onde foram feitas combinações de temperatura com horas de molhamento. Para o 
molhamento foliar foram usadas $4,8,12,16,20$ e 24 horas, para a temperatura mínima usou-se $28,26,24,22,20,18,16,14,12,10,8,6$ e $4^{\circ} \mathrm{C}$ e como temperatura máxima os valores da temperatura mínima acrescidos de $8(36,34,32,30,28,26,24,22,20,18,16$, 14 e $\left.12{ }^{\circ} \mathrm{C}\right)$. Em função dos resultados apresentados pela variável 'favorabilidade climática' (fav), construiu-se dois gráficos tridimensionais com temperatura, horas de molhamento e favorabilidade. $\mathrm{O}$ arquivo auxiliar de clima foi usado em duas execuções do programa, uma para a cultivar Carioca e outra para a Rosinha.

Além dos testes já descritos para as rotinas 'Latência' e 'Favorabilidade', foram executadas simulações usando os dados dos plantios de 1990, 1991 e 1992. Foram usados dados climáticos dos respectivos anos. Observou-se o comportamento das variáveis 'período latente' $(p)$, 'favorabilidade climática' (fav) e também a variável 'incremento diário na área infectada' (id). Foram feitos gráficos para cada ano de plantio, com a plotagem do valor das variáveis.

Para a rotina 'Sensibilidade do Hospedeiro' testaram-se as variáveis 'suscetibilidade da planta' (ahf) e 'suscetibilidade do "cohort" ' (acf), mas apenas a variável ahf foi plotada em um gráfico com seu valor para cada dia de simulação. Executou-se o programa uma vez e observou-se os valores das variáveis. A variável acf apresenta comportamento semelhante à ahf.

\subsubsection{Validação do modelo}

O processo de validação do modelo FERRUGEM consistiu em se comparar os dados gerados pelo simulador com os dados observados no campo nos diversos plantios. Utilizou-se o termo "Caso" para denominar cada uma das estações de plantio ou tratamento. A Tabela 2 traz a descrição de cada Caso.

Para os dados de proporção de doença (y) coletados no campo (dados reais), foi calculado um intervalo de confiança de $90 \%$ sugerido por HAU et alii (1985), visando diminuir o erro amostral na comparação com os dados simulados. Para a plotagem dos dados foram transformados os valores médio, máximo e mínimo de proporção de doença em logito $(\ln (y /(1-y))$.

No simulador foi feita a calibração para a variável 'taxa básica de infeç̧ão corrigida máxima' $(R m)$, pois seu valor altera-se em função da cultivar e do espectro de raças do patógeno. Foram feitas várias simulações, trocando-se o valor da variável $R m$ e comparando-se os resultados com os dados observados buscando-se o melhor ajuste. 
Tabela 2. Parâmetros usados nos diversos Casos para a validação do modelo para simulação de epidemias de ferrugem do feijoeiro.

\begin{tabular}{|c|c|c|c|c|c|c|c|c|}
\hline Nome & Inóculo & $\begin{array}{c}\text { Esporosl } \\
\mathrm{ml}\end{array}$ & Época & Cultivar & $\begin{array}{c}\text { Dia inicial } \\
\text { da } \\
\text { simulação }\end{array}$ & $\begin{array}{l}\text { Dia final da } \\
\text { simula- } \\
\text { ção* }\end{array}$ & $R m$ & $\begin{array}{c}\text { Proporçáa } \\
\text { o de } \\
\text { doença } \\
\text { inicial }\end{array}$ \\
\hline Caso 1 & natural & - & julho/ 90 & Carioca & 14 & 71 & 26 & $2,15.10^{-5}$ \\
\hline Caso 2 & natural & - & julho/91 & Carioca & 8 & 78 & 26 & $1,59 \cdot 10^{-6}$ \\
\hline Caso 3 & natural & - & julho/92 & Carioca & 26 & 72 & 26 & $3,78 \cdot 10^{-6}$ \\
\hline Caso 4 & natural & - & julho/90 & Rosinha & 14 & 71 & 40 & $4,32.10^{-6}$ \\
\hline Caso 5 & natural & - & julho/91 & Rosinha & 11 & 56 & 40 & $9,05.10^{-7}$ \\
\hline Caso 6 & natural & - & julho/92 & Rosinha & 22 & 72 & 40 & $5,76.10^{-6}$ \\
\hline Caso 7 & artificial & $10^{2}$ & maio/91 & Rosinha & 42 & 76 & 40 & $2,62.10^{-5}$ \\
\hline Caso 8 & artificial & $10^{3}$ & maio/91 & Rosinha & 42 & 76 & 40 & $5,56.10^{-5}$ \\
\hline Caso 9 & artificial & $10^{4}$ & maio/91 & Rosinha & 42 & 76 & 40 & $4,42.10^{-5}$ \\
\hline Caso 10 & artificial & $10^{5}$ & maio/91 & Rosinha & 42 & 76 & 40 & $1,78.10^{-4}$ \\
\hline Caso 11 & artificial & $10^{6}$ & maio/91 & Rosinha & 42 & 76 & 40 & $3,99.10^{-5}$ \\
\hline
\end{tabular}

Após realizada a calibração foram executadas uma ou várias simulações para cada caso. O programa teve como dados de entrada a época de início da epidemia, representada em números de dias após a emergência das plantas, a proporção de doença nesse dia, o dia final de simulação e um arquivo com dados de temperatura e de molhamento para cada dia.

Para os Casos 1 a 6 padronizou-se como dia de início das simulações o dia da segunda avaliação de campo que apresentasse doença. Para os Casos de 7 a 11 usouse 0 42ㅇ dia após a emergência (15 dias após inoculação) como dia de início das simulações. A quantidade de doença usada para inicialização ("Input") foi a proporção média de doença observada no campo no dia determinado para o início. Após a primeira simulação, se pela observação visual, o ajuste entre os dados simulados e observados não fosse satisfatório, fazia-se uma segunda, alterando-se a quantidade de inóculo inicial para outro valor, mas dentro do intervalo de confiança calculado. Se mesmo assim os dados simulados ficassem discordando muito dos observados, fazia-se uma terceira simulação 
alterando-se o valor da variável 'taxa básica de infecção corrigida máxima' $(R m)$, e usavase novamente como quantidade de doença inicial o valor médio de proporção de doença observado em campo.

A comparação entre os dados gerados pelo simulador e os dados observados em campo foi realizada, para cada simulação, de quatro maneiras:

- através de comparação gráfica dos resultados;

- através de regressão linear dos dados simulados contra os observados;

-através de comparação dos resultados da área abaixo da curva de progresso da doença;

-através de comparação dos coeficientes $b_{0}$ e $b_{1}$ das equações de regressão dos dados simulados e observados.

O simulador apresentou como resultado os valores de proporção de doença e o logito desse valores, calculados para cada dia desde o início da epidemia até o dia final. Os valores simulados, em forma de curva, juntamente com os observados no campo, em forma de pontos, foram plotados em gráficos, com logito no eixo das ordenadas e dias após emergência no eixo das abcissas. No mesmo gráfico, a área dentro do intervalo de confiança de $90 \%$, calculada para os dados observados, foi plotada em uma tonalidade diferente.

A regressão linear foi feita para cada simulação, utilizando-se os dados de proporção de doença simulados contra os observados. Fez-se uma análise de variância da regressão e usou-se o teste de $\mathrm{F}$, ao nível de $5 \%$ de significância. Além disso observou-se a constante $\left(b_{0}\right)$ e o coeficiente angular $\left(b_{1}\right)$ da equação de regressão, e o coeficiente de determinação $\left(r^{2}\right)$, esperando-se que seus valores não diferissem de 0,1 e 1 , respectivamente. Para a regressão não foram usados os dados anteriores ao dia de início da epidemia simulada e nem aqueles em que as avaliações de campo não constataram presença da doença.

A área sob a curva de progresso de doença (ASCPD) foi calculada para os dados observados usando-se a proporção de doença encontrada nos dias das avaliações, e para os dados simulados foram usados os valores de quantidade de doença calculado para cada dia de simulação.

Foi feita também a comparação dos dados simulados e observados baseada no teste de t. Foram comparados a constante $\left(b_{0}\right)$ e o coeficiente angular $\left(b_{1}\right)$ das equações obtidas pela análise de regressão linear da severidade de doença expressa 
em logito. O teste foi realizado para todas as simulações após se fazer a regressão linear dos dados observados e dos simulados, sendo:

$$
t=b_{10}-b_{1 s} / \sqrt{\operatorname{var} b_{10}+\operatorname{var} b_{1 s}}
$$

onde $b_{1 o}$ é o coeficiente angular da equação obtida com a regressão dos dados observados versus o tempo, $b_{l s}$ é o coeficiente angular da equação obtida com a regressão dos dados simulados contra o tempo, var $b_{10}$ é a variância de $b_{1 o}$, e var $b_{1 s}$ é a variância de $b_{1 s}$. A comparação dos valores da constante $\left(b_{0}\right)$ também foi feita com 0 teste de $t$, substituido-se na equação os valores de $b_{I}$ pelos valores de $b_{0}$.

\subsubsection{Análise de sensitividade}

Avaliou-se a variação dos dados simulados em função da alteração em valores das variáveis, constantes e rotinas do programa para simulação de epidemias de ferrugem do feijoeiro. Os resultados obtidos do simulador estão expressos de três maneiras no formato de um gráfico tridimensional; no formato de curvas de progresso de doença plotadas em gráficos; e no formato de uma tabela. Em todos os casos, a sensitividade do modelo à alteração nos parâmetros testados foi determinada pela variação na proporção de doença no fim da epidemia, normalmente 700 dia, como sugerido por BERGER ${ }^{1}$. Para os resultados expressos na forma gráfica, foram usados como valor base os dados obtidos no ensaio conduzido em julho de 1990 com a cultivar Carioca. Já para a tabela foi usada uma versão modificada do simulador, onde constantes substituiram as principais subrotinas do programa.

O gráfico tridimensional visou determinar a sensitividade do modelo para a interação entre as variáveis 'dia da observação inicial de doença' (ti) e 'proporção de doença inicial no tecido do hospedeiró (fi). A faixa de valores usada foi de 0,000001 a 0,01 para $f i$, e de 1 a 50 para $t i$. Os valores de $f i$ foram transformados em $\log _{10}(f i)$.

As curvas de progresso da doença foram plotadas em quatro gráficos. 0 primeiro visou determinar a sensitividade do modelo aos dados climáticos (horas de molhamento e de temperatura), representados pela variável 'favorabilidade climática' $(f a v)$. A curva gerada pelo simulador para as condições climáticas de julho de 1990 foi plotada juntamente com as curvas geradas para julho de 1991 e junho de 1992 . O

\footnotetext{
1 BERGER, R.D. (University of Florida, Plant Pathology Department) Comunicação pessoal, 1993.
} 
segundo gráfico procurou demonstrar a sensitividade do modelo em relação ao crescimento do hospedeiro. Foram plotadas seis curvas de progresso da doença, sendo cada uma obtida em função da troca do valor das constantes $b 1, b 2, b 3$ e $b 4$, pertencentes à rotina 'Crescimento do Hospedeiro'. O valor das constantes havia sido determinado por análise de regressão não linear dos dados de crescimento observados nos ensaios de julho de 1990, julho de 1991 e junho de 1992, para as cultivares Carioca e Rosinha. $\mathrm{O}$ terceiro gráfico demonstrou a sensitividade do modelo à alteração da variável 'taxa básica de infecção corrigida máxima' $(R m)$. Foram traçadas mais quatro curvas além da curva padrão com $R m=26$. As demais curvas usaram uma $R m \pm 10 \%$ e $\pm 20 \%$, o valor padrão. $\mathrm{O}$ quarto gráfico visou demonstrar a sensitividade do modelo à troca nos valores de 'período latente'. Foram traçadas cinco curvas, com valores de 'período latente' constantes iguais a 8, 9,10,11 e 12, respectivamente, substituindo a rotina 'Latência'.

A tabela visou demonstrar a sensitividade do modelo a algumas variáveis, rotinas e constantes contidas no modelo. Para realizar os testes, foram substituidas as rotinas 'Favorabilidade', 'Latência' e 'Sensibilidade do Hospedeiro' pelos valores bases 0,8 , 10 e 0,26 , respectivamente. As variáveis 'proporção de doença inicial' ( $f i)$, 'dia da observação da quantidade de doença inicial' ( $t i)$ e 'taxa básica de infecção corrigida máxima' $(R m)$ foram fixadas em $0,00001,10$ e 26 , respectivamente. Os valores para as constantes $b 1$ e $b 3$ da rotina 'Crescimento do Hospedeiro' foram os mesmos usados para a simulação de julho de 1990 da cultivar Carioca, 2654 e 0,00362 respectivamente. Variaram-se os valores dos parâmetros em $\pm 10 \%$ e $\pm 20 \%$, como sugerido por BERGER ${ }^{1}$, e observou-se a alteração da quantidade de doença no $70 \underline{0}$ dia $(y 70)$.

${ }^{1}$ BERGER, R.D. (University of Florida, Plant Pathology Department) Comunicaçảo pessoal, 1993. 


\section{RESULTADOS}

\subsection{Verificação do modelo}

\subsubsection{Teste da caixa preta}

Quando foram incorporadas rotinas testadas, sempre se obteve o mesmo resultado. Houve incremento diário na quantidade de doença gerada pelo simulador: A retirada da rotina 'Crescimento do Hospedeiro' impediu a execução do programa e conseqüentemente a obtenção de resultados. $\mathrm{O}$ mesmo ocorreu com a retirada da rotina 'Favorabilidade'. As rotinas 'Latência', 'Distribuição Primeiras Infecções' e 'Infecções Secundárias', quando suprimidas, uma de cada vez, impediram o incremento na quantidade de doença. O valor da variável 'proporção de doença total' $(y)$ manteve-se em zero. A retirada da rotina 'Suscetibilidade da Planta', ou da rotina 'Suscetibilidade do "cohort" ', componentes da rotina 'Sensibilidade do Hospedeiro', ocasionou um incremento excessivo na quantidade de doença. A tendência de queda no valor de $y$ no fim do ciclo do hospedeiro não foi observada.

\subsubsection{Teste da caixa branca}

Os resultados de verificação da rotina 'Crescimento do Hospedeiro' encontram-se na Figura 1. Para cada ano de plantio e para cada cultivar foram obtidas diferentes curvas de área corrigida do hospedeiro (cla). As curvas de área total do hospedeiro (la) e área removida ( $r a)$ também diferiram. Os resultados apresentados, conforme o esperado, foram equivalentes aos obtidos em experimentos para os mesmos anos e mesmas variedades em condições de campo (BACCHI, 1993). 

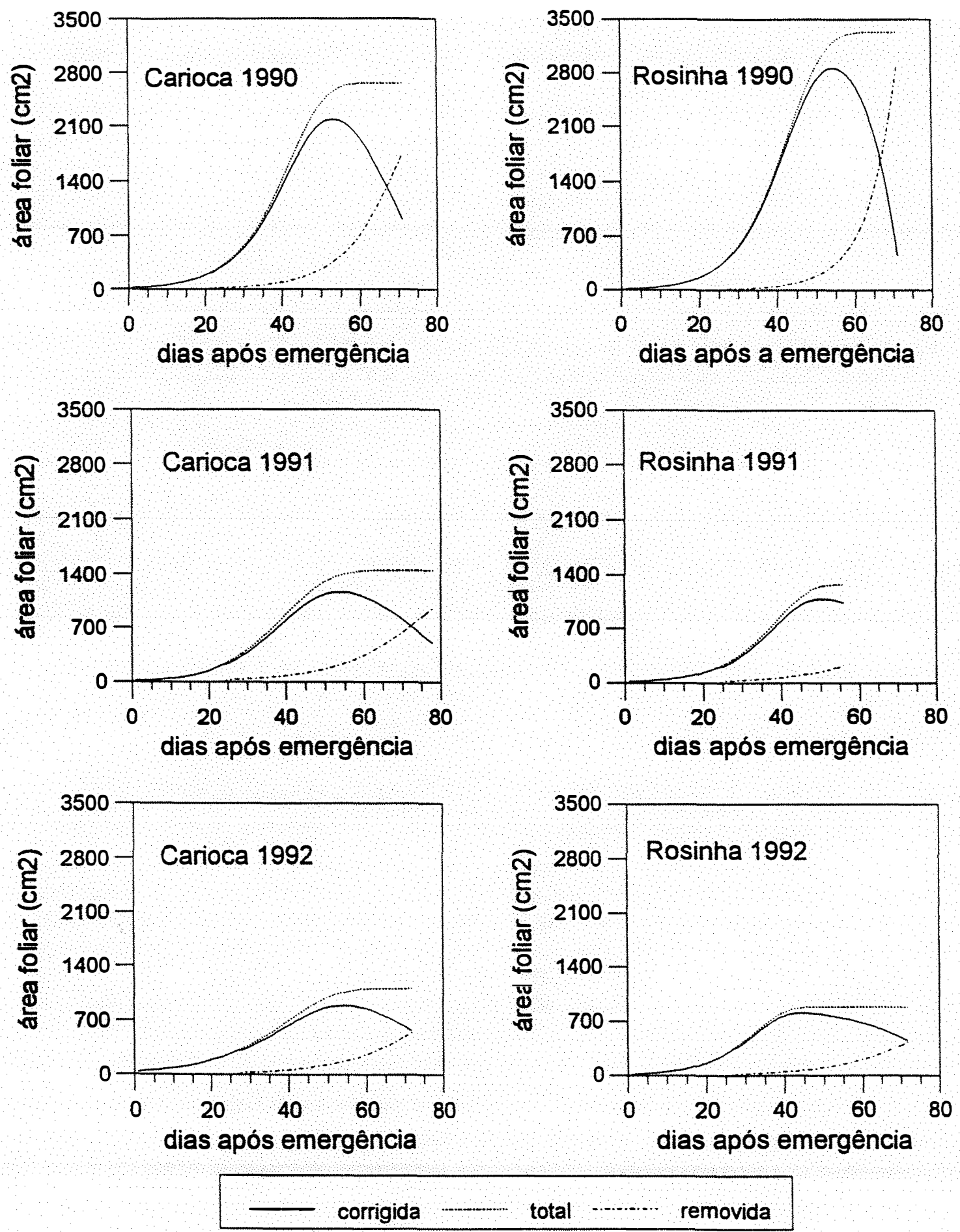

Figura 1 - Curvas de área foliar total, removida e corrigida do hospedeiro para 2 cultivares em 3 épocas de plantio, obtidas em execuçōes do programa para simulação de epidemias de ferrugem do feijoeiro. 
$\mathrm{Na}$ Figura 2a, observa-se que o teste de verificação realizado para a rotina 'Latência' apresentou resultados semelhantes aos experimentos realizados em câmara de crescimento (BACCHI, 1993). Para as temperaturas testadas o período latente' variou de 8 a 55 dias, sendo o menor valor obtido para $18{ }^{\circ} \mathrm{C}$ de temperatura mínima, a qual foi testada juntamente com $26^{\circ} \mathrm{C}$ como temperatura máxima. Não se observou variação do 'período latente' em função da idade do hospedeiro.

$\mathrm{Na}$ Figura $2 \mathrm{~b}$, podem ser observados os resultados da variável 'suscetibilidade da planta' ( $a h f)$. Obteve-se uma curva sigmoidal com o valor iniciando próximo a $100 \%$ nos primeiros dias e reduzindo até chegar a zero por volta do 700 dia. 0 mesmo comportamento apresentou a variável 'suscetibilidade do "cohort" $\quad$ (acf), com uma pequena variação na inclinação da curva.

Os gráficos obtidos na verificação da rotina 'Favorabilidade' (Figura 3) apresentaram formato semelhante àqueles gerados pelos experimentos em câmaras de crescimento (BACCHI, 1993). A diferença está na forma de expressar os resultados. Na câmara de crescimento os resultados foram expressos em número de pústulas por folha. Assim como nos experimentos, a cultivar Rosinha apresentou valores maiores de favorabilidade para as mesmas condições de temperatura e molhamento foliar.

O comportamento semelhante à realidade biológica, esperado para a rotina 'Latência' e 'Favorabilidade', foi confirmado nas simulações realizadas para os anos de plantio (Figuras 4, 5 e 6). Pode-se observar que o 'período latente' e a 'favorabilidade' variaram em função das condições climáticas. Houve também variação entre os anos de plantio, já que as condições climáticas foram diferentes. Novamente, observou-se que a 'favorabilidade climática' (fov) para a cultivar Rosinha foi maior que para a cultivar Carioca, sob as mesmas condições de temperatura e molhamento foliar.

Na Figura 7, observa-se o comportamento da variável incremento diário na área foliar infectada' (id). Houve variação entre os anos de plantio e entre as cultivares. Os maiores valores de id foram observados entre o $40 \underline{0}$ e o $50 \underline{0}$ dia, em um ciclo médio do hospedeiro de 75 dias. A cultivar Rosinha apresentou maiores valores de id que a cultivar Carioca. O ano de 1990 propiciou maiores valores de $i d$. 

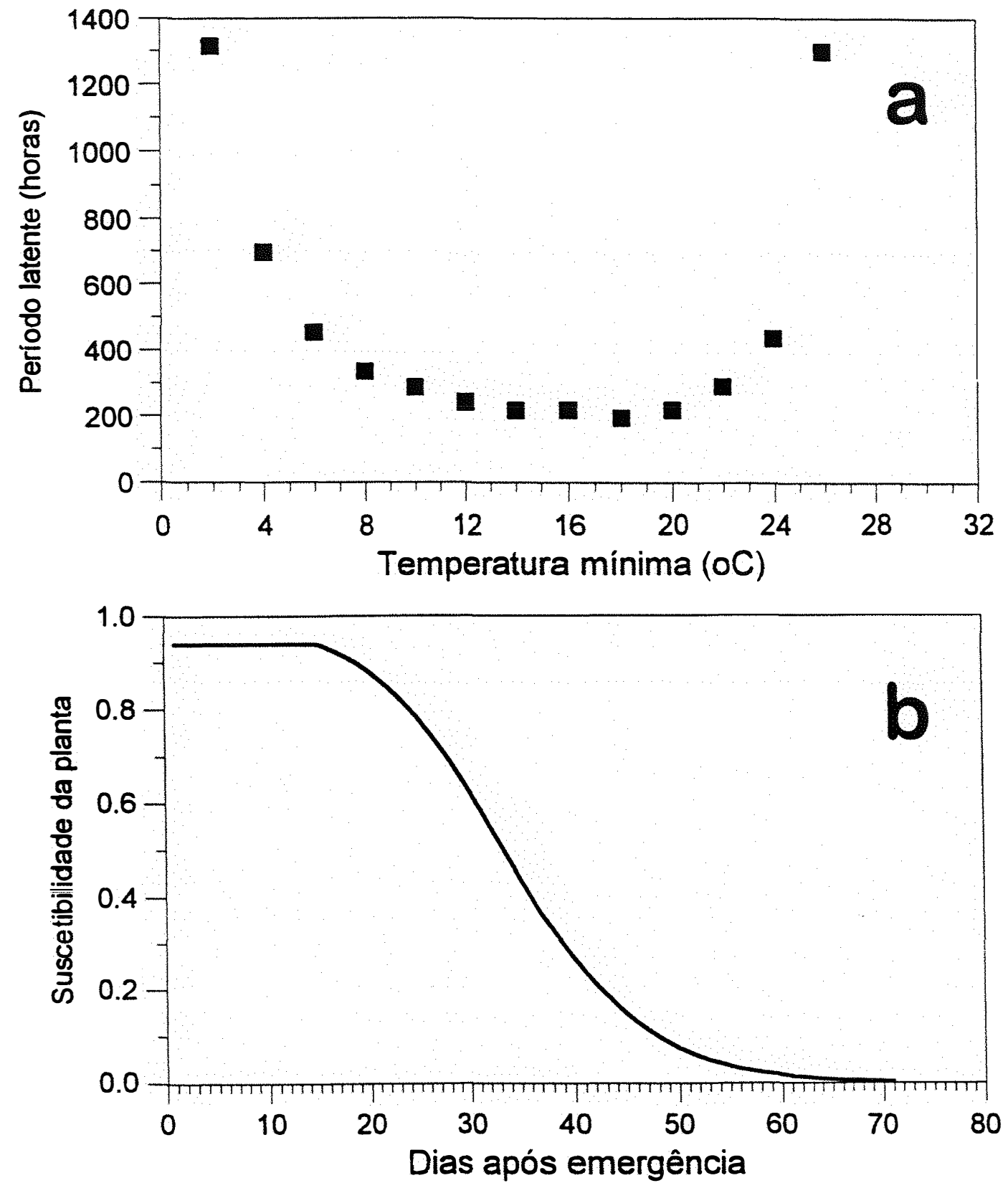

Figura 2 - Valores obtidos na execução do programa para simulação de epidemias de ferrugem do feijoeiro: a) valores do 'periodo latente' ( $p$ ) em função da temperatura mimina; $b$ ) valores da variável 'suscetibilidade da planta' (ahf). 
a) Carioca

b) Rosinha
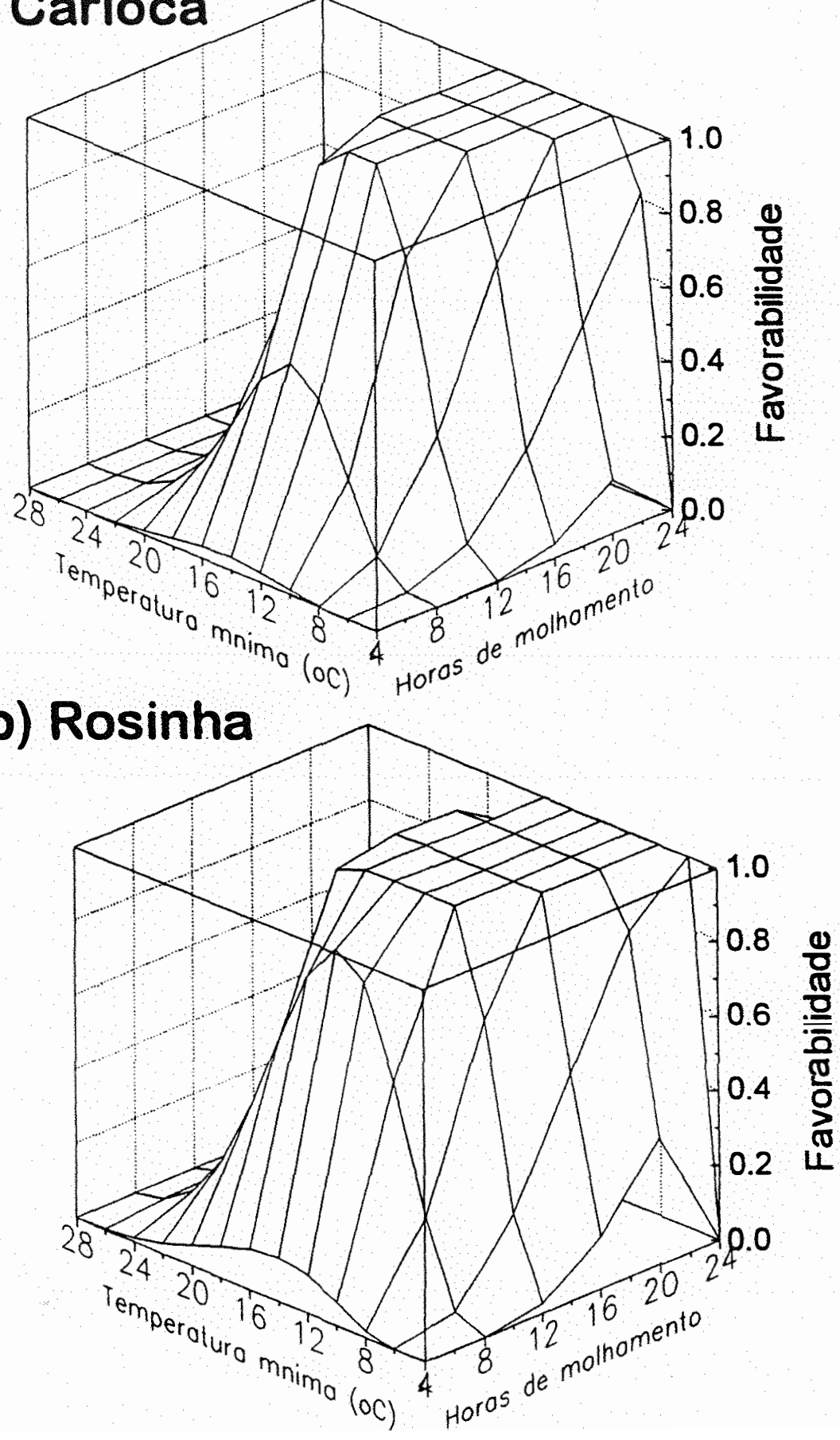

Figura 3 - Valores de 'favorabilidade climática' (fav) em função da temperatura e molhamento foliar, para. a cultivar Carioca (a) e Rosinha (b), gerados pelo programa para simulação de epidemias de ferrugem do feijoeiro. 

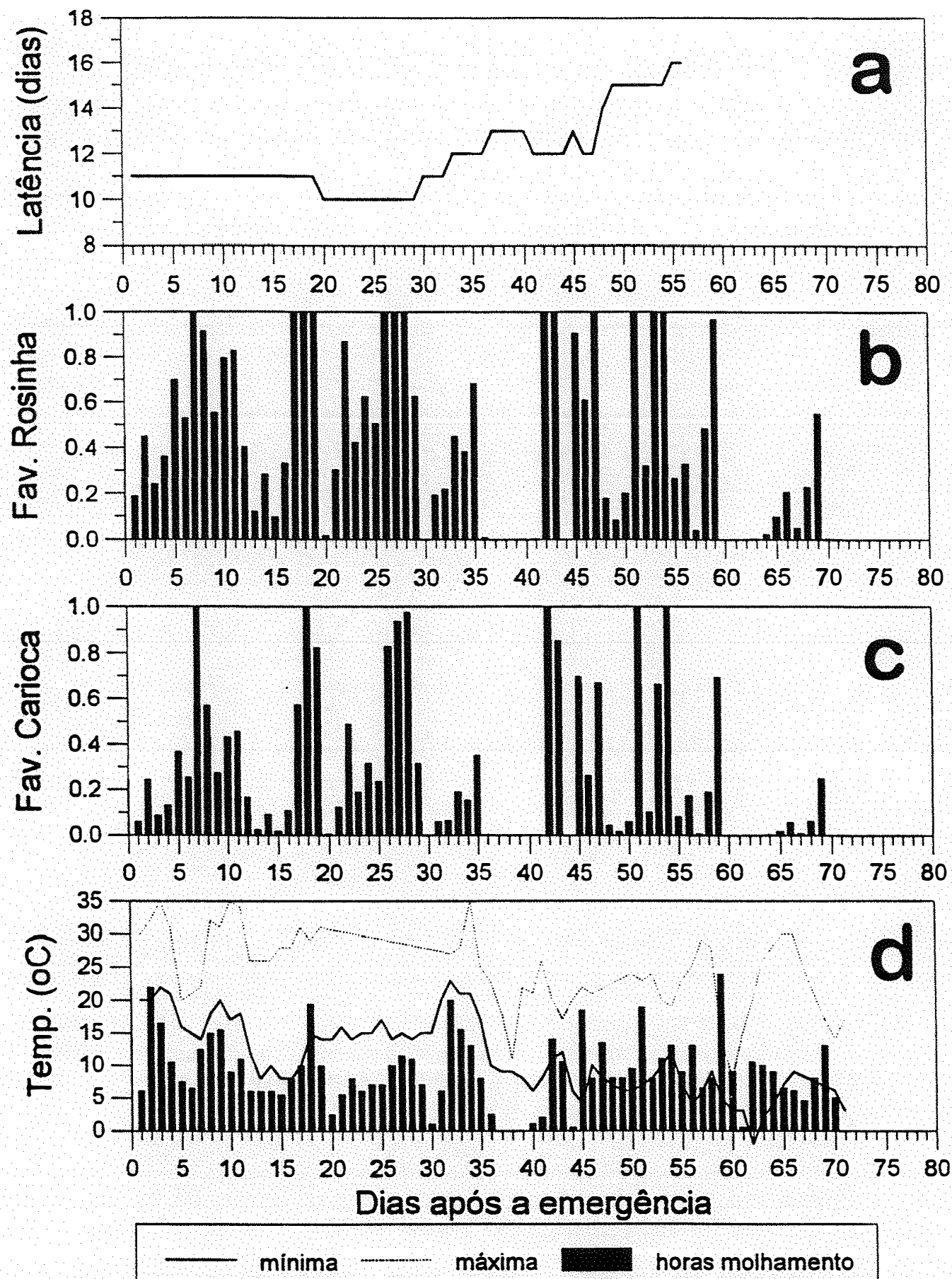

Figura 4-Dados gerados pelo programa para simulaçāo de epidemias de ferrugem do feijoeiro, para o plantio de 1990: a) 'periodo latente' (p); b) 'favorabilidade climática' (fav) para cv. Rosinha; c) 'favorabilidade climática' (fav) para a cv. Carioca. d) Temperatura máxima, minima e horas de molhamento observadas no experimento de 1990. 

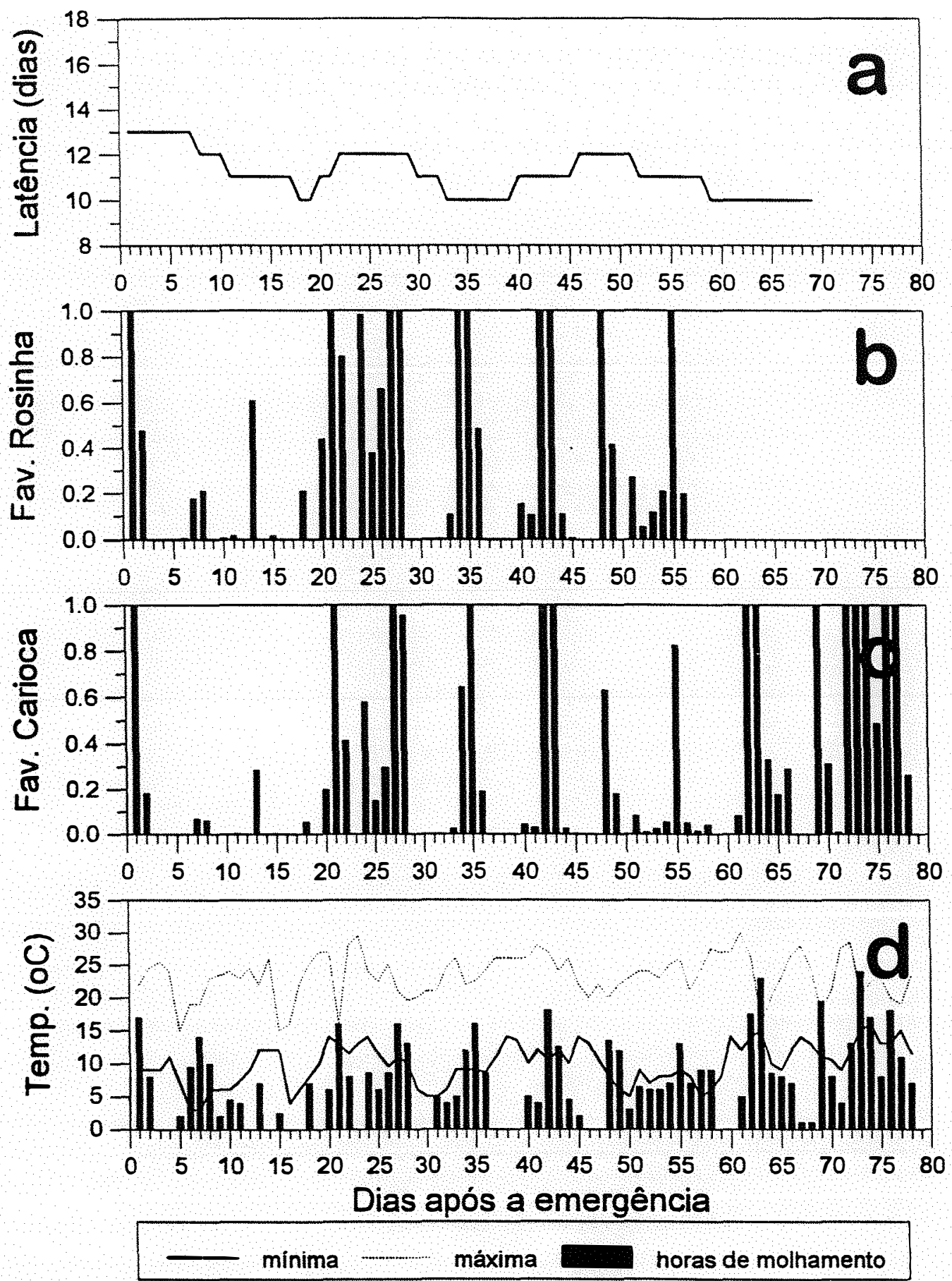

Figura 5 - Dados gerados pelo programa para simulaçáo de epidemias de ferrugem do feijoeiro, para o plantio ae 1991: a) 'periodo latente' (p); b) 'favorabilidade climática' (fav) para cv. Kosinha, c) 'favorabilidade climática' (fav) para a cv. Carioca. d)Temperatura máxima, minima e horas de molhamento observadas no experimento de 1991. 

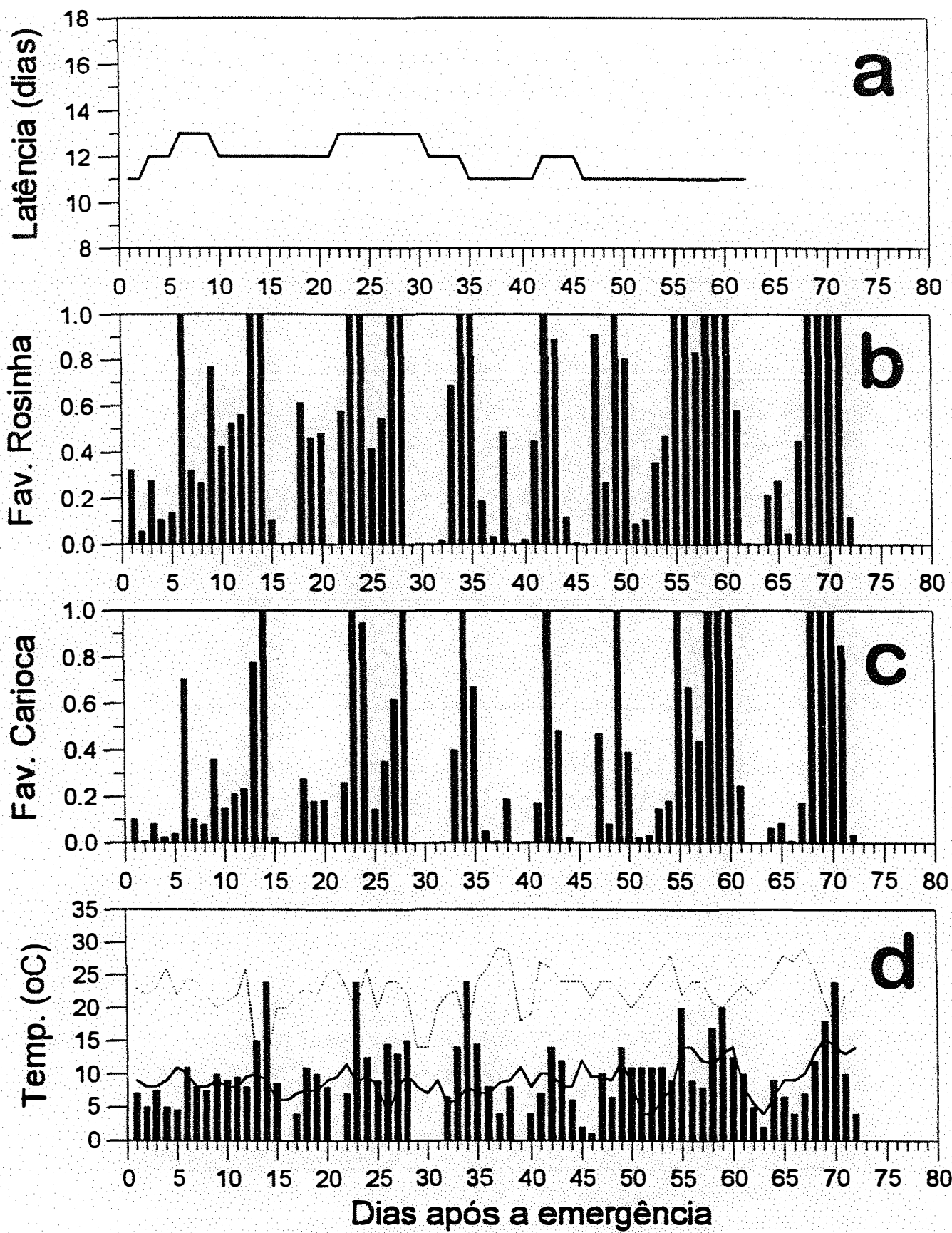

\section{minima}

máxima

horas de molhamento

Figura 6 - Dados gerados pelo programa para simulação de epidemias de ferrugem do feijoeiro, para 0 plantio de 1992: a) 'periodo latente' (p), b) 'favorabilidade climática' (fav) para cv. Rosinha, c) 'favorabilidade climática' (fav) para a cv. Carioca. d) Temperatura máxima, minima e horas de molhamento observadas no experimento de 1992. 

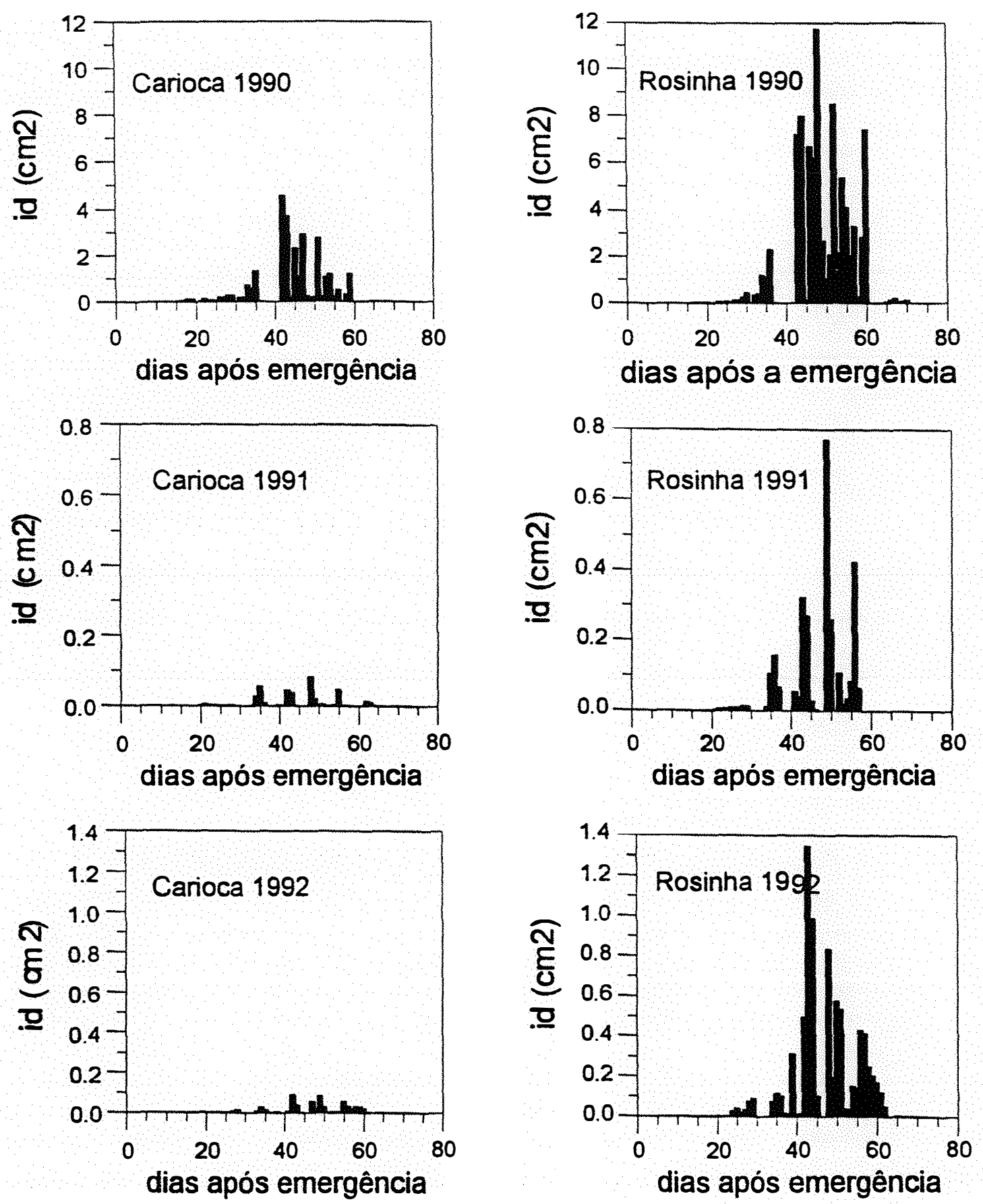

Figura 7 - Valores da variável 'incremento diário na área infectada' (id) gerados pelo programa para simulação de epidemias de ferrugem de feijoeiro, nos anos de 1990, 1991 e 1992, para as cultivares Carioca e Rosinha. 


\subsection{Validação do modelo}

\subsubsection{Experimentos com inóculo natural}

\subsubsection{Caso 1}

Os dados de julho de 1990 serviram para a calibração da variável 'taxa básica de infecção corrigida máxima' $(R m)$. Ficou determinado que uma $R m$ igual a 26 seria ideal para a cultivar Carioca. Dentro do período de 12 a 71 dias, os dados simulados ficaram na maior parte do tempo dentro do intervalo de confiança de $90 \%$ calculado para os dados observados (Figura 8). Obteve-se um excelente ajuste para a quantidade final de doença aos 72 dias e o modelo detectou nos dias finais de simulação a tendência de queda na proporção de doença que houve no campo.

$\mathrm{O}$ valor obtido no teste de $\mathrm{F}$ para a análise de regressão dos dados simulados contra os dados observados foi significativo ao nível de $1 \%$ de probabilidade e o valor do coeficiente de determinação $\left(r^{2}\right)$ foi de 0,82 , indicando um bom ajuste entre dados simulados e observados (Tabela 3). A área sob a curva de progresso da doença (ASCPD) confirma estes resultados, pois para os dados simulados foi 0,126 , apenas $3 \%$ menor que para os dados observados o qual foi 0,130 (Tabela 3 ).

$\mathrm{O}$ valor obtido no teste de $\mathrm{t}$ para comparação das constantes $\left(b_{0}\right)$ e dos coeficientes angulares $\left(b_{I}\right)$ da análise de regressão dos dados simulados e observados não foi significativo, indicando que não houve diferença para os valores encontrados (Tabela 3).

\subsubsection{Caso 2}

Para os dados de julho de 1991, realizaram-se duas simulações, variandose a quantidade de doença inicial. Na primeira simulação (simulação 1) usou-se a quantidade de doença média da segunda avaliação onde se encontrou doença no campo (80 dia após a emergência) e a 'taxa básica de infecção corrigida máxima' igual a 26 , a mesma usada na simulação de 1990 . Os dados obtidos no simulador ficaram a maior parte do tempo dentro do intervalo de confiança de $90 \%$ (Figura 8), a não ser no período de 43 aos 56 dias em que houve uma superestimativa e na última avaliação aos 78 dias em que houve uma subestimativa em $59 \%$. 

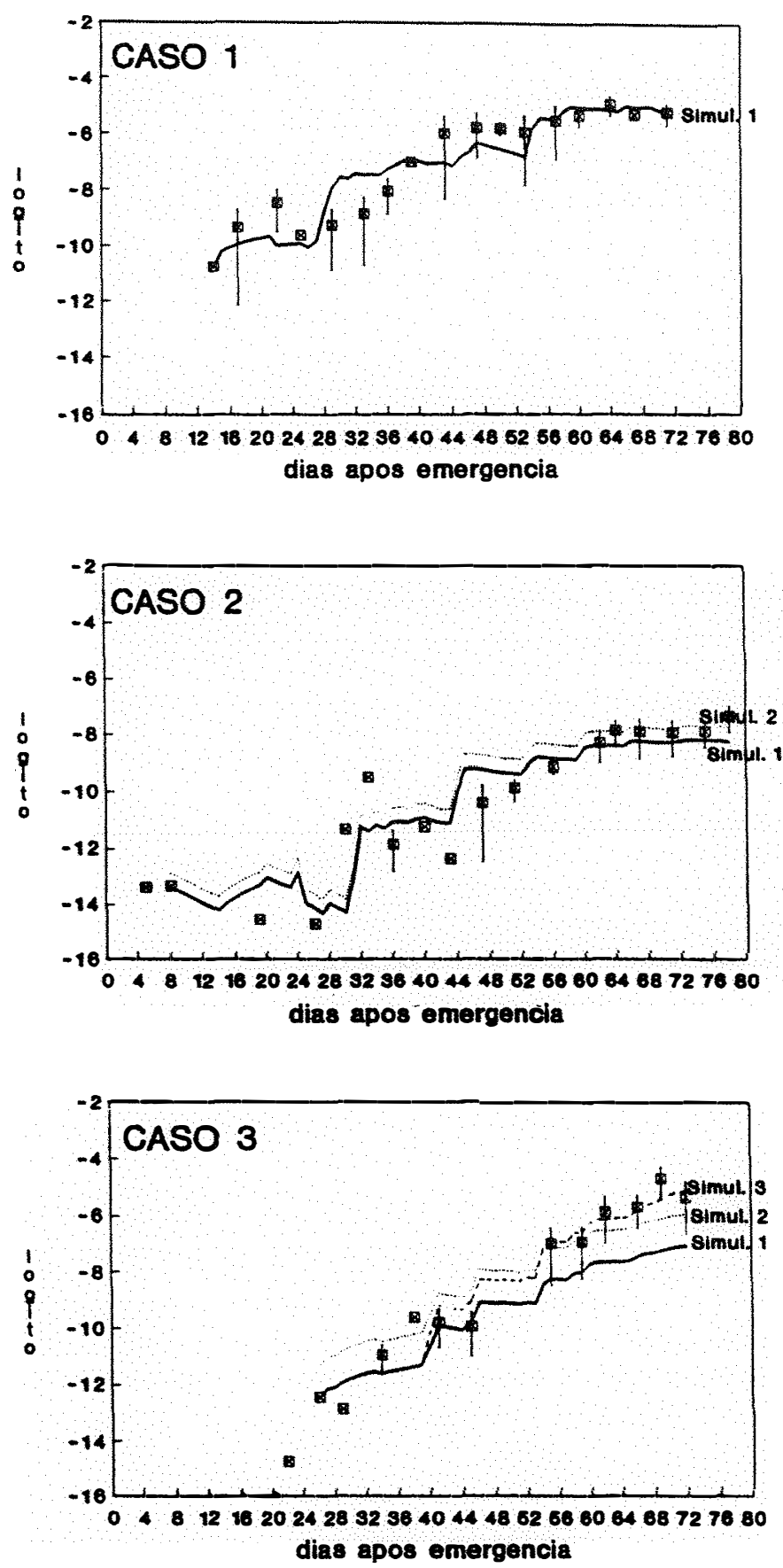

Figura 8 - Curvas de progresso de epidemia geradas pelo simulador e pontos observados no campo juntamente com o intervalo de confiança de $90 \%$, para os Casos 1,2 e 3 , usados, respectivamente, na validação de julho de 1990 , julho de 1991 e junho de 1992 , com a cultivar Carioca e inóculo natural. 
Tabela 3 - Dados obtidos da comparação entre as curvas de progresso de doença observadas e simuladas pelo modelo de simulação de epidemias de ferrugem do feijoeiro, para a simulação 1 de cada Caso. Teste de $F$ para a regressão dos dados simulados contra os observados. Teste de t para a regressão do logito dos dados simulados e observados contra o tempo.

\begin{tabular}{|c|c|c|c|c|c|c|c|c|}
\hline \multirow[b]{2}{*}{ Casos ${ }^{* *}$} & \multicolumn{2}{|c|}{ ASCPD } & \multirow[b]{2}{*}{$r^{2}$} & \multirow[b]{2}{*}{$b_{0}$} & \multirow[b]{2}{*}{$b_{1}$} & \multirow{2}{*}{$\begin{array}{l}\text { Teste } \\
\text { de } F^{*}\end{array}$} & \multicolumn{2}{|c|}{ Teste de $t^{\star}$} \\
\hline & simulada & observada & & & & & $b_{0}$ & $b_{1}$ \\
\hline Caso 1 & 0.126 & 0.130 & 0.82 & $-7,0.10^{-4}$ & 0.96 & 0.01 & n.s. & n.s. \\
\hline Caso 2 & 0.006 & 0.008 & 0.82 & $3,0.10^{-5}$ & 0.52 & 0.01 & n.s. & n.s. \\
\hline Caso 3 & 0.010 & 0.062 & 0.76 & $9,0.10^{-5}$ & 0.09 & 0.01 & 0.05 & 0.01 \\
\hline Caso 4 & 0.232 & 0.281 & 0.81 & $-2,0.10^{-4}$ & 0.83 & 0.01 & n.s. & n.s. \\
\hline Caso 5 & 0.007 & 0.002 & 0.96 & $-4,0.10^{-6}$ & 3.06 & 0.01 & 0.05 & 0.01 \\
\hline Caso 6 & 0.181 & 0.234 & 0.45 & $2,0.10^{-3}$ & 0.45 & 0.05 & n.s. & n.s. \\
\hline Caso 7 & 0.007 & 0.025 & 0.73 & $6,0.10^{-5}$ & 0.17 & 0.01 & n.s. & n.s. \\
\hline Caso 8 & 0.015 & 0.032 & 0.96 & $6,0.10^{-5}$ & 0.43 & 0.01 & n.s. & n.s. \\
\hline Caso 9 & 0.012 & 0.040 & 0.92 & $8,0.10^{-5}$ & 0.24 & 0.01 & n.s. & n.s. \\
\hline Caso 10 & 0.049 & 0.104 & 0.86 & $3,2.10^{-4}$ & 0.36 & 0.01 & n.s. & n.s. \\
\hline Caso 11 & 0.011 & 0.269 & 0.45 & $1,7.10^{-4}$ & 0.02 & n.s. & n.s. & n.s. \\
\hline
\end{tabular}

ASCPD - Área sob a curva de progresso de doença, $r^{2}$ - coeficiente de determinação - bo constante da equação de regressão - $b_{1}$ - coeficiente angular da equação de regressão. * nível de significância. * Somente primeira simulação.

Na segunda simulação (simulação 2) usou-se uma quantidade de doença inicial de $2,6.10^{-6}$, que é maior que a quantidade média, mas está dentro do intervalo de confiança de $90 \%$ que vai até $4,99.10^{-6}$. Obteve-se um melhor ajuste para as avaliações finais apesar de acentuar a superestimativa do periodo de 43 aos 56 dias (Figura 8).

$\mathrm{O}$ valor obtido no teste de $\mathrm{F}$ para a análise de regressão foi significativo ao nível de $1 \%$ de probabilidade para os dois valores utilizados como quantidade de doença inicial, e o coeficiente de determinação $\left(r^{2}\right)$ foi de 0,82 (Tabela 3 ) para ambas as simulações. Pelos critérios acima utilizados não podemos afirmar qual foi a melhor simulação, mas visualmente (Figura 8) e pelos resultados de área sob a curva de progresso de doença (Tabela 3) pode-se dizer que o uso da quantidade de doença média apresentou melhores resultados. A ASCPD foi de 0,00786 para os dados observados, 0,00639 (19\% a menos) para a simulação 1 que utilizou a quantidade de doença inicial 
média, e 0,01045 (33\% a mais) para a simulação 2, usando-se a quantidade de doença inicial maior. $O$ valor obtido no teste de $t$ para $b_{0}$ e $b_{1}$ não foi significativo.

\subsubsection{Caso 3}

Para a simulação 1, partindo-se da padronização de utilizar como quantidade inicial de doença a proporção de doença média da segunda avaliação de

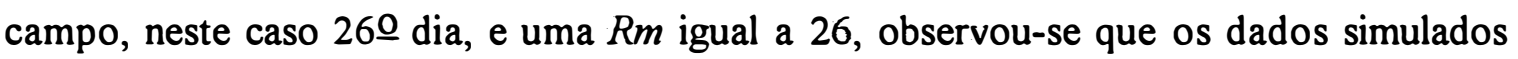
ficaram dentro do intervalo de confiança de $90 \%$ a maior parte do tempo (Figura 8), mas no período de 62 aos 72 dias, nas quatro últimas avaliações, houve uma grande subestimativa da quantidade de doença, chegando a $82 \%$ na avaliação dos 72 dias .

$\mathrm{Na}$ simulação 2, utilizando-se uma quantidade de doença inicial de 1,18. $10^{-5}$, que era o valor máximo permitido dentro do intervalo de confiança de $90 \%$ para o

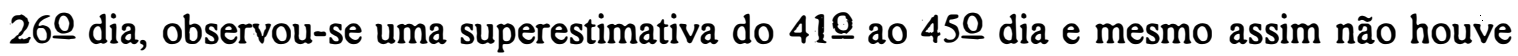
um bom ajuste nas avaliações finais (Figura 8), indicando que a $R m$ estava subestimada, pois é ela a responsável pela inclinação da curva dos dados simulados.

Para a simulação 3, trocando-se o valor da $R m$ de 26 para 60 e mantendose o valor da quantidade de doença inicial média do 260 dia observou-se um bom ajuste dos dados simulados, mas isso indicou que houve alguma falha para o Caso, pois deveria haver concordância de valores da $R m$ para os plantios no mesmo local com a mesma cultivar.

Nos testes de F para a análise de regressão houve significância ao nível de $1 \%$ de probabilidade, tanto para as duas simulações em que foi utilizada $R m=26$ (Simulações 1 e 2) como para a que usou $R m=60$ (Simulação 3). O coeficiente de determinação $\left(\mathrm{r}^{2}\right)$ foi 0,76 para as três simulações. As diferenças ficaram claras na área sob a curva de progresso da doença, onde para os dados observados foi 0,0618 , para a simulação 1 foi 0,0102 (83 \% a menos), na simulação 2 foi 0,0318 (48\% a menos), e na simulação 3 foi 0,0504 (18\% a menos), indicando o melhor ajuste da simulação 3, a qual usou $R m=60$.

Os valores do teste de t para o coeficiente angular $\left(b_{1}\right)$ e para a constante da equação de regressão $\left(b_{0}\right)$, confirmaram os resultados anteriores. Foi significativo ao nível de $5 \%$ de probabilidade para as simulações que usaram $R m=26$, e não significativo somente para a simulação que usou $R m=60$. 


\subsubsection{Caso 4}

A calibração realizada determinou como 40 o melhor valor para a $R m$, para a cultivar Rosinha. Dentro do período de 14 a 71 dias o ajuste dos dados simulados em relação aos observados pode ser dividido em três fases. Numa primeira fase do $29 \underline{0}$ ao 36 o dia houve uma pequena superestimativa da doença (Figura 9). A segunda fase culmina no 530 dia com a tendência dos dados simulados em ficar abaixo do intervalo de confiança de $90 \%$ calculado para os dados observados. Em compensação, na fase final da simulação, do 600 ao 71 을 dia, houve um excelente ajuste por parte dos dados simulados, inclusive com o modelo acompanhando a queda na proporção de doença verificada nos dados observados na avaliação do 71 ㅇ dia.

O coeficiente de determinação $\left(r^{2}\right)$ da análise de regressão foi 0,81 e os valores de $b_{0}$ e $b_{1}$ foram respectivamente $-0,0002$ e 0,83 indicando uma boa correlação entre dados observados e simulados (Tabela 3). Além disso o valor para o teste de $F$ foi significativo ao nível de $1 \%$ de probabilidade. A ASCPD dos dados simulados foi apenas $17 \%$ menor que para os dados observados, os valores foram respectivamente 0,232 e 0,281 . O valor obtido no teste de $t$, que compara a constante e o coeficiente angular da equação de regressão dos dados simulados com os observados, não foi significativo, tanto para $b_{0}$ como para $b_{1}$.

\subsubsection{Caso 5}

Para os dados de julho de 1991 realizaram-se três simulações buscando-se o melhor ajuste, sendo que todas usaram como dia inicial da epidemia a segunda avaliação, que apresentou doença no campo (11ㅇ dia).

Na primeira simulação (simulação 1) usou-se a quantidade de doença média para o dia de início da epidemia e uma $R m$ igual a 40 , que foi determinada para a cultivar Rosinha na calibração realizada no plantio de julho de 1990 . Observando-se a Figura 9, verifica-se que os dados simulados ficaram dentro do intervalo de confiança de $90 \%$ desde a fase inicial da epidemia até o 330 dia, mas do 360 ao 560 dia ficaram superestimadas, chegando a $203 \%$ acima na última avaliação. O mesmo ocorreu com a área sob a curva de progresso da doença que foi 0,00676 para os dados simulados, cerca de $220 \%$ acima da observada a qual foi 0,00211 (Tabela 3 ). 

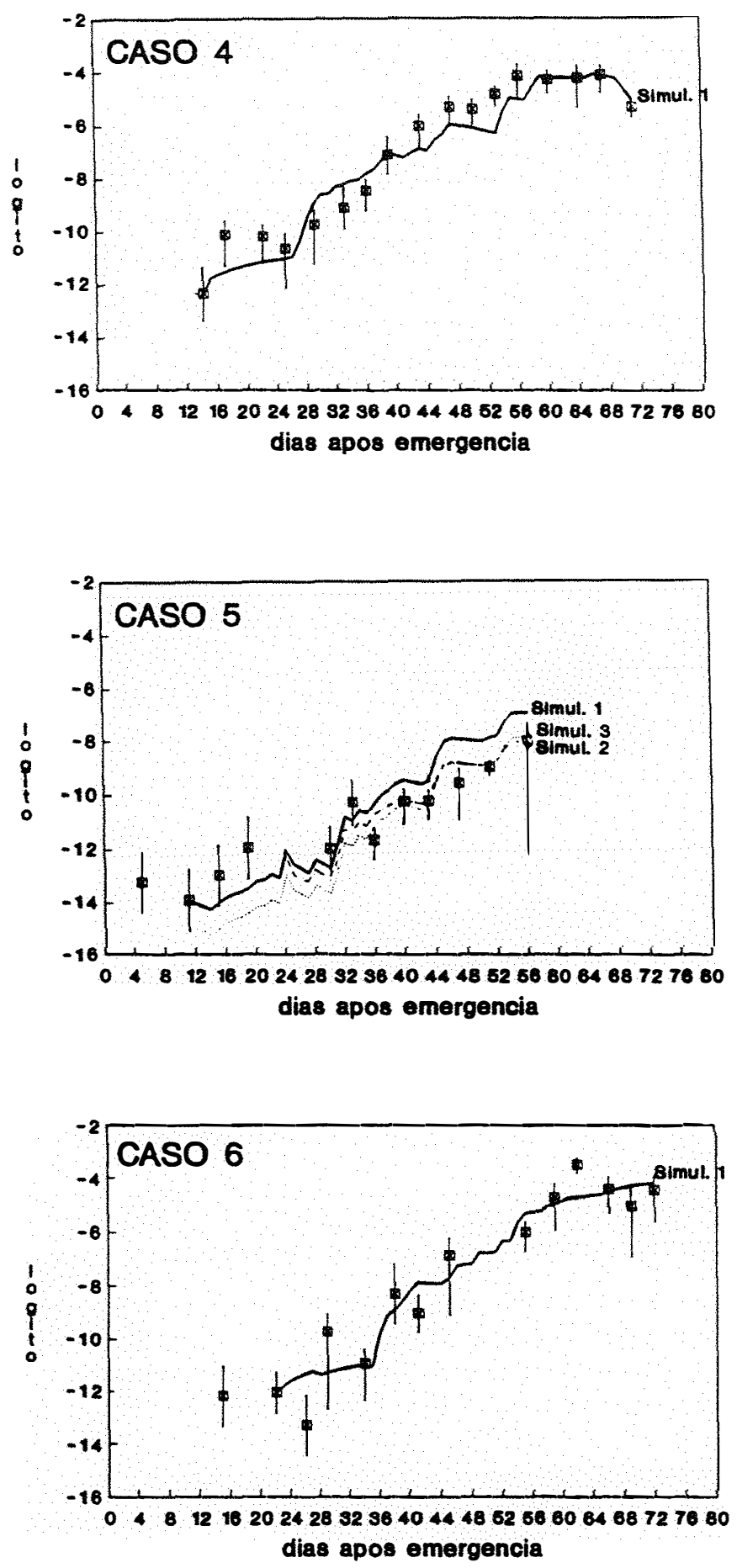

Figura 9 - Curvas de progresso de epidemia geradas pelo simulador e pontos observados no campo juntamente com o intervalo de confiança de $90 \%$, para os Casos 4 , 5 e 6, usados, respectivamente, na validação de julho de 1990, julho de 1991 e junho de 1992, com a cultivar Rosinha e inóculo natural. 
$\mathrm{Na}$ segunda simulação (simulação 2) buscou-se um melhor ajuste, diminuindo-se a quantidade de doença inicial para cerca de $30 \%$ da quantidade média, e manteve-se a $R m$ em 40 . O valor utilizado como quantidade de doença inicial estava dentro do intervalo de confiança de $90 \%$, que partia de zero chegando até $2,83.10^{-6}$ como valor máximo. Observando-se a Figura 9 , verifica-se uma tendência de subestimativa por parte dos dados simulados desde a fase inicial até por volta do 300 dia, mas como se trata de valores muito baixos para quantidade de doença, os dados simulados permanecem dentro do intervalo de confiança de $90 \%$. Pode-se verificar, também, que na fase final de simulação houve um bom ajuste dos dados simulados. A área sob a curva de progresso da doença foi 0,00262 , cerca de $24 \%$ a mais, ficando bem mais próxima do valor observado.

Visando proporcionar um melhor ajuste para os dados na fase inicial da epidemia fez-se uma nova simulação (simulação 3 ), usando-se o valor médio para a quantidade de doença inicial e diminuindo-se o valor da $R m$ de 40 para 25 . Isto fez com que os dados simulados se ajustassem melhor aos observados desde o início da epidemia (Figura 9). A área sob a curva de progresso da doença também melhorou, ficando em 0,00258, apenas $18 \%$ acima da ASCPD observada.

O valor obtido no teste de $\mathrm{F}$ para a análise de regressão dos dados simulados contra os observados foi significativo ao nivel de $1 \%$ de probabilidade para as três simulações realizadas. $\mathrm{O}$ coeficiente de determinação $\left(r^{2}\right)$ foi de 0,96 para as simulações 1 e 2 , e 0,93 para a simulação 3 , apesar de que os melhores valores de $b_{0}$ e $b_{1}$ foram obtidos na terceira simulação. Os valores obtidos no teste de $t$, foram significativos ao nivel de $5 \%$ de probabilidade para as simulações que usaram $R m=40$, e não foram significativos para a simulação que usou $R m=25$.

\subsubsection{Caso 6}

A simulação realizada para os dados de julho de 1992 utilizou $R m=40$, a segunda avaliação de campo em que foi observada doença (220 dia), e a quantidade de doença média observada na segunda avaliação $\left(5,76 \cdot 10^{-6}\right)$. Houve um ótimo ajuste dos dados simulados dentro do intervalo de confiança de $90 \%$ calculado para os dados observados (Figura 9), com exceção para o 630 dia em que o simulado ficou subestimado, provavelmente devido a algum erro experimental. 
A área sob a curva de progresso da doença simulada $(0,181)$ também ficou subestimada em $23 \%$ já que a quantidade de doença amostrada no campo no 63 응 dia colaborou para elevar a ASCPD observada $(0,234)$. Apesar do bom ajuste verificado visualmente na Figura 9, os valores obtidos na análise de regressão dos dados simulados contra os dados observados não foram satisfatórios. O coeficiente de determinação $\left(r^{2}\right)$ foi $0,45, b_{0}$ foi 0,002 e $b_{1}$ foi 0,45 . Isso pode ser atribuído à grande oscilação verificada entre 0 620 e o 69o dia. Mesmo assim, o valor obtido no teste de $F$ para a análise de regressão foi significativo ao nível de $5 \%$ de probabilidade e os valores obtidos para o teste de $t$ não foram significativos.

\subsubsection{Experimentos com inoculação artificial}

As Figuras 10 e 11 demonstram que, para os Casos 7 a 11 , quando se usou a quantidade de doença média na inicialização (simulações 1), os dados simulados tenderam a ficar abaixo dos observados, apesar de permanecerem dentro do intervalo de confiança de $90 \%$. Apenas nos Casos 7 e 11 a quantidade de doença simulada ficou abaixo do intervalo de confiança, na última avaliação.

Quando se usou uma quantidade de doença acima da quantidade média (simulações 2), mas dentro do intervalo de confiança de $90 \%$ calculado para o dia da inicialização, houve um melhor ajuste dos dados simulados em relação aos observados (Figuras 10 e 11). Os dados simulados, para a maioria dos Casos, permaneceram dentro do intervalo de confiança. Somente no Caso 11, na última avaliação, ficaram abaixo desse intervalo. Nos Casos 8, 9 e 10, verificou-se a tendência dos dados simulados superestimarem a quantidade de doença do 490 ao 560 dia, apesar de ocorrer um melhor ajuste nas avaliações finais, do 590 ao 760 dia. Nos Casos 7 e 11 os dados simulados tenderam a ficar abaixo dos observados.

Os valores obtidos no teste de $\mathrm{F}$ foram significativos ao nível de $1 \%$ de probabilidade para a maioria dos Casos, com exceção ao Caso 11, o qual não foi significativo (Tabela 3). Os valores obtidos no teste de $t$ não foram significativos para todos os Casos, tanto para a comparação das constantes como dos coeficientes (Tabela 3). 

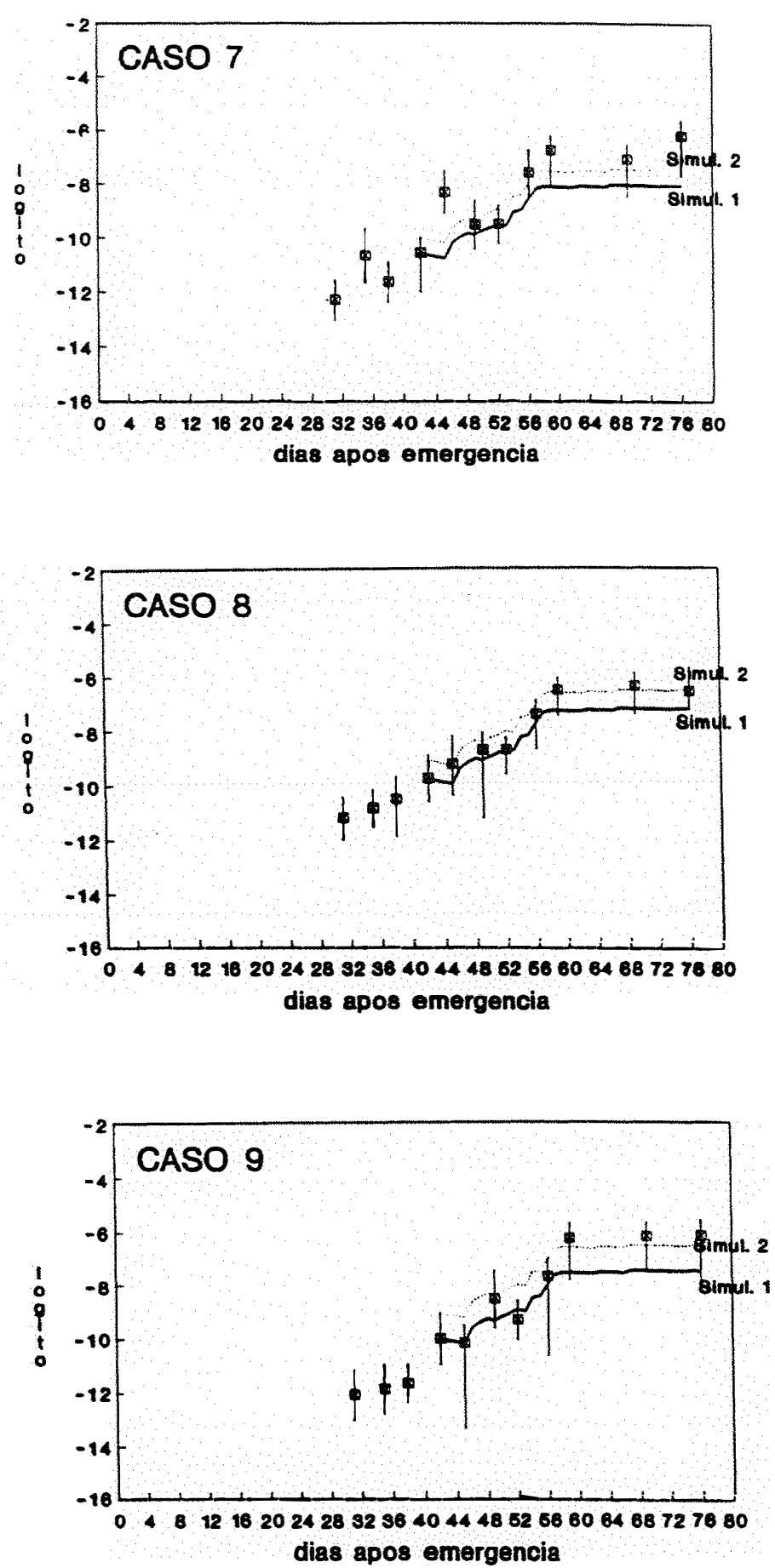

Figura 10 - Curvas de progresso de epidemia geradas pelo simulador e pontos observados no campo juntamente com o intenvalo de confiança de $90 \%$, para os Casos 7,8 e 9 , usados na validaçáo de maio de 1991 com inoculaçáo artificial de $10^{2}, 10^{3}$ e $10^{4}$ uredosporos $/ \mathrm{ml}$, respectivamente, para a cultivar Rosinha. 

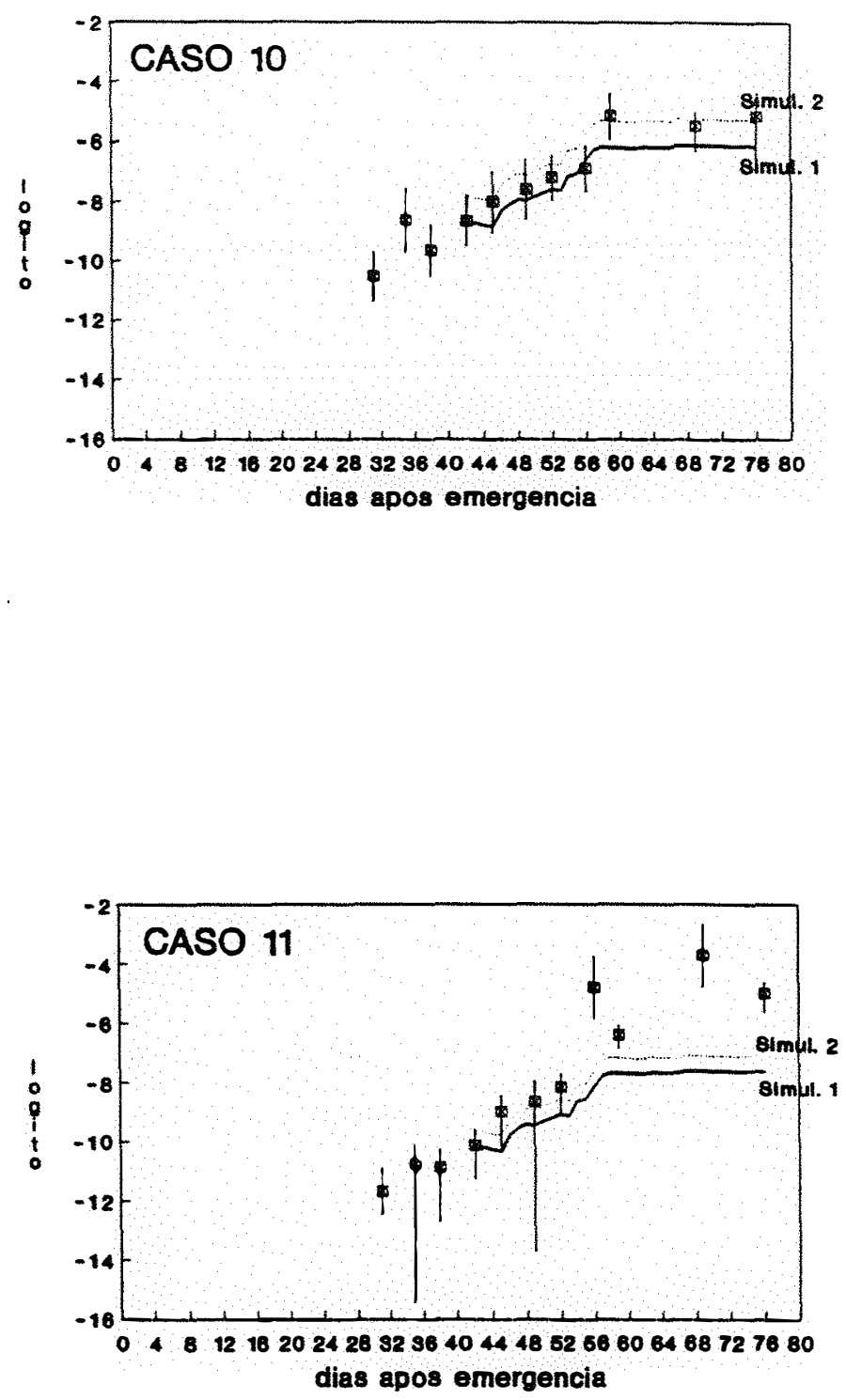

Figura 11 - Curvas de progresso de epidemia geradas pelo simulador e pontos observados no campo juntamente com o intervalo de confiança de $90 \%$, para os Casos 10 e 11 , usados na validaçáo de maio de 1991 com inoculaçáo artificial de $10^{5}$ e $10^{6}$ uredosporos $/ \mathrm{ml}$, respectivamente, para a cultivar Rosinha. 


\subsection{Análise de sensitividade do modelo}

A sensitividade da proporção de doença inicial $(f i)$ e do dia da observação inicial de doença $(t i)$ pode ser observada na Figura 12. Verifica-se que as maiores quantidades de doença no $70 \underline{0}$ dia $(y 70)$ ocorreram com os maiores níveis de proporção de doença inicial $\left(\log _{10}(0,01)=-2\right)$ e com os menores valores para o dia da observação inicial de doença $(t i=1)$. Os valores de $y 70$ mantiveram-se baixos $(<10 \%)$ desde $f \hat{i}=0,000001\left(\log _{10}=-6\right)$ até $f \hat{\imath}=0,0001\left(\log _{10}=-4\right)$. Quando a observação inicial de doença deu-se a partir da metade do ciclo $(t i=35)$, somente foram observados valores acima de $5 \%$ para $y 70$ quando $f i$ foi igual a 0,01 .

A sensitividade dos parâmetros favorabilidade, crescimento do hospedeiro, taxa $R m$ e do período latente, pode ser observada nas curvas de progresso da doença da Figura 13. Na Figura 13a, verifica-se que as curvas que usaram dados climáticos de julho de diferentes anos apresentaram comportamento variado, principalmente a partir do $45 \underline{0}$ dia. No último dia simulado ( $71 \underline{0} \mathrm{dia})$ as diferenças em relação a $y 71$ de 1990 foram $-24 \%$ e $42 \%$ para 1991 e 1992, respectivamente, e entre 1991 e 1992 chegou a 87\%. Para as curvas geradas com os diferentes dados de crescimento do hospedeiro (Figura 13b), a variação foi ainda maior. No $70 \underline{0}$ dia a diferença entre a quantidade de doença $(y 70)$ de 1990 partiu de $-45 \%$ chegando até a $459 \%$. As maiores diferenças ocorreram entre os dados de 1990 e 1992 . A alteração no valor da $R m$ em $\pm 10 \%$ e $\pm 20 \%$ o valor inicial (26), provocou variações maiores que essa porcentagem na $y 70$ (Figura 13c). Um valor $20 \%$ menor para $R m$ equivaleu a $-46 \%$ em $y 70,-10$ a $-25 \%,+10$ a $+30 \%$ e +20 a $66 \%$. Para o 'período latente' (Figura 13d), as alterações em $\pm 20 \%$ acentuaram ainda mais o $y 70$. Tomando-se como padrão o 'período latente' $(p)$ de 10 dias, a diferença é 373\% para $p=8,108 \%$ para $p=9,-53 \%$ para $p=11$ e $-77 \%$ para $p=12$.

Para se fazer uma comparação da sensitividade dos principais parâmetros que influenciaram a quantidade final de doença pode-se observar a Tabela 4. Todos foram sensitivos às alterações em $\pm 20 \%$ e $\pm 10 \%$ de seu valor inicial, e em geral os parâmetros que faziam parte da equação de cálculo de área infectada foram mais sensitivos. A alteração em $\pm 20 \%$ do valor da variável 'taxa básica de infecção corrigida máxima' $(R m)$, ou da 'favorabilidade climática' $(f a v)$, ou da 'suscetibilidade de hospedeiro' (acf), afetaram a quantidade de doença no 70 o dia $(y 70)$ de igual forma, em cerca de $50 \%$. O 'período latente' $(p)$, entre os parâmetros analisados, foi o que provocou as 
maiores variações em $y 70$. A alteração em $\pm 20 \%$ do valor de $p$ afetou $y 70$ entre 76 a $110 \%$. As constantes $b 1$, responsável pela área foliar máxima, e $b 3$, responsável pelo formato da curva de crescimento do hospedeiro, também foram sensitivas. Alteração do valor de $b 3$ em $\pm 20 \%$ provocou variações entre 65 a $89 \%$ em $y 70$. Essas variações foram maiores do que para $b l$, onde os resultados ficaram entre 17 e $27 \%$. Os parâmetros proporção de doença inicial $(f i)$ e dia da observação da quantidade de doença inicial ( $t i$ ) foram os que provocaram as menores variações em $y 70$. Para $f i$ foi de 13 a $15 \%$ e para $t i$ foi de 4 a $15 \%$.

Tabela 4. Análise de sensitividade das variáveis, constantes e rotinas usadas no simulador para ferrugem do feijoeiro. Valores expressos em proporção de doença no 70 으 dia $(y 70)$ e em variação percentual em função do valor base.

\begin{tabular}{|c|c|c|c|c|c|c|c|c|c|}
\hline \multirow{2}{*}{$\begin{array}{r}\text { Parâ- } \\
\text { metro } \\
f i\end{array}$} & \multirow{2}{*}{$\begin{array}{l}\text { Valor } \\
\text { base } \\
0.01\end{array}$} & \multicolumn{2}{|c|}{$-20 \%$} & \multicolumn{2}{|c|}{$-10 \%$} & \multicolumn{2}{|c|}{$+10 \%$} & \multicolumn{2}{|c|}{$+20 \%$} \\
\hline & & 0.396 & $-14.8 \%$ & 0.432 & $-7.1 \%$ & 0.496 & $6.7 \%$ & 0.526 & $12.9 \%$ \\
\hline$t i$ & 10 & 0.394 & $-15.3 \%$ & 0.427 & $-8.1 \%$ & 0.507 & $9.0 \%$ & 0.486 & $4.4 \%$ \\
\hline$R m$ & 26 & 0.246 & $-47.0 \%$ & 0.349 & $-24.9 \%$ & 0.587 & $26.0 \%$ & 0.702 & $50.8 \%$ \\
\hline fav & 0.8 & 0.246 & $-47.0 \%$ & 0.349 & $-24.9 \%$ & 0.587 & $26.0 \%$ & 0.702 & $50.8 \%$ \\
\hline acf & 0.26 & 0.246 & $-47.0 \%$ & 0.349 & $-24.9 \%$ & 0.586 & $26.0 \%$ & 0.702 & $50.8 \%$ \\
\hline$p$ & 10 & 0.978 & $110.1 \%$ & 0.804 & $72.6 \%$ & 0.227 & $-51.1 \%$ & 0.111 & $-76.2 \%$ \\
\hline$b 1$ & 2654 & 0.338 & $-27.3 \%$ & 0.409 & $-12.1 \%$ & 0.511 & $9.8 \%$ & 0.549 & $17.9 \%$ \\
\hline b3 & 0.0036 & 0.053 & $-88.7 \%$ & 0.240 & $-48.4 \%$ & 0.642 & $37.8 \%$ & 0.769 & $65.1 \%$ \\
\hline
\end{tabular}

A proporção de doença para os valores base dos parâmetros foi 0.46571 A variação percentual (\%) no 700 dia para os vários parâmetros foi calculada como $\%=(y 70-0.46571) / 0.46571$. 


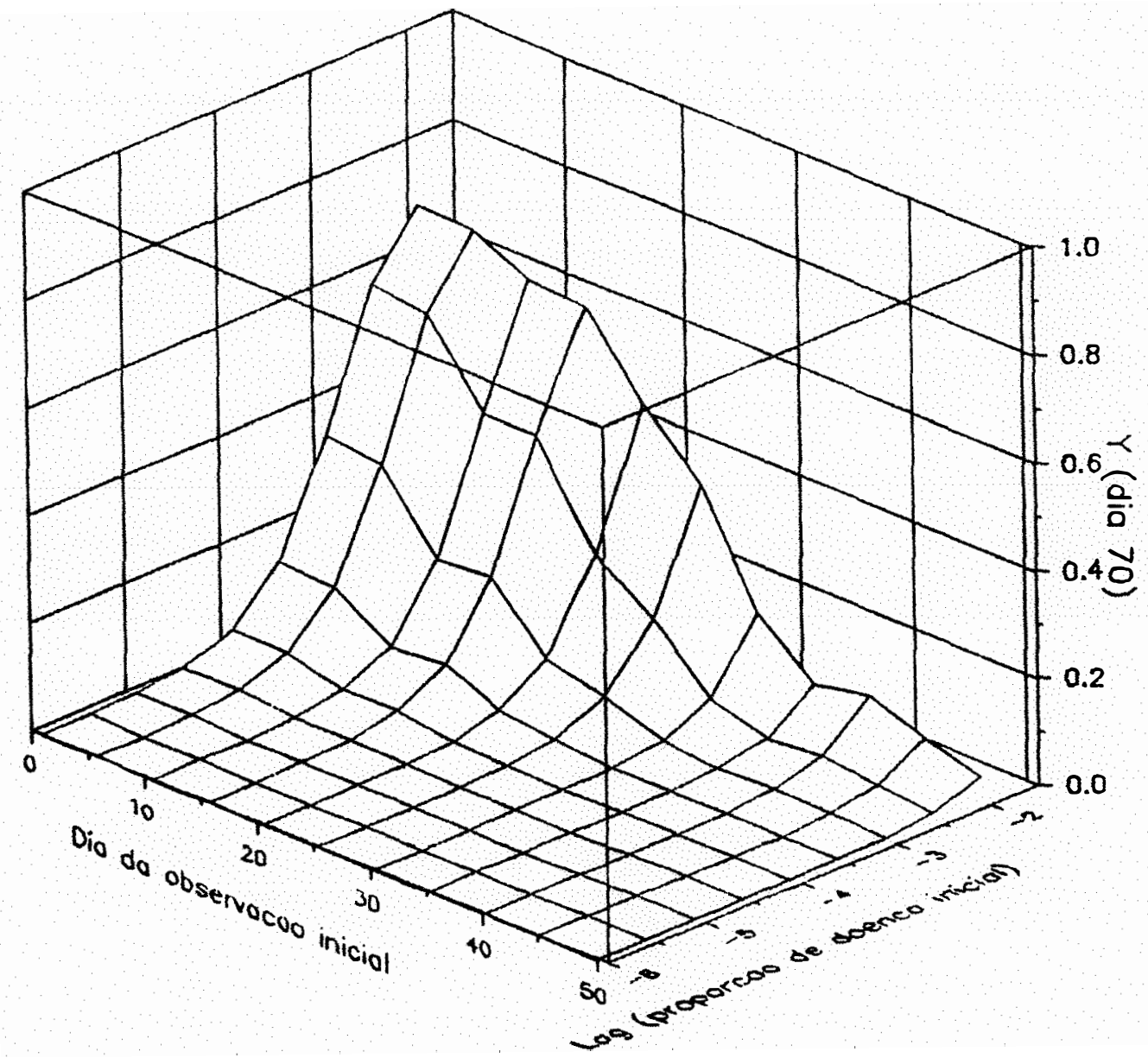

Figura 12. Quantidade de doença gerada pelo simulador para ferrugem do feijoeiro no 700 dia (y70), variando-se o dia da observação e a proporção de doença inicial, usando dados do ensaio de julho de 1990 com a cultivar Carioca. 


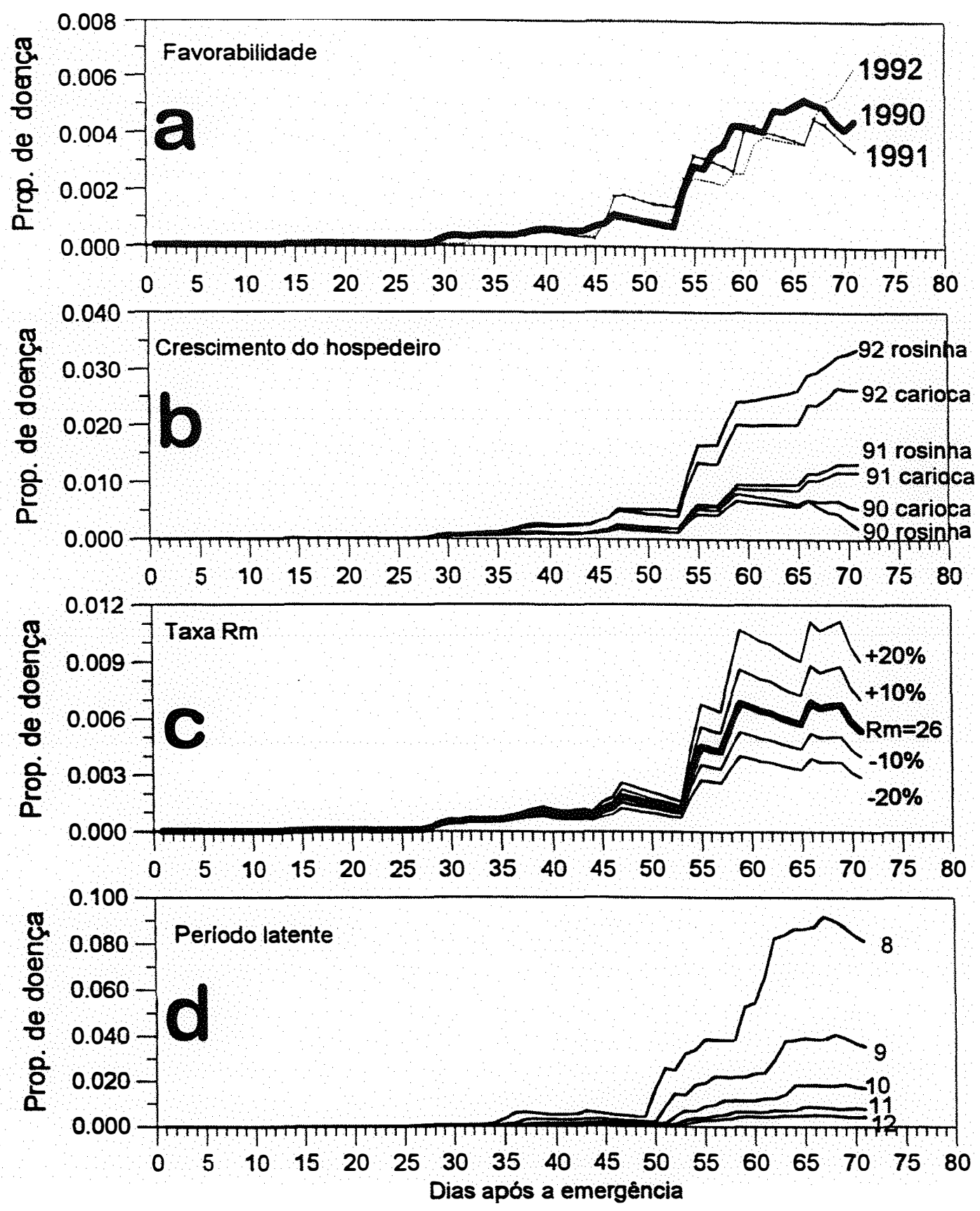

Figura 13. Curvas de progresso de doença geradas pelo simulador para ferrugem do feijoeiro em função da alteraçáo de: a) favorabilidade, foram usados os dados climáticos de julho de 1990 , julho de 1991 e junho de 1992, b) crescimento do hospedeiro, foram usados os dados observados em 1990, 1991 e 1992 para as cultivares Rosinha e Carioca. Para a variável $R m$ (c) e 'periodo latente' (d) alterou-se em $\pm 20 \%$ o valor base ( 26 e 10, respectivamente). 


\section{DISCUSSÃO}

O modelo foi elaborado com o objetivo de simular epidemias de ferrugem do feijoeiro o mais próximo do real quanto possivel. Futuramente o modelo será incrementado com outras rotinas, definidas através de novos experimentos, permitindo que se torne um modelo de previsão de perdas.

\subsection{Verificação do modelo}

A maioria dos trabalhos não descreve os testes de verificação dos modelos. O modelo para ferrugem do amendoim, descrito por SAVARY et al. (1990), é um dos poucos exemplos que detalha a verificação. TENG (1981) recomendou a verificação para evitar erros que podem passar despercebidos nos demais testes.

No modelo para simulação de epidemias de ferrugem do feijoeiro, além dos testes descritos no ítem 3.3.1, fez-se a verificação de cada rotina em sua consistência lógica. Visou-se achar erros de programação e também diminuir o tamanho do programa. Fez-se uma depuração das rotinas com acompanhamento do valor das variáveis a cada passo da execução do programa. Não se achou nenhum erro que interferisse no resultado final apresentado pelo simulador. Apenas trocou-se a posição das rotinas dentro do programa para facilitar o seu entendimento.

Seguindo-se sugestão de PRESSMAN (1987), o teste da caixa preta foi executado apenas para as subrotinas que compõem a rotina 'Ciclo Diário'. As demais rotinas não foram testadas por se tratarem de rotinas auxiliares. Por exemplo, a rotina 'Saida dos dados' é responsável pela criação de um arquivo com os valores das variáveis para cada dia de simulação. Porém não interfere diretamente no resultado das variáveis. O teste da caixa preta confirmou a importância das rotinas 'Favorabilidade' e 'Crescimento do Hospedeiro', sem as quais o programa não atinge o final de sua execução. As rotinas 'Latência', 'Distribuição Primeiras Infecções' e 'Infecções Secundárias' também são 
fundamentais, pois sem elas não se tem o progresso da epidemia. Já a rotina 'Sensibilidade do Hospedeiro' influencia apenas na quantidade de doença apresentada pelo simulador. Ela dá mais exatidão às simulações.

$\mathrm{O}$ teste da caixa branca foi executado para as principais rotinas dentro da rotina 'Ciclo Diário'. Para a rotina 'Crescimento do Hospedeiro' os resultados gerados pelo simulador são equivalentes aos observados em campo. Portanto, a verificação serviu para confirmar que não há influência negativa deste fator sobre a quantidade de doença simulada. Para tornar o simulador um modelo de previsão será necessário criar uma nova rotina 'Crescimento do Hospedeiro'. A rotina deverá simular um incremento na área foliar do hospedeiro e não esperar que os dados de crescimento sejam coletados e inseridos no programa.

Nos trabalhos desenvolvidos por BACCHI (1993), determinou-se que há correlação entre a idade do hospedeiro e o periodo latente. No programa para simulação de epidemias de ferrugem do feijoeiro esse fator não está incorporado. $O$ 'periodo latente' calculado pela rotina 'Latência' independe da idade do hospedeiro, conforme foi verificado pelos testes. Em futuras versões do programa, este dado deverá ser acrescentado à rotina 'Latência'.

A sensibilidade do hospedeiro, determinada pelas variáveis 'suscetibilidade da planta' ( $a h f)$ e 'suscetibilidade do "cohort" ' (acf), colaboram para reduzir a quantidade de doença no fim do ciclo do hospedeiro, conforme foi verificado nos testes. Os dados usados para se determinar o valor de ahf e acf foram obtidos em experimentos conduzidos com plantas de cevada (HAU et al., 1985). Para aumentar a exatidão dessas rotinas, é interessante que sejam feitos experimentos com o feijoeiro procurando determinar-se a variação na suscetibilidade em função da idade do hospedeiro.

A rotina 'Favorabilidade' pode ser considerada a principal rotina dentro da rotina 'Ciclo Diário'. SAVARY et al. (1990) fixaram seus testes de verificação apenas em uma rotina com função semelhante à rotina 'Favorabilidade'. No modelo para fernugem do feijoeiro, a verificação dessa rotina determinou que ela não sofre influência direta da idade do hospedeiro. A influência da idade do hospedeiro dá-se de maneira indireta. Na equação principal do programa a variável fav, determinada pela rotina 'Favorabilidade', é multiplicada pela variável acf e a ahf da rotina 'Sensibilidade do Hospedeiro'. Os valores da variável 'favorabilidade climática' ( $f a v)$ foram maiores para a cultivar Rosinha porque os experimentos haviam determinado isso. Verificou-se que o programa está usando os dados corretamente para calcular a 'favorabilidade climática' das duas cultivares. 
A verificação da rotina 'Ciclo Diário' em sua totalidade deu-se na observação da variável 'incremento diário na área infectada' (id). Os resultados apresentados pela variável estavam de acordo com o esperado. Verificou-se que os valores de id sofrem influência de todas as rotinas testadas. A variável id também demonstrou a diferença entre as cultivares Carioca e Rosinha. Em condições de campo a cultivar Rosinha apresenta mais doença que a Carioca. O mesmo comportamento foi apresentado pela variável $i d$ para as duas cultivares.

\subsection{Validação do modelo}

\subsubsection{Análise nos anos de cultivo.}

Para que o processo de validação fosse aceitável, as simulações foram executadas com os mesmos valores para todas as variáveis, com exceção para a quantidade de doença inicial e dia de início e de término da epidemia. A discussão foi baseada apenas na simulação 1 de cada Caso. Foi usada a transformação dos dados em logito (BERGER ${ }^{1}$ ) para que se pudesse observar o comportamento dos dados simulados nas fases iniciais da epidemia. $O$ Caso 1 para a cultivar Carioca e o Caso 4 para a cultivar Rosinha nortearam a construção do modelo e foram usados para calibração da taxa de progresso da doença $(R m)$.

\subsubsection{Análise visual dos gráficos.}

A maioria dos autores utilizam apenas a análise visual de gráficos para validar seus modelos (AUST et al., 1983; HAU et al., 1985; SAVARY et al., 1990; TIMMERMANS, 1990; DJURLE \& YUEN, 1991). Para o modelo de simulação da ferrugem do feijoeiro, a análise visual foi apenas um dos critérios utilizados.

Em julho de 1990 obteve-se um bom ajuste para as duas cultivares (Casos $1 \mathrm{e}$ 4). Inclusive as severidades decrescentes no fim do ciclo foram corretamente descritas pelo simulador.

Em julho de 1991, nos plantios que usaram apenas inóculo natural (Casos 2 e 5), os dados observados apresentaram uma severidade bem baixa, não ultrapassando

1 BERGER, R.D. (University of Florida, Plant Pathology Department) Comunicação pessoal, 1993. 
$0,1 \%$. Em condições normais de epidemia é de se esperar que a cultivar Rosinha tenha niveis de doença maiores que a cultivar Carioca, mas isto não ocorreu nesse plantio já que a ASCPD foi quase quatro vezes maior para a cultivar Carioca. Para explicar o fato tem-se duas suposições: a primeira é a tendência do aumento do erro experimental das avaliações quando são baixos os valores de severidade e a segunda, e mais provável é a ocorrência de uma interação antagonística entre $U$. appendiculatus e outro patógeno que provocou murcha nas plantas e antecipou o ciclo do hospedeiro. Devido a esses fatores, pode-se considerar que 0 simulador apresentou bons resultados apesar de ter subestimado a quantidade de doença para a cultivar Carioca e superestimado para a Rosinha.

Em junho de 1992 (Casos 3 e 6), para a cultivar Rosinha, a doença no campo foi constatada no 150 dia e a simulação foi inicializada no 220 dia. Apesar de ter havido uma oscilação na quantidade de doença detectada no fim da avaliação, os resultados obtidos na simulação foram válidos. Para a cultivar Carioca a doença foi constatada no 220 dia e a inicialização da simulação foi no 260 dia. Essa inicialização tardia pode explicar a falha do modelo em quantificar a epidemia, já que há no modelo uma rotina que diminui a taxa de infecção à medida que aumenta a idade do hospedeiro. Com isso pode-se afirmar que a rotina 'Sensibilidade do Hospedeiro' necessita de verificação, através de experimentos, para ser ajustada.

Em maio de 1991, nos plantios em que foi feita inoculação artificial (Casos 7 a 11), os resultados obtidos permitiram verificar o comportamento do simulador sob diferentes quantidades de doença inicial. Observou-se que, de uma maneira geral, os dados simulados tenderam a acompanhar os observados. Inclusive o pico de aceleração da epidemia ocorrido entre o 50 o e o 60 o dia foi captado. Em todos os Casos, no fim da epidemia, os dados simulados ficaram abaixo dos observados. Um primeiro fator que pode explicar essa tendência foi a queda na quantidade de doença dos dados simulados, logo após a inicialização. Esta queda está associada à falta dos dados climáticos antes do 420 dia. Sendo assim, o simulador considerava 0 valor zero para a variável 'favorabilidade climática' antes desse dia. Isso provocava uma queda na quantidade de doença, o que provavelmente não ocorreu no campo. Outro fator pode ser a maior resistência por parte do hospedeiro nas fases finais do seu ciclo. Isso está ligado à rotina 'Sensibilidade do Hospedeiro', que necessita de experimentos para comprová-la. 


\subsubsection{Validação Estatística}

Os testes estatísticos utilizados foram sugeridos por TENG (1981). Poucos autores utilizaram estes tipos de testes para a validação. Entre eles tem-se SALL (1980) e YANG et al. (1991).

Nas validações executadas, o teste de $F$ da análise de regressão dos dados simulados contra os observados foi significativo ao nível de $5 \%$ de probabilidade para a maioria dos Casos, com exceção para o Caso 11, o qual não foi significativo. Isso ocorreu devido à grande oscilação na quantidade de doença observada nas últimas avaliações. A variação se deve provavelmente a um erro experimental associado a coleta dos dados no campo. Um teste de F significativo indica que houve regressão entre os dados simulados e observados, sendo grande a probabilidade de ajuste dos dados. Portanto, para os Casos em que isso ocorreu, podemos nos basear no valor de $r^{2}, b_{0} \mathrm{e}$ $b_{1}$ para verificar o ajuste entre as duas variáveis, pois sabe-se que devem tender a $1,0 \mathrm{e}$ 1 , respectivamente. Verifica-se que valores de $r^{2}$ foram maiores que 0,8 na maioria dos Casos (Figura 14a). Valores de $b_{0}$ ficaram próximos a zero (Figura 14b). Já os valores de $b_{1}$ tenderam a 1 (Figura 14c), mas apresentaram desvios consideráveis.

O teste de $t$ realizado para comparar a constante da equação de regressão $\left(b_{0}\right)$ dos dados observados com a $b_{0}$ dos dados simulados não foi significativo para a maioria dos Casos, com exceção para os Casos 3 e 5 , significativos ao nível de $5 \%$ de probabilidade (Tabela 3). Esses Casos também apresentaram o teste de $\mathrm{t}$ significativo ao nível de $1 \%$ de probabilidade (Tabela 3 ) para a comparação do coeficiente angular $\left(b_{l}\right)$ da equação de regressão. Isso significa que somente para esses dois Casos houve diferença entre as retas de regressão do logito dos dados simulados em relação aos observados. O que pode ser comprovado visualizando-se os gráficos obtidos (Figuras $8 \mathrm{e}$ 9).

Alguns autores (SEEM \& HAITH, 1986; HARRISON, 1990) alertam quanto à tendência dos testes estatísticos de invalidar modelos ao invés de validá-los. Seguindo-se o exemplo de YANG et al. (1991), os resultados dos testes realizados nas validações foram interpretados mais como uma referência do que uma conclusão estatística. Entretanto, o modelo pode ser considerado estatisticamente válido. 

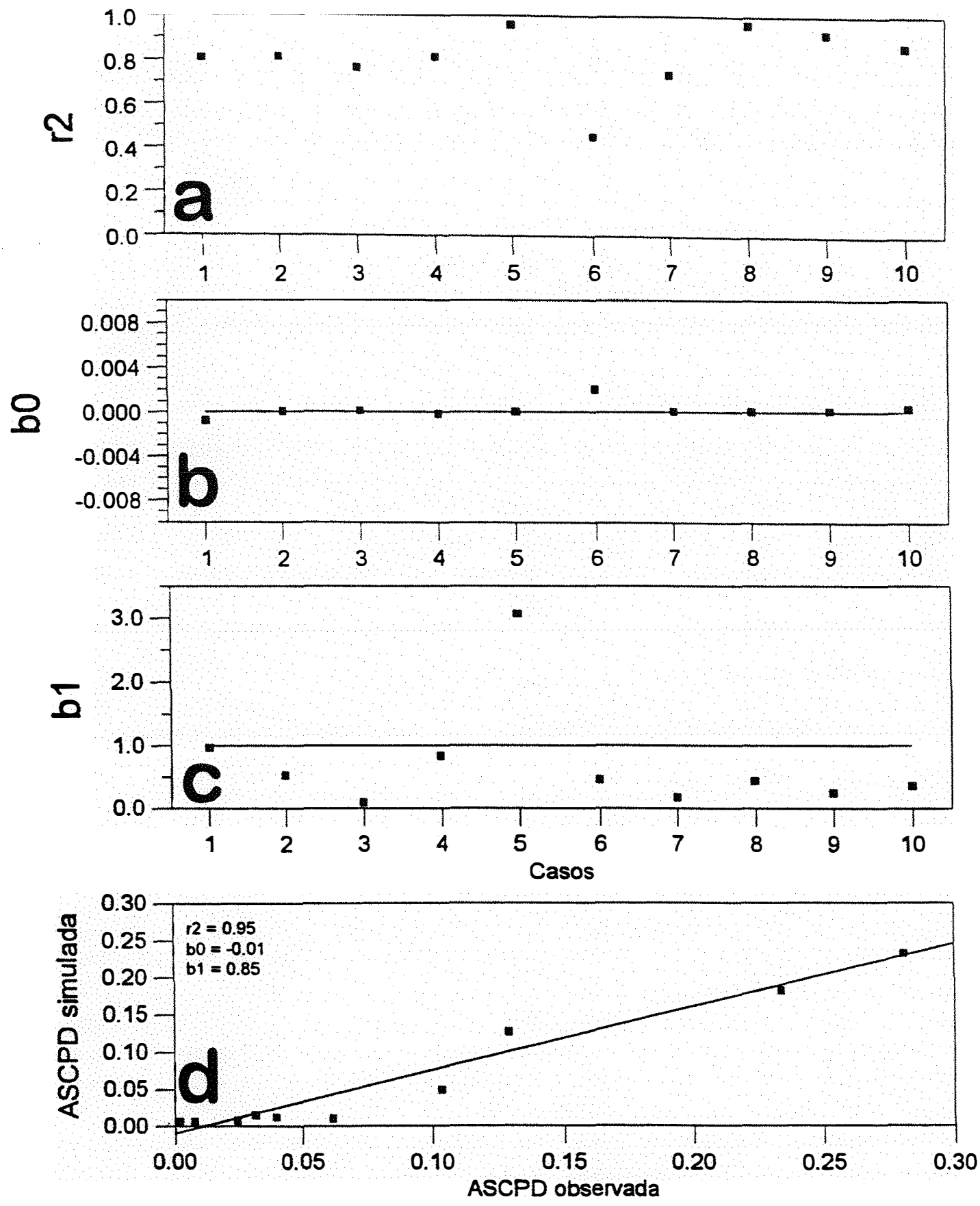

Figura 14. Resultados de $r^{2}$ (a), bo (b) e $b_{1}$ (c) da regressão entre os dados observados e simulados para epidemias de ferrugem em feijoeiro, para os Casos que apresentaram teste de $F$ significativo a $5 \%$ de probabilidade- Para $r^{2}, b_{0}$ e $b_{1}$ e eram esperados valores 1,0 e 1 respectivamente. Regressão da área sob a curva de progresso da doença (ASCPD) simulada contra a observada (d). 


\subsubsection{3. Área sob a curva de progresso da doença (ASCPD).}

A área sob a curva de progresso da doença é utilizada como um parâmetro de comparação para perdas de produtividade em modelos que relacionam perdas e doença. É interessante que o modelo apresente resultados de ASCPD o mais próximo possivel da ASCPD observada, já que se pretende, no futuro, utilizá-lo como modelo de previsão de perdas. Além disso, a ASCPD capta pequenas variações na curva, não detectadas na regressão dos dados simulados contra os observados. BOWEN \& PEDERSEN (1989) utilizaram a ASCPD para validar um modelo de simulação para milho.

Fazendo-se uma regressão da ASCPD simulada contra a observada para todos os Casos (Figura 14d), verifica-se uma ótima correlação dos dados. Apenas o Caso 11, que apresentou teste de $\mathrm{F}$ não significativo, não foi usado na regressão. Os Casos onde a ASCPD foi maior apresentaram um melhor ajuste à reta de regressão. Já, para os valores pequenos o ajuste foi pior. É interessante que o modelo se ajuste bem aos dados de maior quantidade de doença, pois quando isso ocorre se torna importante uma previsão de epidemias. Apesar de se verificar uma tendência de subestimar a quantidade de doença por parte do simulador, os resultados apresentados podem ser considerados satisfatórios, sendo esse mais um aspecto positivo na validação do modelo.

\subsubsection{Problemas que influenciaram as simulações.}

A calibração é a troca de valores de variáveis para permitir um melhor ajuste do modelo com os dados observados. Segundo Loomis et al. ${ }^{1}$, citados por CARTER (1986). Vale ressaltar que isso só deve ser feito quando for impossivel determinar o valor da variável sob condições de campo. No modelo FERRUGEM fez-se a calibração para a variável 'taxa básica de infecção corrigida máxima' $(R m)$, que foi fixada em 26 para a cultivar Carioca e 40 para a cultivar Rosinha. A $R m$ pode variar somente se houver alteração no espectro de raças da população do patógeno devido à pressão de seleção ou se forem consideradas cultivares distintas (WEBER ${ }^{2}$ ). Como não houve evidências de alteração de raças do patógeno, assumiu-se uma única $R m$ para cada

1 LOOMIS, R.S.; RABBINGE, R.; NG, E. Explanatory models in crop physiology. Annual Review of plant physiology, Palo Alto, 30:339-67, 1979. 
cultivar. Em virtude dos experimentos de 1990 terem sido melhor descritos pelo simulador (Casos 1 e 3), assumiu-se que os valores da $R m$ deste ano seriam os mais promissores. Isso confirmou-se nos demais plantios com excę̧ão para o Caso 4 (Rosinha em 1991), onde se obteve um melhor ajuste com uma $R m$ igual a 25, e o Caso 5 (Carioca em 1992), onde a $R m$ igual a 60 propiciou melhores resultados (Figura 9).

Para os Casos que usaram inóculo natural, foi feita a inicialização na data da segunda avaliação de campo em que se constatou a doença, com exceção para os Casos 1 e 4, que se apresentavam consistentes desde a primeira avaliação. Quando inicializa-se na primeira deteç̧ão de doença, pode ainda estar ocorrendo a entrada de esporos externos, colaborando para o aumento na quantidade inicial de inóculo. Logo que se constate a presença da doença é aconselhável inicializar o modelo em um dia fixo, depois da emergência, todo ano (WEBER ${ }^{1}$ ), mas devido à diferença entre os dias de aparecimento da doença, constatados nos diferentes anos, não foi possível seguir este esquema. Assim, as simulações para 1992 iniciaram-se após o 200 dia tanto para a cultivar Rosinha como para a Carioca. O fato da inicialização para a cultivar Carioca ter sido no 260 dia, aliado à sensibilidade decrescente do hospedeiro no final do ciclo, pode ser uma explicação para a baixa quantidade final de doença demonstrada pelo simulador (Figura 8).

O simulador FERRUGEM foi construído baseado no modelo "daily cohort" (BERGER \& JONES, 1985, BERGER, 1989) e por isso possui rotinas que reduzem a 'taxa básica de infecção corrigida máxima' à medida que aumentam a idade do "cohort" e a idade do hospedeiro. Entretanto, os parâmetros para essas rotinas foram determinados através de suposição, já que experimentos para definí-los são muito dificeis de se conduzir. Usou-se dados do patossistema oídio da cevada (HAU et al., 1985), e talvez seja esse o fator que explique a tendência do modelo, visível nos Casos 1, 2, 4, 7, 8, 9, 10 e 11 (Figuras 1, 2, 3 e 4), de superestimar a doença na fase inicial de simulação e subestimá-la numa fase posterior, próximo ao fim do ciclo. Futuros experimentos ou mesmo uma calibração com os dados obtidos, visando ajustar a rotina 'Sensibilidade do Hospedeiro', podem propiciar ainda melhores resultados para o simulador. Inclusive a falha do simulador no Caso 5 , para a cultivar Carioca em 1992, pode estar associada à rotina 'Sensibilidade do Hospedeiro'. A inicialização da simulação deu-se numa fase

1. 2 WEBER, G.W. (Justus-Liebig-University of Giessen, Department of Phytopathology) Comunicação pessoal, 1993. 
adiantada do ciclo, quando a rotina de sensibilidade determina uma maior resistência por parte do hospedeiro.

Não se deve esquecer que observações de doença usadas para a validação de um modelo dificilmente são medidas ou amostradas sem erro e em alguns casos esses erros podem ser mais significativos que aqueles advindos dos modelos (HAU, 1988). Considerando que há um aumento nos erros das avaliações com o decréscimo na severidade de doença, isto pode explicar as diferenças entre dados simulados e observados para os Casos em que a quantidade de doença não foi elevada. Uma maneira de se minimizar o erro experimental foi o cálculo do intervalo de confiança para os dados observados.

\subsection{Análise de sensitividade do modelo}

É interessante se executar uma análise de sensitividade com os parâmetros do modelo. Para os parâmetros mais sensitivos, uma pequena alteração no seu valor provoca uma grande variação na resposta do modelo (TENG, 1981). Determinando-se esses parâmetros, pode-se aumentar a precisão do modelo, realizando-se medidas mais cuidadosas de seus valores. DJURLE \& YUEN (1991) usaram a análise de sensitividade para determinar qual foi o parâmetro mais importante no desenvolvimento de uma epidemia.

No simulador para ferrugem do feijoeiro, a equação responsável pelo cálculo da área infectada (cid) foi o centro do modelo pelo que se presumiu que as variáveis responsáveis pelo seu cálculo fossem as mais sensitivas. As variáveis 'proporção de doença inicial' ( $f$ ) e 'dia da observação' ( $t i)$ foram as menos sensitivas e não estavam diretamente ligadas à equação do cálculo da área infectada. Mesmo assim, a interação entre $f i$ e $t i$ provocou grandes alterações na quantidade final de doença $(y>0)$, conforme ficou claro na Figura 12.

As variáveis 'taxa básica de infecção corrigida máxima' $(R m)$, 'favorabilidade climática' (fav), e 'sensibilidade do hospedeiro' (acf) apresentaram a mesma sensitividade. $R m$, fav e acf são diretamente proporcionais à 'área infectada' (cid), por isso o mesmo comportamento na análise de sensitividade. Na versão original do simulador, sem as modificações para a análise de sensitividade, a variável $R m$ não tem seu valor alterado no transcorrer da simulação.Já as variáveis fav e acf têm um novo valor para cada dia simulado. Daí a importância em se determinar com exatidão os cálculos 
presentes nas subrotinas que fornecem os valores de fav e acf. Isto pode ser comprovado observando-se a Figura 13, onde o uso de diferentes condições de 'favorabilidade climática' causou uma variação de até $87 \%$ na quantidade final de doença.

A variável 'período latente' $(p)$, foi a mais sensitiva entre as testadas: Ela afeta a equação da área infectada por influenciar o valor da área doente no dia anterior (ya(i-1)), que é um dos termos da equação. BERGER \& JONES (1985) já haviam determinado que o 'período latente' é um dos parâmetros mais sensitivos em modelos de epidemias. Na Figura 13 pode-se observar claramente a diferença de $373 \%$ entre a $y 70$ que usou $p=8$ e $p=10$. Na Tabela 4 , a variação de $y 70$ para o 'período latente' ficou subestimada, atingindo apenas $110 \%$, pois a quantidade de doença estava próxima a $100 \%$.

A rotina 'Crescimento do Hospedeiro' demonstrou-se um parâmetro sensitivo quanto aos diferentes formatos de curvas utilizados conforme demonstrado pela Figura 13. A constante $b 1$, responsável pela determinação da área foliar máxima do hospedeiro, surpreendentemente afetou pouco a quantidade final de doença $(y 70)$. A constante $b 3$, responsável pelo formato da curva de crescimento do hospedeiro, foi mais sensitiva, confirmando a Figura 13, e apresentou efeitos interessantes na y70. Quando havia um crescimento antecipado no ciclo do hospedeiro, a doença se apresentava mais severa no fim da simulação. Isso pode ser verificado com o uso de um valor maior de $b 3$.

Entre os parâmetros testados, a 'favorabilidade climática' (fav), a 'sensibilidade do hospedeiro' (acf), a 'taxa básica de infecção corrigida máxima' $(R m)$, o 'período latente' ( $p$ ) e a constante $b 3$ da rotina 'Crescimento do Hospedeiro', foram os que demonstraram maior sensitividade. Portanto, os seus valores no transcorrer da simulação irão afetar grandemente a quantidade final de doença. $\mathrm{A} R m$ é o único parâmetro que mantém um mesmo valor do início ao fim da simulação, o qual foi definido através de uma calibração. Os demais parâmetros dependem de rotinas para o seu cálculo em cada dia simulado. A 'favorabilidade climática' ( $f a v)$ e o 'período latente' $(p)$ possuem equações bem determinadas por experimentos. A 'sensibilidade do hospedeiro' (acf) necessita de ensaios para se quantificar o aumento na resistência de folhas de feijoeiro à infecção. No simulador foram usados dados da cevada (HAU et al., 1985), que forneceram bons resultados, mas geraram dúvidas quanto à exatidão. Para o crescimento do hospedeiro, seria interessante uma rotina que calculasse o incremento independente do ano de plantio. Mas, para a construção dessa rotina, deve-se tomar cuidado com o formato da curva de crescimento resultante, por ser este um parâmetro sensitivo. $\mathrm{O}$ formato poderá ser 
afetado por fatores externos, não previstos no modelo, como irrigação e tratos culturais, entre outros, os quais dificultariam a construção da rotina de crescimento. Porém, o esforço para obtenção dessa rotina deve ser executado, caso se pretenda transformar o simulador em um modelo de previsão de epidemias. 


\section{CONCLUSÕES}

As principais rotinas do programa para simulação de epidemias de ferrugem do feijoeiro apresentaram consistência lógica e estavam condizentes com a realidade biológica observada em experimentos.

Pela análise visual dos gráficos apenas o Caso 3 foi inválido, provavelmente devido a uma falha da rotina 'Sensibilidade do Hospedeiro'. A análise pelo teste $\mathrm{F}$ considerou como inválido apenas o Caso 11, provavelmente devido a um erro experimental associado às avaliações de campo. A ASCPD considerou o modelo válido. Houve correlação entre a análise pelo teste t e a análise visual dos gráficos.

Apesar da falha no Caso 3, determinada pela análise visual e pelo teste $t$, pode-se considerar o simulador válido. $O$ teste de $\mathrm{F}$ e a ASCPD confirmam a validade, atribuindo maior importância aos Casos que apresentaram maior quantidade de doença.

Todas as variáveis associadas ao cálculo da área infectada apresentaram-se sensitivas. $O$ 'periodo latente' foi o parâmetro mais sensitivo. $O$ formato da curva de crescimento do hospedeiro foi um parâmetro mais sensitivo que a quantidade de área foliar máxima. 


\section{REFERÊNCIAS BIBLIOGRÁFICAS}

AGRIOS, G.N. Plant Pathology. 3.ed., New York, Academic Press, 1988. 803 p.

ALEXOPOULOS, C.J. Introductory mycology, 3.ed., New York, John Wiley \& Sons, 1979. $632 \mathrm{p}$.

AUST, H.J.; HAU, B.; KRANZ, J. Epigram - a simulator of barley powdery mildew. Zeitschrift für Pflanzenkrankheiten und Pflanzenschutz, Stuttgart, 90(3):24450, 1983.

AZEVEDO FILHO, A.J. de B.V.de Análise econômica de projetos: "software" para situações deterministas e de risco envolvendo simulação. Piracicaba, 1988. 127p. (Mestrado - Escola Superior de Agricultura "Luiz de Queiroz"/USP)

BERGAMIN FILHO, A. Análise Matemática de Epidemias. In: GALLI, F.; coord. Manual de Fitopatologia: princípios e conceitos. Piracicaba, Agrômica Ceres, 1978. v.1, p.242-56.

BERGAMIN FILHO, A. Disease progress of south american leaf blight of rubber in different brasilian regions. Eur. J. For Path, 14:386-91, 1984.

BERGER, R.D. Comparison of the Gompertz and Logistic equations to describe plant disease progress. Phytopathology, St. Paul, 71:716-9, 1981.

BERGER, R.D. Description and aplication of some general models for plant disease epidemics. In: LEONARD, K.J. \& FRY, W.E. Plant disease epidemiology Genetics, resistance and management. McGraw-Hill, 1989, v.2, p.125-49

BERGER, R.D. \& JONES, J.W. A general model for disease progress with funtions for variable latency and lesion expansion on growing host plants. Phytopathology, St. Paul, 75:792-7, 1985. 
BOWEN, K.L. \& PEDERSEN, W.L. A model of corn growth and disease development for instructional purposes. Plant Disease, St. Paul, 73(1):83-86, 1989.

CAMPBELL, C.L. \& L.V. MADDEN. Introduction to plant disease epidemiology. New York. John Willey, 1990. p.329-52.

CARDOSO, J.E. Ferrugem In: ZIMMERMAN, M.J. de O.; ROCHA, M.; YAMADA, T. Cultura do feijoeiro, fatores que afetam a produtividade. Piracicaba, POTAFÓS, 1988, p.479-90.

CARTER, N. Simulation modelling In: McLEAN, G.D.; GARRET, R.G.; RUESINK, W.G. Plant virus epidemics - monitoring, modelling and predicting outbreaks. London, Academic Press, 1986. cap. 10, p.193-215.

DJURLE, A. \& YUEN, J.E. A simulation model for Septoria nodorum in winter wheat. Agricultural Systems, England, 37:193-218, 1991.

FEGIES, N.C. Desenvolvimento de modelo para simulação da progressão de doenças de plantas. Piracicaba, 1985. 102 p. (Mestrado - Escola Superior de Agricultura "Luiz de Queiroz"/ USP).

FEGIES, N.C. \& BERGAMIN FILHO, A. Modelos de simulação em fitopatologia. Summa Phytopathologica.Piracicaba, 12:45-62, 1986.

FRY, W.E. Disease forecasting: Epidemiological considerations. In: Principles of plant disease management. New York, Academic Press, 1982. p.105-25.

GASPAROTTO, L. Epidemiologia do mal das folhas (Microcyclus ulei (P. Henn)v. Arx) da seringueira (Hevea spp.), Viçosa, 1988. 124p. (Doutorado Universidade Federal de Viçosa)

GROTH, J.V.; URS, N.V.R.R. Differences among bean cultivars in receptivity to Uromyces phaseoli var. typica. Phytopathology, St. Paul, 72:374-78, 1982.

HARRISON, S.R. Regression of a model on real-system output: an invalid test of model validity. Agricultural Systems, England, 34:183-90, 1990.

HARRISON, S.R. Validation of agricultural expert systems. Agricultural Systems, England, 35:265-85, 1991.

HAU, B. Moddeling epidemics of polyciclic foliar diseases and development of simulators. In: KRANZ, J. \& ROTEM, J. Experimental techniques in plant disease epidemiology. Berlin, Springer-Verlag, 1988, p.267-77. 
HAU, B.; AUST, H.F.; KRANZ, J. Problems in modelling powdery mildew epidemics. European Plant Protection Bulletin, 13:259-62, 1983.

HAU, B.; EISENSMTTH, S.P.; KRANZ, J. Construction of temporal models: II. Simulation of aerial epidemics. In. GILLIGAN, C.A. Advances in plant pathology: mathematical modelling of crop disease. London Academic Press, 1985. v.3. p.31-65.

IMHOFF, M.W.; MAIN, C.E.; LEONARD, K.J. Effect of temperature, dew period, and age of leaves, spores and source pustules on germination of bean rust urediospores. Phytopathology, St. Paul, 71:577-583, 1981.

IMHOFF, M.W., LEONARD, K.J.; MAIN, C.E. Patterns of bean rust lesion size increase and spore production. Phytopathology, St. Paul, 72:441-46, 1982.

ISHIGURO, K. \& HASHIMOTO, A. Computer-based forecasting of rice blast epidemics in Japan. In:RICE blast modeling and forecasting. Manila, International Rice Research Institute, 1991. p.39-51.

JEFFERS, J.N.R. Practitioner's handbook on the modelling of dynamic change in ecosystems. New York, John Wiley, 1988. cap.5, p.29-42.

JONES, A.L.; LILLEVIK, S.L.; FISHER, P.D.; STEBBINS, T.C. A microcomputerbased instrument to predict primary apple scab infection periods. Plant Disease. St. Paul, 64:69-72, 1980.

JONHSON, K.B. The role of predictive systems in disease management. In. TENG, P.S Crop loss assesment and pest management. APS Press, 1987. 176-90 p.

KIMATI, H. Doenças do Feijoeiro. In: GALLI, F. coord. Manual de Fitopatologia Piracicaba, Agrômica Ceres, 1980. v.2, p.297-318.

KNUDSEN, G.R.; SPURR JR., H.W.; JOHNSON, C.S. A computer simulation model for cercospora leaf spot of peanut. Phytopathology, St. Paul, 77(8):1118-21, 1987.

KRANZ, J. Epidemics of plant diseases. Berlin, Springer Verlag, 1974. 170 p.

KRANZ, J. \& HAU, B. Systems analysis in epidemiology. Annual Review of Phytopathology, Palo Alto, 18:67-87, 1980. 
KRANZ, J. \& ROYLE, J. Perspectives in mathematical modeling of plant disease epidemics. In: SCOTT, P.R. \& BAINBRIDGE, A. Plant disease epidemiology. Oxford, Blackwell, 1978. p. 111-19.

KRANZ, J.; MOGK, M.; STUMPF, A. EPIVEM- ein simulator furr apfelschorf. Zeitschrift für Pflkrankheiten und Pflanzenschutz, Stuttgart, 80:181-87, 1973.

KRAUSE, R.A. \& MASSIE, L.B. Predictive systems: modern approaches to disease control. Annual Review of Phytopathology, Palo Alto, 13:3 1-47, 1975.

KRAUSE, R.A.; MASSIE, L.B.; HYRE, R.A. Blitecast: a computerized forecast of potato late blight. Plant Disease Reporter, 59:95-98, 1975.

MADDEN, L.V. Quantification of disease progression. Protec. Ecol.,2: 159-76, 1980.

MACKENZIE, D.R. Scheduling fungicide aplications for potato late blight with blitecast. Plant Disease, St. Paul, 65:394-399, 1981.

MENDES, B.M.J. Influência da temperatura e do tipo de folha na quantificação de parâmetros epidemiológicos monocíclicos da ferrugem do feijoeiro (Uromyces phaseoli var. typica Arth.), Piracicaba, 1985, 83 p. (Mestrado - Escola Superior de Agricultura "Luiz de Queiroz"/ USP)

MENDES, B.M.J. Influência de parâmetros de clima e do hospedeiro no desenvolvimento da ferrugem do feijoeiro (Uromyces phaseoli var. typica Arth.), Piracicaba, 1987, 102 p. (Doutorado - Escola Superior de Agricultura "Luiz de Queiroz"/USP)

MENDES, B.M.J.; FEGIES, N.C.; PAIVA, S.B.; BERGAMIN FILHO, A. Período infeccioso: um componente epidêmico mal definido. In. VI Congresso Paulista de Fitopatologia, Botucatu, 1984, p.56 (Resumo).

MENDES, B.M.J. \& BERGAMIN FILHO, A. Adaptação da técnica da cultura de folha destacada para a quantificação dos parâmetros epidemiológicos monocíclicos da ferrugem do feijoeiro (Uromyces phaseoli var. typica). Fitopatologia Brasileira, Brasília, 11:103-14, 1988.

MENDES, B.M.J. \& BERGAMIN FILHO, A. Influence of temperature, wetness duration, and leaf type on the quantification of monocyclic parameters of bean rust. Journal of Phytopathology. Stuttgart, 126:183-89, 1989a. 
MENDES, B.M.J. \& BERGAMIN FILHO, A. Influência da idade da folha na quantificação dos parâmentros monocíclicos da ferrugem do feijoeiro (Uromyces phaseoli var. typica). Fitopatologia Brasileira, Brasilia, 14(1):26-28, $1989 \mathrm{~b}$.

MENDES, B.M.J. \& BERGAMIN FILHO, A. Análise da curva de progresso da ferrugem do feijoeiro (Uromyces phaseoli var. typica) em condições naturais de infecção. Fitopatologia Brasileira, Brasília, 15:314-17, 1990.

MENTEN, J.O.M. \& BERGAMIN FILHO, A. Componentes monocíclicos da resistência do feijoeiro a Uromyces appendiculatus e suas relações com os parâmetros epidemiológicos xo e r. Summa Phytopathologica, Piracicaba, 7:18, 1981.

MICHALSKI, R.S.; DAVIS, J.H.; BISHT, V.S.; SINCLAIR, J.B. A computer-based advisory system for diagnosing soybean diseases in Illinois. Plant Disease, St. Paul, 67:459-63, 1983.

MORA NUÑEZ, O.A. Variabilidade patogênica de Uromyces phaseoli var. typica Arth. no Brasil e o problema da identificação de raças fisiológicas. Viçosa, 1986. 68 p. (Mestrado - Universidade Federal de Viçosa).

MORGAN, B. J. T. Elements of simulation. London, Chapman and Hall, 1984, 351 p.

NASSER, L.C.B.; CHAVES,G.M.; ZAMBOLIM,L. Avaliação dos prejuízos causados por Uromyces phaseoli typica Arth. em diferentes estágios de desenvolvimento de duas variedades de feijão em função do número de aplicações de oxicarboxim. Fitopatologia Brasileira, Brasília, 2:92, 1977.

NAYLOR, T.H.; BALINTFY, J.L.; BURDICK, D.S.; CHU, K. Computer simulation techniques. New York, John Wiley, 1966. 402 p.

PARLEVIET, J.E. Components of resistance that reduce the rate of epidemic development. Annual Review of Phytopathology, Palo Alto, 17:203-222, 1979.

PEAK, C.M.; FITZELL, R.D.; HANNAH, R.S. \& BATTEN, D.J. Development of a microprocessor-based data recording system for predicting plant disease based on studies on mango anthracnose. Computers and Eletronics in Agriculture, 1:25162, 1986.

PENNING de VRIES, F.W.T.; JANSEN, D.M.; TEN BERGE, H.F.M.; BAKEMA, A. Simulation of ecophysiological processes of growth in several annual crops. Wageningen, PUDOC/RRR, 1989.

PRESSMAN, R.S.; Software engineering, 2.ed. Singapore, McGraw Hill, 1987. 567 p. 
SALL, M.A. Epidemiology of grape powdery mildew: a model. Phytopatholoygy, St. Paul, 70(4):338-42, 1980.

SAVARY, S.; DE JONG, P.D.; RABBINGE, R.; ZADOKS, J.C. Dinamic simulation of groudnut rust: a preliminary model. Agricultura Systems, England, 32:113-141, 1990.

SAVARY, S. \& ZADOKS, J.C. Analysis os crop loss in the multiple pathosystem goundnut - rust - late leaf spot. I. Six experiments. Crop Protection, 11:99-109, 1992.

SEEM, R.C. \& HAITH, D.A. System analysis in epidemiology. In: LEONARD, K.J. \& FRY, W.E. Population dynamics and management. v. 1. New York, MacMillan, 1986. p.232-52.

SHOOMAN, M.L. Software Engineering: design, reliability, and management. Londres, McGraw-Hill, 1985, 683p.

SUTTON, J.C. Predictive value of weather variables in the epidemiology and management of foliar diseases. Fitopatologia Brasileira, Brasilia, 12(4):305-12, 1988.

TENG, P.S. Validation of computer models of plant disease epidemics. Zeitschrift für Pflanzenkrankheiten und Pflanzenschutz, Stuttgart, 88:49-63, 1981.

TENG, P.S. A comparison of simulation approaches to epidemic modeling. Annual Review of Phytopathology. Palo Alto, 23:351-79, 1985.

TENG, P.S.; BLACKIE, M.I.; CLOSE, R.C. A simulation analisys of crop yield loss due to rust disease. Agricultural Systems, England, 2:198, 1977.

TENG, P.S.; KLEIN-GEBBINK, H.W.; PINNSCHIMIDT, H. An analysis of the blast pathosystem to guide modeling and forecasting. In:RICE blast modeling and forecasting. Manila, International Rice Research Institute, 1991. p. 1-30

TENG, P.S. \& ROUSE, D.I. Understanding computers: application in plant pathology. Plant Disease, St. Paul, 68(6):539-43, 1984.

TENG, P.S. \& ZADOKS, J.C. Computer simulation of plant disease epidemics, In: Yearbook of science and technology. New York, McGraw-Hill, 1980. 23-31 p. 
TIMMERMANS, Y. A warning system for fire blight on pears in Belgium: preliminary model and practical prospects. Acta Horticulturae, 273:121-132, 1990.

TOWSEND, G.R. Reactions of varieties of snap beans to rust. Plant Disease Reporter, 22:2-4, 1938.

TRAVIS, J.W. \& LATIN, R.X. Development, implementation and adoption of expert systems in plant pathology. Annual Review of Phytopathology, Palo Alto, 29:343-60. 1991.

VANDERPLANK, J.E. Plant diseases: epidemics and control, New York, Academic Press, 1963. $349 \mathrm{p}$.

VARGAS, E. La Roya. In:SCHAWARTZ, H.F. \& GALVEZ, G.E. ed. Problemas de producción del frijol: enfermidades, insectos, limitaciones edáficas y climáticas de Phaseolus vulgaris. Cali, 1980. p.19-36.

VENTURA, J.A. Modelo de previsão do mal de sigatoka em bananeiras da cultivar prata. Viçosa, 1984, 92p. (Mestrado - Universidade Federal de Viçosa)

VIEIRA, C. Doenças e pragas do feijoeiro. Viçosa, Universidade Federal de Viçosa, 1983. p.71-82.

WAGGONER, P.E. \& HORSFALL, J.G. EPIDEM, a simulator of plant disease written for a computer. Bull. Conn. Agric. Exp. Stn., 80p. 1969.

WAGGONER, P.E. Assembling and using models of epidemics. In:KRANZ, J. Epidemics of plant diseases: mathematical analysis and modeling. 2.ed., Berlin, Springer-Verlag, 1990, p.230-60.

YANG, X.B., DOWLER, W.M.; TSCHANZ, A.T. A simulation model for assesing soybean rust epidemics. Journal of Phytopathology, 133: 1887-200, 1991.

ZADOKS, J.C. Methodology of epidemiological research. Annual Review of Phytopathology, Palo Alto, 10:253-76, 1972.

ZADOKS, J.C. Simulation of epidemics: problems and applications. EPPO Bulletin, Paris, 9(3):227-234, 1979.

ZADOKS, J.C. \& SCHEIN, R.D. Epidemiology and plant disease management. Oxford University Press, 1979, 389p. 
APENDICE: listagem do programa para simulação de epidemias de ferrugem do feijoeiro.

Program gwver1;

f Daily Cohort Model completely reworked by G. E. Weber

Version july 08, $1993 p=f(T e m p)$

Adapted to verification, validation and sensitivity analisys test by M.G. Canteri

Latency is computed in hours and then rounded to days.

Host sensitivity:

1. sensitivity decreasing with increasing age of cohort

2. sensitivity decreasing with increasing age of plant

Both processes are modelled with logistic saddle functions.

With boolean variable pfix set to 'true', fixed latency duration can also be

modelled.

Removal of cohort area causes proportionate removal of all stages of infected

cohort area. Infections on removed cohorts or on removed tissue do not

contribute to the total amount of infections, as opposed to Berger's original

model. Consequently removed disease does not contribute to the production

of new infections, which is also contrary to Berger's original model.

Disease severity y refers to green host area as the difference of total minus removed area. In Berger's original model severity y was a proportion of the total host area.

Initialisation:

On the first day of disease occurance 'ti', cohorts older than $p$ days are

initialized with the observed amount of disease. Furthermore all

existing

cohorts are initialized with latent infections. The amount of latent infections is a free guess. It is planed to link the amount of latent infections to the value of the fourability 'fav'.

This procedure is quite troublesome. For Carioca October 89 removal of host

tissue starts rather fast. On the first day of infection (day 10) the first two cohorts are the only ones older than 8 days (latency) but unfortunately

they were already removed. Factor $f$ is sel to 0 and no latent infections are

initialized so that no dlsease develops at all!

The problem with earty removal was solved by setting the beginning of

removal to the time when removals were first obsened in the freld. \}

$\{\$ N+, E+\}$

[\$M 55520,0,555360)

uses crt, dos, gkemel, gdriver, gwindow, gshell;

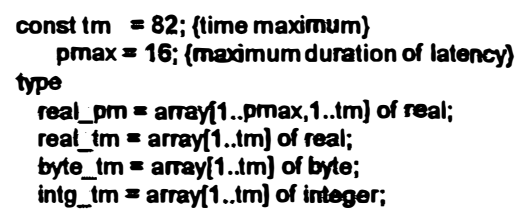

var (host:)

Id, (daily increment of host area and present cohort area)

ild, (buffer for Id)

la, fotal host area to date)

rI. (daily removal of host area)

cla, ftotal leaf area corrected for removals, say green host tissue\}

ra, \{total removed host area to date\}

(disease:)

id, (daily increment of infected area)

ta, (total infected area on green host tissue to date)

ya, (total diseased area on green host tissue to date)

y. $\quad$ fotal disease proportion $=$ ya $/ \mathrm{cla}$ )

ye, (experimentally observed total disease proportion]

cti, ftotal green area infected to date for cohort originated on day n)

ci, \{cohort infectious area)

(weather:)

fav, (daily weather favourability)

fav2, (altemative computation\}

fav3,

fav4,

ac, \{accumulated hourly temperature weights for day i)

wet, \{daily leaf wetness duration\}

Tpmin, (daily temperature maximum)

Tpmax (daily temperature minimum) :real_tm;

lat (latency (in days) of infections originating on day i\} :byte_tm;

pi (buffer for computation of lat\} : intg_tm;

cl (age-structured latent infections on cohort) : real_pm;

data, \{determines input data sel)

host, (determines host development)

tmax, (last day to be modelled\}

ti. (day of first infection)

tr. (day of first removal of host tissue)

k. (auxilliary index)

i. \{time in days\}

p. (latent period in days)

$n$, (number of cohort (equals day of appearance)\}

m \{age class of latent infections\} :byle;

a, \{coefficient determinig cohort sensitivity\}

b. (coefficient determinig cohort sensitivity)

c. (iraction of fil assumed latent on day ti\}

ah, (coeficieient determinig plant sensitivity)

bh, [coeficieient determinig plant sensitivity)

fi, (proportion of initially infectious diseased host tissue)

cid, [daihy infected area on Id[i] increment\}

acf, (cohort susceptibility decreasing with age of cohort)

ahf, (plant susceptibility decreasing with plant age)

$\mathrm{Rm}$, (maximum infection rate)

norm (cultivar specific factor to limit fave=1.0\} : real;

(cultivar specific parameters for weather favourabllity:)

b1, \{b1 through b5 are temperature parameters of a beta function\}

b2, (minimum temperature)

b3. (maximum temperature)

b4.

b5

b6. (b6 and b7 give the influence of leaf wetness duration -

b7 (for a Richards function) : extended;

exp_data, (name of file containing experimentally observed disease progress\} 
ein name, (name of file containing weather observations and favvalues\}

aus_name, \{name of output data file)

aus2name, (name of auxiliary output file, weather, favourability and latnecy\}

aus3name \{dto., cohort scan\} : string[12];

fav_const, \{true if no weather influence on favourability\} CohortScan, \{ture if outputs for disease on cohort level are requested\}

hostaging. \{true if host sensitivity decreases with plant age) prix \{true if latency $p$ is constant throughout the whole run\} : boolean;

aus3 \{auxiliary output file\} text

\begin{tabular}{|c|c|}
\hline $\begin{array}{l}\text { procedure PGraf; } \\
\text { var } A, B \text { : PlotArray; } \\
\text { ymin,ymax: real; } \\
\text { n: byte; } \\
\text { f }\end{array}$ & $\{$ Graf $\}$ \\
\hline
\end{tabular}

var I: byte;

begin \{Generatefunction \}

ymin $:=1000$;

ymax $:=-1000$

for $i:=1$ to $N$ do begin

if $p[i]<y$ min then ymin: $=p[i]$;

if $p[i]>$ ymax then ymax: $=p[i]$

A[l, 1] : $=i$ :

$A[1,2]:=p[i] ;$ end;

if ymin < 0 then ymin $:=1.1^{*}$ ymin else ymin :=0.9 0. ymin;

if ymax $<0$ then ymax $: 0.9 *$ ymax olse ymax $:=1.1^{*}$ ymax

end; [Generatefunction \}

$\{$. ... . . . . . . . . . . . . . . . . . . . . . . . . . . . . . $\}$

procedure GenesateYE(var a: plotarray; var $n$ : byte);

var junk: real:

ein: text;

\{structure of ein: day, logit, y\}

begin \{GenerateYE\} (reads experimentalty observed disease

severities from file)

assign(ein,exp_data);

resef(ein):

$n:=0$;

while not eof(ein) do begin

$n=n+1$

readln(ein, $A[n, 1]$,junk, $A[n, 2])$;

$A[n, 2] ;=A[n, 2]$;

if $a[n, 2]>y m a x$ then ymax:=1.1*a[n,2];

end; (while)

end; fGeneratere)

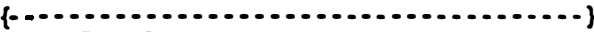

begin (PGra)

InitGraphic;

Clearscreen:

\{ Initialize the graphics system \}

Generdefunction(A, tmax, y, ymin, ymax);

[ Generate the

polygon ?

GenerateYE(b, n);

DefineWindow(1, 0, 0, XMarGlb, YMarGlb);

Definetleader(1, 'Diseose Severity);

1

DefineWorld(1, 0, ymin, tm, (0.01)ymax);

SelectWorid(1)

SelectWindow(1):

SetBackground(0);

SetheaderOn;

DrauBorder:

DrzwAis $(8,-8,0,0,0,0,0,0$, falso)

Dranpolygan(A, ti, tmax, 0, 0, 0)

Reselaris;

Drenpulygen $(b, 1, n,-1,4,0)$;

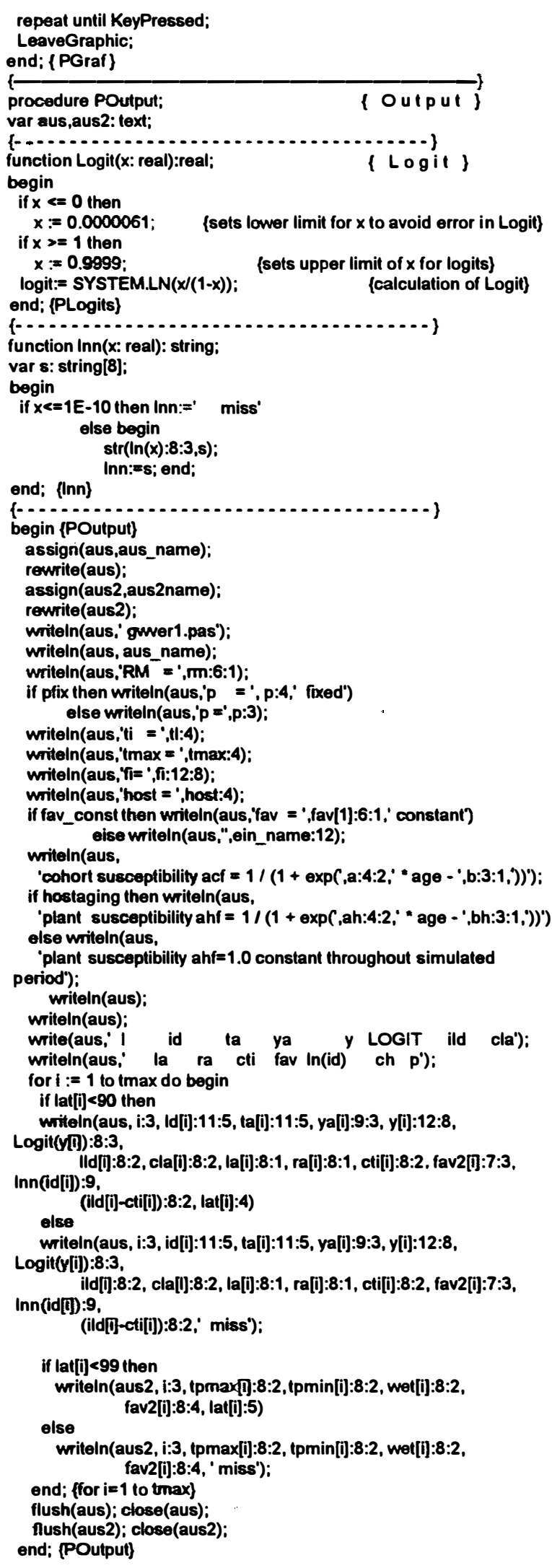




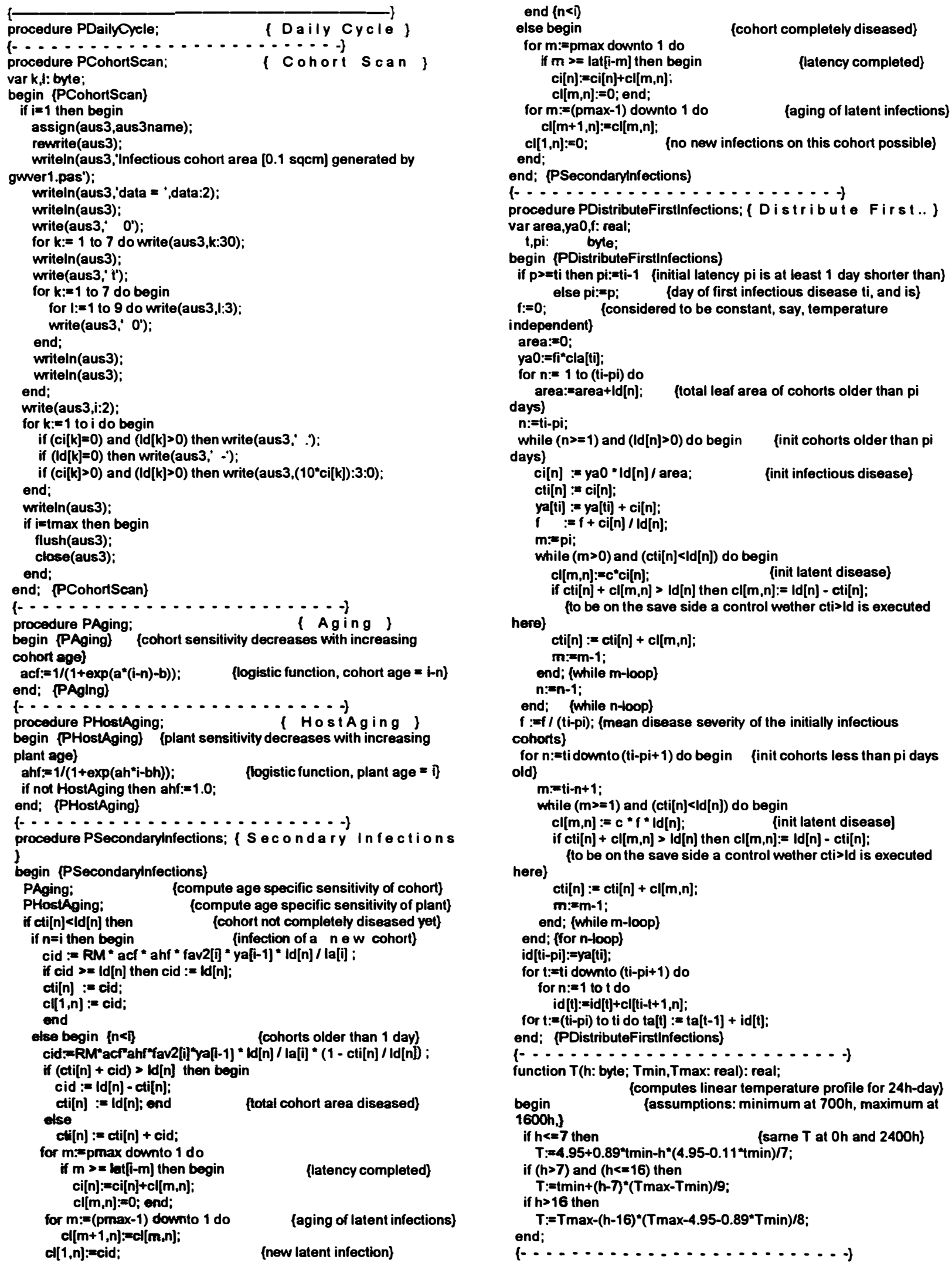


procedure PFavourability(var fav: real_tm; Tmin,Tmax,w: real);

var $0, \mathrm{ww}, \mathrm{h}, \mathrm{mn}$ : byte:

min,Temp,Tmean: real;

buff,efi: extended:

ts,th: array[1..24] of real:

$\{$ Favourability\}

begin

if $w=0.0$ then $w:=1 E-05 ; \quad$ ( $w=0$ would lead to computation of $\ln (0)=$ error!)

if fav_const then fav2[i]:=1.0

else begin

1

Mean effect of coolest hours

It is considered that wetness occurs during the night hours, or in general

during the coolest period of the day. Therefore, the $w$ lowest hourly temperatures are selected, and fav is computed as the arithmetic mean of the $w$ predicted effects.

)

buff: $=0$;

for $h:=1$ to 24 do begin

Temp: $=T(h-1, T$ min, Tmax):

if Temp $<=b 2$ then Temp:=b2+0.01;

if Temp $>=b 3$ then Temp:=b3-0.01

th[h]:=temp; (hourly temperatures\} end;

uw:=trunc(round $(w+0.1)) ; \quad\{8.5$ hours are treated alike 9 hours wotness]

for $0:=1$ to $\mathrm{mw}$ do begin (sort hourly temperatures in ascending order\}

min:=100;

for $h:=1$ to 24 do

if th[h]<min then begin

min:m[h]:

mn : $=h$;

end;

th[mn]:=100;

ts[o]:=min;

end;

for $h:=1$ to $\mathrm{uw}$ do begin ftemperatures during wetness period are considered day is)

eff: $=\{$ norm $\} b 1{ }^{*} \exp \left(b 4^{*}(n)(T s[h]-b 2)\right) \quad$ (coolest period of each

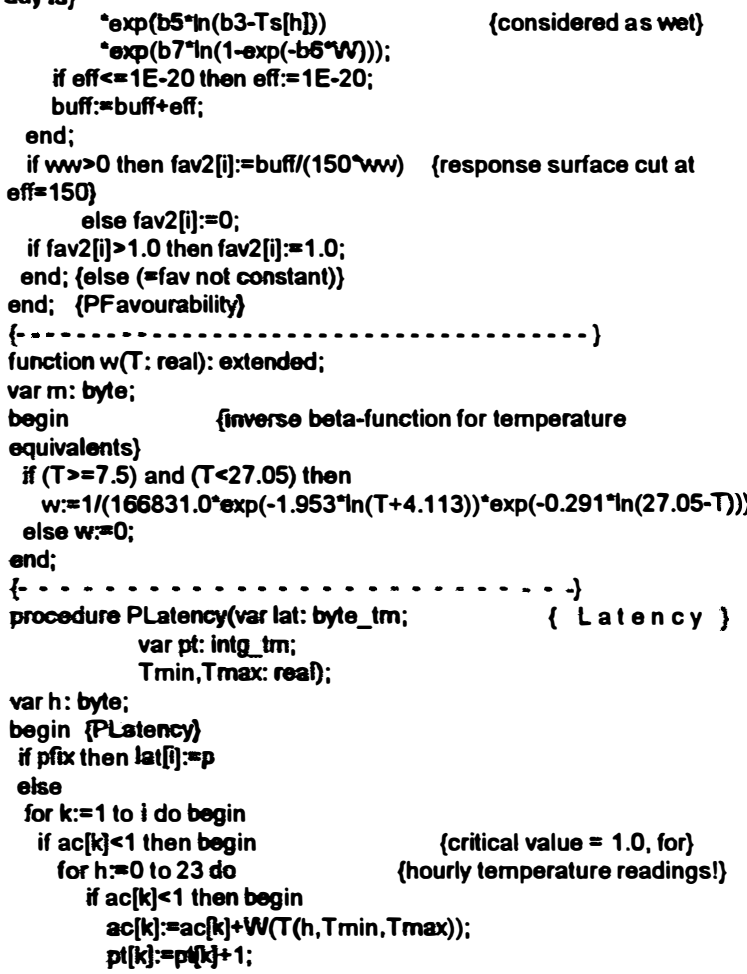

\{critical value $=1.0$, for (hourly temperature readings!)

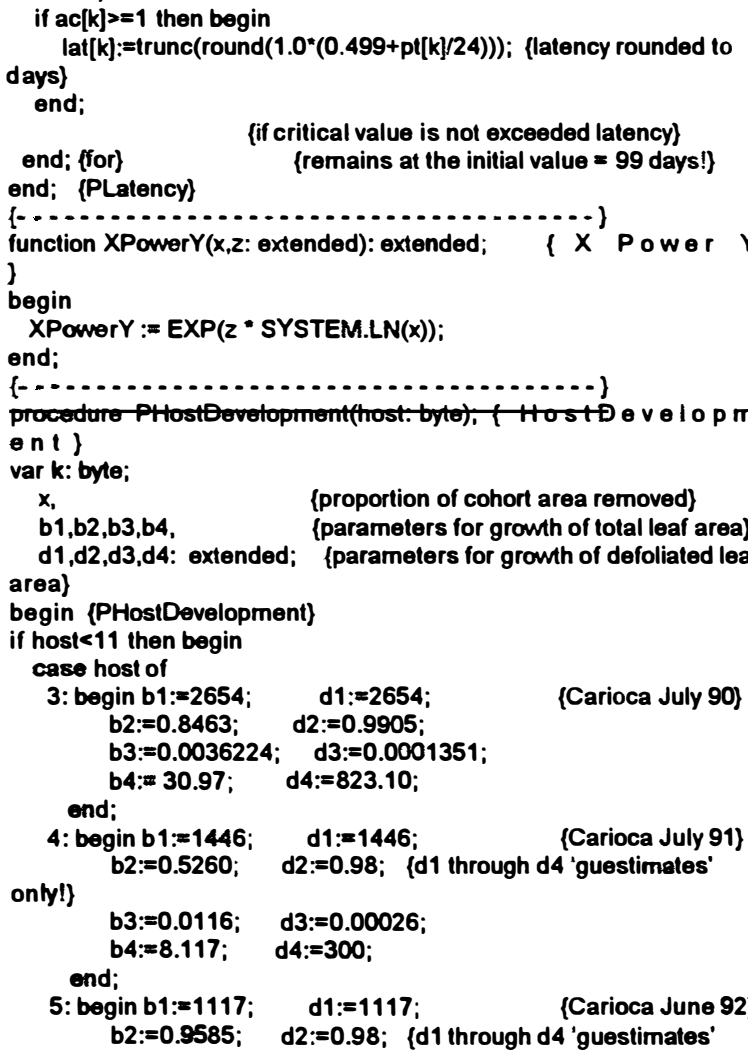

if $\mathrm{ac}[k]>=1$ then begin

lat $[k]$ :=trunc $($ round $(1.0 *(0.499+p t[k] / 24)))$; (latency rounded to

end; (for)

critical value is not exceeded latency

\{remains at the initial value $=99$ days \}

end; \{PLatency\}

begin

end:

ent )

var k: byte

(proportion of cohort area removed)

(parameters for growth of total leaf area) area)

begin (PHostDevelopment)

host<11 then begin

case host of

only! b3: $=0.00103 ; \quad d 3:=0.00026$;

end; $b 4=80.702 . \quad d 4:=300$

8: begin b1:=3328; $d 1:=128557$; $\quad$ [Rosinha July 90) b2: $=0.6532 ; \quad$ d2: $=0.9656$; (assymptotes not identical!\} b3: $=0.007930 ; \quad d 3:=0.0003439$; b4:=14.344; d4:=377.28;

9: begin b1:=1259; $\quad d 1:=1259$;

\{Rosinha July 91\} only!)

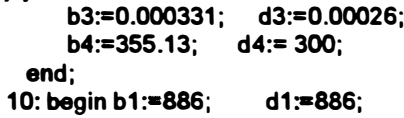

10: begin b1: $=886$; $\quad$ d1:=886;

only!\} .9947; d2:=0.98; \{d1 through d4 'guestimates'

end; b3: $=0.000163 ; \quad d 3:=0.00026$ $b 4:=777.5 ; \quad d 4:=300$;

end; \{case host of\}

la[i] := b1 * (1 - exp (-XPowerY((b2+b3*i),b4)));

if is=tr then

ra[i] := d1 * (1 - exp(-XPowerY((d2+d3*i),d4)))

else ra[i]:=0;

if $i>1$ then begin

Id[i] := la[i]-la[i-1];

rl[i] := ra[i]-ra[i-1];

cla $[i]:=$ cla $[i-1]+I d[i]-r l[i] ;$ end

else begin

Id[i] := la[i];

ri[i] := ra[i];

cla[i]:= Id[i] - rl[i]; end;

ild[i] : = Id[i]:

end; (If host<11) 
while $(k<=i)$ and $(r[i]>0)$ do begin (routine to remove oldest leaves first)

$k:=k+1$;

if $L D[k]>0$ then (cohort not completely removed yet\}

if $R L[i]<=L D[k]$ then begin (daily removal $<=$ cohort area)

$x:=$ rIligld[k]; $\quad$ (fraction of renoval from cohort area)

$c i[k]:=c i[k] *(1-x) ; \quad$ (infectious area removed partially\}

for $m:=1$ to pmax do (latent infections removed partially)

$c|[m, k]:=c|[m, k] *(1-x)$;

$L D[k]:=L D[k]-R L[i] ; \quad$ (partial removal of cohort area)

$R L[i]:=0.0$;

end

else begin

$R L[i]:=R L[i]-L D[k]$

$L D[k]:=0$; area\} for $m:=1$ to pmax do (complete removal of latent cohort

$$
\text { end: }
$$

end; (while loop)

end; (PHostDevelopment)

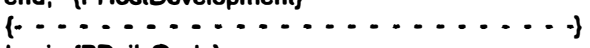

begin (PDailyCycle)

for $i:=1$ to tmax do begin

PHostDevelopment(host);

\{time loop\}

PLatency(lat,pt,tpmin[i],tpmax[i]);

PFavourability(fav,tpmin[i],tpmax[i],wet[i]);

if $i=t i$ then PDistributeFirstinfections;

$n:=1$;

while (i>ti) and ( $n<=i)$ do begin

if Id [n] $>0$ then PSecondaryinfections;

ya[i]:=ya[i]+ci[n]

id[i]:=id[i]+cl[1,n]

ta[i]:=ta[i]+ci[n];

for $m:=1$ to pmax do ta[i]:=ta[i]+cl[m,n]

$n:=n+1$;

end; \{unile mfoop\}

if CohortScan then PCohortScan;

y[i]:-ya[i]/cle[i];

if $y[i]>=1$ then $y[i]:=0.9999$;

end; (i loop)

end; [PDailyCycle]

procedure PInput; $\quad$ (Input $\}$

var j1,j2,j3,j4: real;

day: byte;

ein1: text; (structure of ein1: day, tmax, tmin, orv, fav_r, fav_c) begin \{Plnput\}

a := 0.3; (determines cohort sensitivity as influenced by cohort age)

b $:=4.0 ;$ (dto.)

ah :=0.15; (coefficient determinig plant sensitivity)

bh $:=5.0$; (coefficient determinig plant sensitivity]

c := 0.4; $\quad$ (fraction of latent disease for initialisation)

p :=12;

pfix := false;

(latent period)
\{true if latency is constant throughout run

hostaging := true

fav_const := false;

aus2name := 'Rj92.fav';

aus3name $:=$ 'cj0.coh'

CohortScan:=false;

(host coding: $1-5=$ Carioca $7 / 89,10 / 89,7 / 90,7 / 91,6 / 92$ weibul

6-10 = Rosinha dto.

data:=3;

case date of

3: begin

aus_name := 'lat2.ves';

ein name := "lat2.asc",

$\exp$ data := 'p9007cs.dat';

tr $:=22$;

host := 3;

RM $:=26$

ti $=14$ : $t \max :=71 ;$
fi $:=2.158-5$

end;

4: begin

aus name $:=$ 'car91.ve4'

ein name $:=$ 'p9107tw.asc'

exp_data $:=$ 'p9107cm.dat';

tr $:=25$;

host : $=4$;

RM := 26; (=estimate of 1990)

$\mathrm{ti}:=8$; $\quad$ (first disease on day 5 )

tmax $:=78$;

fi :=1.590-06;

end;

5: begin

aus_name := 'car92.ve4';

ein_name := 'p9206tw.asc'

exp data := 'p9206cs.dat';

Ir $:=28$;

host $:=5$;

RM : $=26$; [1990 estimate is 26]

ti $:=26$;

tmax $:=72$;

fi :=3.78e-6

end;

8: begin

aus name $:=$ 'ros90.ve4'.

ein name: : 'p9007tw.asc';

exp_data := 'p9007rs.dat';

Ir $:=28$;

host := 8;

RM $:=40.0$

ti $:=14 i$

tmax := 71:

fi $:=4.320-06$;

end;

9: begin

aus_name := 'ros91.ve4';

ein name $:=$ 'p9107tw.asc'

exp data := 'p9107rm.dat'.

tr $:=25$;

host := 9;

$R M=40$;

ti $:=11$;

tmax $:=56$;

fi $:=90-07$;

end

10: begin

aus name $:=$ 'ros92.ve4'

ein_name $:=$ 'p9206tw.asc';

exp_data := 'p9206rs.dat';

tr $:=28$;

host $:=10$

RM := 40;

ti $:=22$;

tmax :=72;

fi $:=5.76 e-6$

end;

end; \{case\}

if (datac=5) then begin

b1 := 3.445E-11; \{Carioca parameters BMDP job 6 file etwe3.out)

W)

b2 :=6.9;

(Response surface of disease efficiency by $T$ and

b3 := 32.0;

b4 := 3.7539;

b5 :=7.8192;

b6 : $:=0.20$

b7 $:=7.0$

norm := 1.0/297.92; foccurs at $T=14.6 \mathrm{C}$ \} foutdated value !!!

end

else begin

b1 $:=0.000002307 ;$ Rosinha parameters BMDP job 5 file

etwr2.out\}

b2 := 6.9;

b3 := 32.0; 


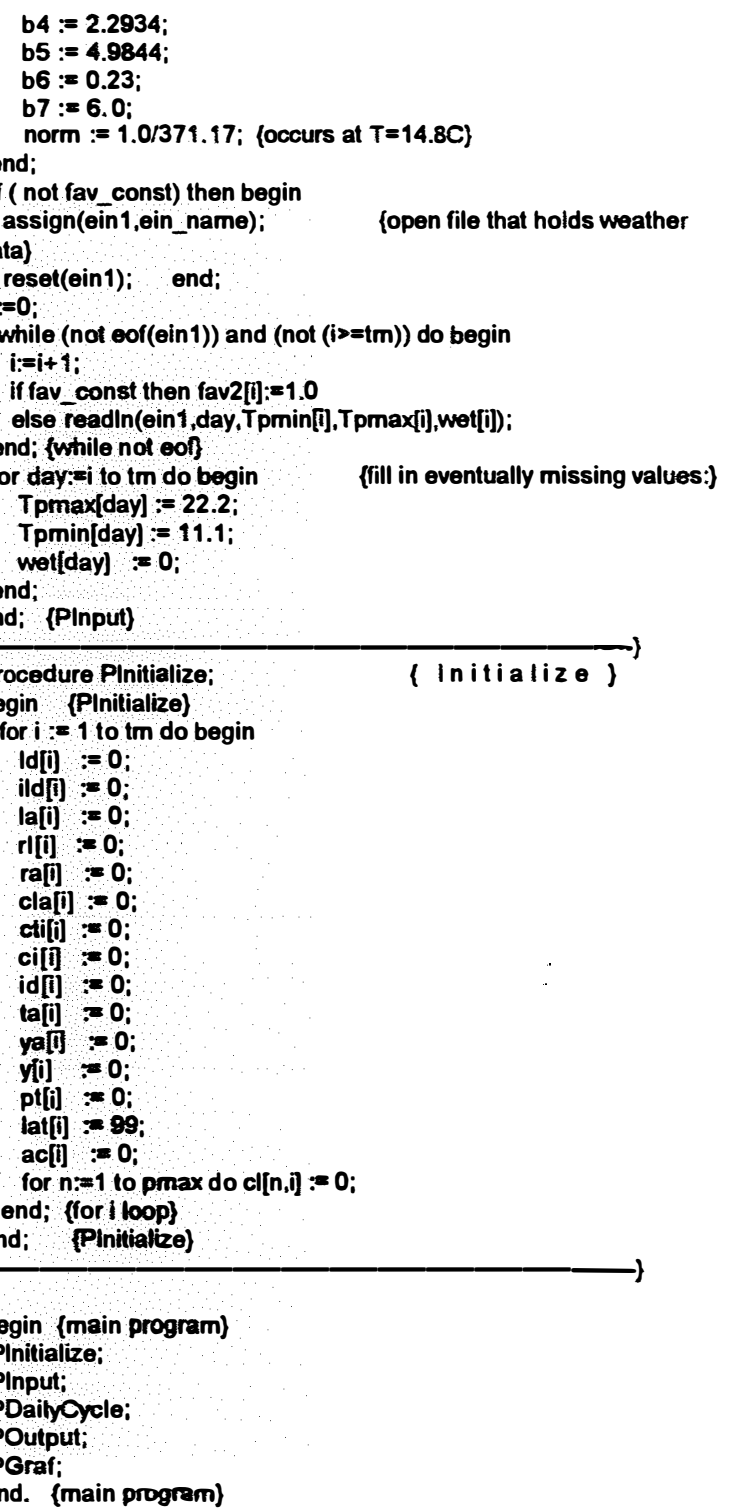

